\title{
Proceedings of the second meeting of the French-speaking society SF-DOHaD
}

\section{LONG CONFERENCES \\ PRECONCEPTIONAL PROGRAMMING}

Periconception nutrition and long-term impacts

T. Fleming

Centre for Biological Sciences, University of Southampton,

Southampton, UK

Email: tpf@soton.ac.uk

There is evidence across mammalian species including the human that the periconceptional (PC) period is vulnerable to environmental influences that may change the programme of development and have lasting effects on disease risk into adulthood. We have studied the effect of maternal undernutrition (low-protein diet, LPD) during the PC period in mice. Even restricting LPD to just the preimplantation period with normal nutrition for the rest of gestation and postnatal life (Emb-LPD) is sufficient to induce increased cardiovascular, metabolic and behavioural disease in adult offspring. We have found the timeline of programming initiates through EmbLPD diet-induced reduction in insulin and branched-chain amino-acid (BCAA) concentrations within maternal serum and/or uterine fluid. These changes are sensed by blastocysts via the mTOR signal pathway. This sensing mechanism associates with altered programming, even if Emb-LPD blastocysts are transferred to control mothers. Similarly, in vitro cultured embryos with reduced insulin and BCAAs and subsequent transfer lead to similar adult disease phenotype to maternal Emb-LPD treatment. Programmed embryos undergo compensatory responses within the extra-embryonic cell lineages (trophectoderm; primitive endoderm) to promote nutrient retrieval during gestation to promote foetal growth. These responses include increased proliferation, endocytosis and motility of the affected tissues. However, embryonic lineages show evidence of increased apoptosis and reduced survival signalling. Derivation of embryonic stem cell lines from blastocysts from diet-treated mothers retain programming characteristics over several passages and permit mechanistic analyses and reduced use of animals. These lines have also been effective in identifying epigenetic mechanisms underlying lineagespecific programming responses. Lastly, Emb-LPD compensatory responses induced within extra-embryonic lineages cause increased perinatal growth. However, perinatal weight in programmed offspring correlates positively with disease risk in later life. These data therefore show a continuum of biological processes from maternal PC diet to adverse adult phenotype.

Disclosure of Interest: None.

\section{MICROBIOTA AND PROGRAMMATION}

Could the intestinal microbiota be programmed by early-life environment?

C. Michel

INRA-Nantes University, UMR1280, PhAN, Nantes, France

Email: Catherine.michel@univ-nantes.fr

Programming of intestinal microbiota composition may contribute to $\mathrm{DOHaD}$. Indeed, increasing evidence suggests that, depending on its composition (which determines its activity), intestinal microbiota deeply affects host physiology far beyond the digestive sphere. ${ }^{1}$ Similarly, it is well admitted that the composition of neonatal intestinal microbiota is particularly sensitive to perinatal environment, including early nutrition. ${ }^{2}$ Thus, subjecting to that these early modifications persist during one's entire life, intestinal microbiota could act as a mechanistic relay between early environment and adult health. However, although it is generally assumed that the gut microbiota is durably shaped during neonatal period, ${ }^{3}$ whether early alterations in gut microbiota actually persist until adulthood remains to be ascertained. The critical review of the literature related to this issue in either short-term follow-ups in humans or long-time follow-ups in animal studies highlights that this assumption is nongeneric but rather depends on the type of microbiotal modulator used in early life. ${ }^{4}$ This would support the idea that the first settlers play an important role in the development of the gut microbiota and may impact its long-term composition and activity, ${ }^{5}$ and that, under specific circumstances, intestinal microbiota may serve as a relay of neonatal history and contribute to the programming of host physiology.

Disclosure of Interest: None.

\section{References}

1. Robles Alonso V, Guarner F. Linking the gut microbiota to human health. Br J Nutr. 2013; 109, S21-S26.

2. Fouhy F, Ross RP, Fitzgerald GF, Stanton C, Cotter PD. Composition of the early intestinal microbiota: knowledge, 
knowledge gaps and the use of high-throughput sequencing to address these gaps. Gut Microbes. 2012; 3, 203-220.

3. Yatsunenko T, Rey FE, Manary MJ, et al. Human gut microbiome viewed across age and geography. Nature. 2012; 486, 222-227.

4. Morel FB, Oozeer R, Piloquet $\mathrm{H}$, et al. Can pre-weaning modulation of intestinal microbiota by oligosaccharides or amoxicillin program adult one in rats. Nutrition. 2015; 31, 515-522.

5. Scholtens PA, Oozeer R, Martin R, Amor KB, Knol J. The early settlers: intestinal microbiology in early life. Annu Rev Food Sci Technol. 2012; 3, 425-447.

\section{REPRODUCTION: EPIGENETICS, WHY AND HOW?}

Epigenetic and animal reproduction, tools and challenges

M.-A. Sirard

Département des Sciences Animales, Centre de Recherche en Biologie de la Reproduction (CRBR), Institut sur la Nutrition et les Aliments Fonctionnels (INAF), Faculté des Sciences de l'Agriculture et de l'Alimentation, Université Laval, Québec, Canada

\section{Email: Marc-Andre.Sirard@fsaa.ulaval.ca}

Although the reality of intergenerational inheritance has been clearly demonstrated, there is a significant gap in our knowledge of the mechanism behind this phenomenon. Epigenetic, and especially DNA methylation, are now considered as the most likely medium through which the effects of environmental stresses are transmitted to the next generation. DNA methylation has the advantage of being more stable than histones or chromatin modifications and offers some technical advantages as well (add info). Several approaches are available for methylation analysis: whole-genome bisulfite sequencing, also known as BS-Seq (a high-throughput genome-wide analysis of DNA methylation), RRBS or reduced representation bisulfite sequencing (a high-throughput technique used to analyze the genome-wide methylation profiles of $\mathrm{CpGs}$ ), MeDIP or mDIP (consists of isolating methylated DNA fragments via an antibody raised against 5-methylcytosine) and ChIP-on-chip assays (based on the ability of commercially prepared antibodies to bind to DNA methylation-associated proteins such as $\mathrm{MeCP} 2$ ).

All these methods have their own advantages and drawback, and while sequencing-based techniques are gaining in popularity owing to declining costs, their need for several replicates and the amount of material required limit their use. In the field of reproduction, the amount of material is not an issue in the case of sperm, but becomes important when oocyte and early embryos are involved. In this context, the Canadian research network EmbryoGENE has sustained the development of simplified micro-array platforms allowing the capture of 450,000 potential methylation targets covering either the complete bovine or porcine genomes. This is a discovery tool where differences are highlighted and organized by genomic regions: introns, exons, proximal and distal promoter or intergenic regions. This method can be used with $<1000$ cells per replicate and focuses on the discovery of hot spots where methylation changes are significant. The platforms allow simultaneous transcriptome analysis and the linking of RNA and DNA data. The visualization tools allow individual chromosome analysis, $\mathrm{CpGs}$ and DMR distribution and direct view of the impacted regions on a genome browser. A bioinformatic pipeline generates the statistical analysis in a few days.

Recent results demonstrate the value of such tools with embryos that have been exposed to in vitro culture after in vitro fertilization, embryos obtained from oocytes exposed to insulin before fertilization and embryos exposed to high glucose levels for 3 days. Methylation patterns vary depending on the various stresses and surprisingly about half of the methylation changes are associated with the expected pattern (hypomethylation with increased transcription), whereas the other half does not. These short-term changes are potentially maintained and represent new targets for the epigenome assessment of newborns coming from assisted reproduction technologies (ART). Moreover, the targets associated with immediate gene expression changes can be used for mechanistic analysis of the selected sites to better understand the driving forces of DNA methylation in response to the environment. In addition, the bovine model is quite unique and interesting for the analysis of human ART effects based on the number of similarities in the timing and programming of early embryos.

Disclosure of Interest: None.

\section{LATER HEALTH OF PREMATURE AND SMALL FOR GESTATIONAL AGE BABIES}

Preterm birth and intraruterine growth restriction: from perinatal period to long-term consequences at adulthood

U. Simeoni ${ }^{1}$, C. Yzydorczyk ${ }^{1}$, B. Siddeek ${ }^{2}$ and M. Benahmed ${ }^{2}$

${ }^{1}$ Division of Pediatrics \& DOHaD Laboratory, CHUV

University Hospital and UNIL, Lausanne, Switzerland;

${ }^{2}$ INSERM U1065, Nice, France

Email: Umberto.Simeoni@chuv.ch

Follow-up of low birth weight infants has long focused on growth and on neuro-developmental outcomes. However, although most of these patients are doing well, there is increasing evidence of altered early biomarkers of increased risk of long-term noncommunicable chronic diseases. The odds ratio of having hypertension at the age of 20 years are increased. ${ }^{1}$ Renal function studies have shown increased rates of abnormal microalbuminuria at young adulthood. Altered glucose tolerance and insulin resistance have been evidenced at adolescence. The lung, behavior, bone mineral density at adulthood all have been shown to be significantly affected on the long term by preterm birth. 
Such long-term complications of preterm birth are part of the concept of developmental programming, or $\mathrm{DOHaD}$.

Preterm birth involves at least, in part, similar mechanisms of developmental programming to those induced by other conditions that affect early life, such as intrauterine growth restriction, or intrauterine exposure to maternal diabetes, including epigenetic alterations and marks owing to early environmental influences. ${ }^{2,3}$ Early postnatal nutrition is an important factor of long-term health in preterm infants, given the frequency of early extrauterine growth restriction and the need for compensatory growth, which may bear adverse effects in the long term.

Optimized postnatal nutrition and a follow-up extended to early biomarkers of cardio-vascular, renal and metabolic functions of preterm-born patients should be adopted in perinatal centers. $^{4,5}$ Research on specific mechanisms and possible prevention measures must be intensified and supported.

\section{Disclosure of Interest: None.}

\section{References}

1. Ligi I, Grandvuillemin I, Andres V, Dignat-George F, Simeoni U. Low birth weight infants and the developmental programming of hypertension: a focus on vascular factors. Semin Perinatol. 2010; 34, 188-192.

2. Ligi I, Simoncini S, Tellier E, et al. A switch toward angiostatic gene expression impairs the angiogenic properties of endothelial progenitor cells in low birth weight preterm infants. Blood. 2011; 118, 1699-1709.

3. Vassallo PF, Simoncini S, Ligi I, et al. Accelerated senescence of cord blood endothelial progenitor cells in premature neonates is driven by SIRT1 decreased expression. Blood. 2014; 123, 2116-2126.

4. Tauzin L, Rossi P, Grosse C, et al. Increased systemic blood pressure and arterial stiffness in young adults born prematurely. J Dev Orig Health Dis. 2014; 26, 1-5.

5. Parkinson JR, Hyde MJ, Gale C, Santhakumaran S, Modi N. Preterm birth and the metabolic syndrome in adult life: a systematic review and meta-analysis. Pediatrics. 2013; 131, e1240-e1263.

\section{MOTHER AND INFANT NUTRITION}

\section{How to feed preterm infants to limit unfavorable long-term outcome?}

J.-C. Rozé, D. Darmaun, L. Simon, A. Chauty and C. Flamant

Neonatal Intensive Care Unit, Nantes University Hospital, INRA-Nantes University, UMR1280, PhAN, Nantes, France

\section{Email: jeanchristophe.roze@chu-nantes.fr}

Suboptimal neurodevelopment is the main unfavorable longterm outcome of preterm birth. An association between poor early growth during hospitalization in neonatal intensive care unit and suboptimal neurodevelopment has been observed ${ }^{1}$ and this correlation is stronger in boys compared with girls. ${ }^{2}$ Most earlier studies, however, assessed growth based solely on weight gain, and early growth should be evaluated not only in terms of weight but in terms of body composition as well [fat mass and fat free mass (FFM)]. In a recent study, we found the main determinants of FFM at discharge to be antenatal growth, gestational age, postnatal age, initial growth rate (between birth and day 5), and growth between day 5 and discharge, both of which equally affected FFM. Moreover, a higher protein: energy ratio at day 5 is a major determinant of improved FFM at discharge. ${ }^{3}$ Thus, initial (very early) nutrition during the first few days of life seems to have a major impact on the quality of growth. The relationship between future neurodevelopment and initial nutrition or FFM at discharge clearly warrants further study.

The long-term metabolic effect of early nutrition in preterm infants is an emerging subject of study. Young adults born preterm have lower insulin sensitivity and higher blood pressure. ${ }^{4,5}$ A faster weight gain during childhood amplifies this impairment in insulin sensitivity, and seems to be associated with early nutrition. ${ }^{6}$

The breastfeeding paradox refers to the fact that premies that are breastfed early in life may be slower to gain weight, but they have better neurodevelopment at 2 and 5 years of age. ${ }^{7}$ Moreover, in one of the very few available interventional studies conducted on this topic in preterm infant, breastmilk consumption was associated with lower later blood pressure in children born premature. ${ }^{8}$ Thus, breastfeeding should be encouraged. Like other workers, ${ }^{9}$ we strongly endorse human milk feeding as the preferred method to nourish preterm infants during hospitalization and after discharge. Yet supplementation of breastmilk is necessary. Although preterm human milk contains higher concentrations of protein, sodium, zinc and calcium than mature human milk (HM), it falls short of supplying the tremendous quantities of nutrients required by preterm infants. ${ }^{10}$ Therefore, HM supplemented with nutrients is recommended. The question is: how long do we have to supplement? Until the baby is able to suckle? No evidence is currently available on that issue. ${ }^{11}$

\section{Disclosure of Interest: None.}

\section{References}

1. Ehrenkranz RA, Dusick AM, Vohr BR, et al. Growth in the neonatal intensive care unit influences neurodevelopmental and growth outcomes of extremely low birth weight infants. Pediatrics. 2006; 117, 1253-1261.

2. Frondas-Chauty A, Simon L, Branger B, et al. Early growth and neurodevelopmental outcome in very preterm infants: impact of gender. Arch Dis Child Fetal Neonatal Ed. 2014; 99, F366-F372.

3. Simon L, Frondas-Chauty A, Senterre $\mathrm{T}$, et al. Determinants of body composition in preterm infants at the time of hospital discharge. Am J Clin Nutr. 2014; 100, 98-104. 
4. Kajantie E, Hovi P. Is very preterm birth a risk factor for adult cardiometabolic disease? Semin Fetal Neonatal Med. 2014; 19, 112-117.

5. Hofman PL, Regan F, Jackson WE, et al. Premature birth and later insulin resistance. N Engl J Med. 2004; 351, 2179-2186. 6. Regan FM, Cutfield WS, Jefferies C, Robinson E, Hofman PL. The impact of early nutrition in premature infants on later childhood insulin sensitivity and growth. Pediatrics. 2006; 118, 1943-1949.

7. Rozé JC, Darmaun D, Boquien CY, et al. The apparent breastfeeding paradox in very preterm infants: relationship between breast feeding, early weight gain and neurodevelopment based on results from two cohorts, EPIPAGE and LIFT. BMJ Open. 2012; 2, e000834.

8. Singhal A, Cole TJ, Lucas A. Early nutrition in preterm infants and later blood pressure: two cohorts after randomised trials. Lancet. 2001; 357, 413-419.

9. Lapillonne A, Griffin IJ. Feeding preterm infants today for later metabolic and cardiovascular outcomes. J Pediatr. 2013; 162, S7-S16.

10. Trudehope D. Human milk and the nutritional needs of preterm infants. J Pediatr. 2013; 162, S17-S25.

11. Henderson G, Fahey T, McGuire W. Nutrient-enriched formula milk $v$. human breast milk for preterm infants following hospital discharge. Cochrane Database Syst Rev. 2007; 4, CD004862.

\section{PROGRAMMING OF COGNITIVE IMPAIREMENT}

\section{Programmation, methyl donors, epigenetics}

J.-L. Guéant

INSERM U954, Nutrition-Genetics-Environmental Risk Exposure (N-GERE), University of Lorraine, Vandoeuvrelès-Nancy, France

Email: jean-louis.gueant@univ-lorraine.fr

Vitamin $\mathrm{B}_{12}$ (cobalamin, cbl) and folate play key roles in epigenomics as cofactor and co-substrate of methionine synthase (MTR), respectively. This enzyme catalyzes the synthesis of methionine, the precursor of S-adenosylmethionine (SAM). This presentation will review our studies on the nutrigenomic influence of cbl and folate deficiency in the liver, heart and brain, through SAM-dependent epigenomic mechanisms.

The deficiency in folate and vitamin $B_{12}$ during gestation and lactation produces manifestations of fetal programming, with decreased birth weight, increased central fat mass, liver steatosis and myocardium hypertrophy in pups. ${ }^{1,2}$ These manifestations result from impaired fatty-acid $\beta$-oxidation and impaired energy metabolism through decreased expression and activity of SIRT1 and PRMT1, and subsequent hyperacetylation and hypomethylation of PGC1- $\alpha$ and dysregulation of nuclear receptors, ER $\alpha$, PPARs, ERR $\alpha$ and HNF-4. ${ }^{3,4}$ The deficiency also impairs the proper development of the brain, with long-term cognitive consequences in aging. ${ }^{1}$ The most discernible consequences of decreased cellular availability of $\mathrm{cbl}$ are reduced proliferation and accelerated differentiation through the PP2A, NGF and TACE pathways and increased reticulum stress through decreased expression of deacetylase SIRT1 and greater acetylation of heat-shock factor protein 1 (HSF1). ${ }^{5,6}$ Folate deficiency sensitizes H19-7 neuronal progenitors to differentiation-associated apoptosis, with increased expression of histone deacetylases (HDAC), leading to impaired vesicular transport and neurite outgrowth. ${ }^{7,8}$ Vitamin shortage downregulates Stat3 signaling through miR-124 upregulation, leading to altered brain development. ${ }^{7}$ The $\mathrm{cbl}$ and folate deficiency during gestation and lactation produces epigenomic deregulations of ER $\alpha$ and ERR $\alpha$, which affect synapsin expression and neuroplasticity in pups. Our recent development of a conditional cMTR mouse will help us to further dissect the specific effects in the brain.

In conclusion, the deficiency in folate and vitamin $\mathrm{B}_{12}$ produces outcomes of fetal programming through epigenomic mechanisms related to imbalanced acetylation/methylation. Some but not all of these effects reflect their key role in SAM synthesis.

\section{Disclosure of Interest: None.}

\section{References}

1. Guéant JL, Namour F, Gueant-Rodriguez RM, Daval JL. Folate and fetal programming: a play in epigenomics? Trends Endocrinol Metab. 2013; 24, 279-288.

2. Guéant JL, Elakoum R, Ziegler $\mathrm{O}$, et al. Nutritional models of foetal programming and nutrigenomic and epigenomic dysregulations of fatty acid metabolism in the liver and heart. Pflugers Arch. 2014; 466, 833-850.

3. Pooya S, Blaise S, Moreno Garcia M, et al. Methyl donor deficiency impairs fatty acid oxidation through pgc-1alpha hypomethylation and decreased ER-alpha, ERR-alpha, and HNF-4alpha in the rat liver. J Hepatol. 2012; 57, 344-351.

4. Garcia MM, Guéant-Rodriguez RM, Pooya $S$, et al. Methyl donor deficiency induces cardiomyopathy through altered methylation/acetylation of PGC-1alpha by PRMT1 and SIRT1. J Pathol. 2011; 225, 324-335.

5. Battaglia-Hsu SF, Akchiche N, Noel N, et al. Vitamin B12 deficiency reduces proliferation and promotes differentiation of neuroblastoma cells and up-regulates PP2A, proNGF, and TACE. Proc Natl Acad Sci USA. 2009; 106, 21930-21935.

6. Ghemrawi R, Pooya S, Lorentz S, et al. Decreased vitamin B12 availability induces ER stress through impaired SIRT1deacetylation of HSF1. Cell Death Dis. 2013; 4, e553.

7. Kerek R, Geoffroy A, Bison A, et al. Early methyl donor deficiency may induce persistent brain defects by reducing Stat3 signaling targeted by miR-124. Cell Death Dis. 2013; 4, e755.

8. Akchiche N, Bossenmeyer-Pourié C, Kerek R, et al. Homocysteinylation of neuronal proteins contributes to folate deficiency-associated alterations of differentiation, vesicular transport, and plasticity in hippocampal neuronal cells. FASEB J. 2012; 26, 3980-3992. 


\section{Exposure to early-life stress: mechanisms of system-wide epigenetic effects}

N. Provençal

Department of Translational Research in Psychiatry, Max-PlanckInstitute of Psychiatry, Munich, Germany

Email: nadine_provencal@mpipsykl.mpg.de

Exposure to early-life stress (ELS) is a well-known major risk factor for developing psychiatric and behavioural disorders later in life. Both prenatal and postnatal stressors have been shown to have a long-lasting impact on adult pathological states. Epigenetic mechanisms have been shown to be, in part, responsible for the embedding of these long-term changes. It was also shown that the differences in these epigenetic mechanisms depend on the type and timing of stress exposure as well as tissue specific $v$. more global changes. In a model of early-life adversity (maternal deprivation) in rhesus macaques, we have shown using genome-wide analysis that differential rearing leads to differential DNA methylation profiles in two tissues, the prefrontal cortex and T cells $(n=8)$. These differentially methylated promoters tended to cluster by both chromosomal regions and gene functions specific to each tissue with some overlap, such as the immune response and regulation of transcription functions. Studying human blood DNA, we also found altered DNA methylation profiles associated with childhood maltreatment $(n=415)$ as well as chronic aggressive behaviour in men and women $(n=40)$. Here as well, we found that genes with altered DNA methylation were involved in immune response and regulation of transcription functions. One of the mechanisms that might lead to these epigenetic alterations in multiple tissues is a long-lasting disruption of the stress hormone system by excessive glucocorticoids (GC) release after ELS exposure. Stress and GCs are known to regulate hippocampal neurogenesis and to induce long-lasting changes in DNA methylation in specific loci such as the glucocorticoid receptor (GR) and FK506-binding protein 5 (FKBP5) in hippocampal but also in blood cells DNAs. Using a genomewide approach, we analysed gene expression and DNA methylation levels of immortalized human hippocampal progenitor cells treated with dexamethasone (Dex, a potent GR agonist) or vehicle at different stages during neurogenesis $(n=12)$. Our preliminary results revealed an effect of Dex treatment on DNA methylation of more than $800 \mathrm{CpG}$ sites and on mRNA expression of -2800 genes during hippocampal differentiation where a significant portion of these alterations were maintained after differentiation, including FKBP5 locus. Some of these differentially methylated sites were also found differentially methylated in blood cells of adult exposed to childhood maltreatment mention above. These preliminary analyses provide evidence of clustered and genome-wide epigenetic effects of GC activation during hippocampal neurogenesis where the timing of the exposure seems to be critical to induce long-lasting changes. In addition, the broad impact of
ELS on DNA methylation in both the brain and the periphery supports the hypothesis that the response to ELS is system-wide and genome-wide and persists to adulthood. A mechanistic understanding of the long-term epigenetic consequences of stress may allow novel, targeted intervention and prevention strategies for behavioural, psychiatric and other stress-associated disorders.

Disclosure of Interest: None.

\section{EARLY EXPOSURE TO POLLUTANTS AND HEALTH}

Early risk factors for childhood cancer

\section{J. Clavel}

INSERM U1018, Center for Research in Epidemiology and Population Health (CESP), U1018, Team Environmental Epidemiology of Cancers, Villejuif, France

\section{Email: jacqueline.clavel@inserm.fr}

Cancer strikes about 1700 children under the age of 15 in France each year, in almost half the cases, it occurs before the age of 5 years. Unlike adult cancers, childhood cancers develop mainly at the expense of embryonic poorly differentiated cells, and carcinomas are exceptional. Lymphoblastic leukemia are the most common and studied childhood's cancer.

A small number of cancers, $<5 \%$ of the cases, are caused by a constitutional mutation in genes involved in embryonic development, cell differentiation, DNA repair, cell proliferation and survival or the immune system. ${ }^{1,2}$ Apart from any predisposing condition, some associations with polymorphisms of genes involved in lymphocytes differentiation have been identified in leukemia by genome-wide association studies.

In children, carcinogenesis occurs probably in two stages. In a number of cases it has been possible to make the molecular evidence of prenatal origin. The factors that favor the first prenatal stage or the second prenatal or postnatal stage are far from being well known. Exposure to ionizing radiations at high doses is the best known factor, and it causes many types of cancer. Similarly, the roles of Epstein-Barr virus infections (Burkitt's and Hodgkin's lymphomas, nasopharyngeal cancer) and Hepatitis B virus (liver cancer) are well established.

Other factors have been associated repeatedly with cancer risk. This is particularly the case of prenatal exposure to pesticides $^{3}$ and, for leukemia, of exposure to heavy traffic roads or to magnetic fields at extremely low frequencies. ${ }^{4} \mathrm{~A}$ lack of exposure to common infections and other immune stimuli in the first months of life also seems to be a risk factor for leukemia. ${ }^{5}$

\section{Disclosure of Interest: None.}

\section{References}

1. Moore SW. Developmental genes and cancer in children. Pediatr Blood Cancer. 2009; 52, 755-760.

2. Stieglitz E, Loh ML. Genetic predispositions to childhood leukemia. Ther Adv Hematol. 2013; 4, 270-290. 
3. Bailey HD, Fritschi L, Infante-Rivard C, et al. Parental occupational pesticide exposure and the risk of childhood leukemia in the offspring: findings from the Childhood Leukemia International Consortium. Int J Cancer. 2014; 135, 2157-2172.

4. Kheifets L, Ahlbom A, Crespi CM, et al. Pooled analysis of recent studies on magnetic fields and childhood leukaemia. Br J Cancer. 2010; 103, 1128-1135.

5. Rudant J, Lightfoot T, Urayama KY, et al. Childhood acute lymphoblastic leukemia and indicators of early immune stimulation: a Childhood Leukemia International Consortium Study. Am J Epidemiol. 2015; 181, 549-562.

\section{PROGRAMMING AND ALLERGY}

\section{Determinants of the atopic march}

A. Magnan, S. Brouard and M. Bodinier

L'institut du thorax, Université de Nantes, UMR INSERM 1087 CNRS 6291, DHU2020 \& ITUN, UMR INSERM 1064, UMR BIA INRA, Nantes, France

Email: antoine.magnan@univ-nantes.fr

The increase in the prevalence of allergy in the last few decades, and especially of atopic dermatitis and asthma, is related to the increase of the frequency of atopy, a genetic and environmental background predisposing to these diseases. That atopy mainly increased among western countries has prompted researchers to incriminate the western way of life in its inception. Into this way of life, a progressive switch from a daily exposure to large amounts of microbes to a deep avoidance of any microbial contact, notably in the first few months of life is incriminated. This so-called hygiene hypothesis has been evoked in large epidemiological studies and verified experimentally. A defect in proper tolerance settings towards non-pathogen antigens owing to a lack of microbial stimulation of such settings in early life could be the substratum of atopy. Deficient Treg- and Breg-cell populations in allergic subjects, consecutive to inefficient stimulation of innate signals of tolerance, illustrate this impairment. In a model of house dust mite-induced asthma, we have recently demonstrated the importance of the B-cell deficiency and showed that Breg cells passively transferred to allergic mice can reverse the allergic phenotype. ${ }^{1,2}$

Of the above-mentioned determinants of atopy, further allergic sensitizations and atopic diseases in already allergic subjects complete the atopic march. Indeed, it is well demonstrated that atopic dermatitis and food allergies are risk factors for allergic asthma. In a mouse model, we have demonstrated that the first sensitization to food increases the respiratory response to a subsequent inhaled allergen.

Can the atopic march be reversed? It is largely demonstrated that specific immunotherapy is able to prevent asthma in atopic subjects suffering from allergic rhinitis. In addition, it is well known that such treatments prevent from new sensitizations. The action of specific immunotherapy is related to its capacity to restore Treg and Breg capacities. Whether the use of specific or non-specific immunotherapies prevents primarily the atopic march in at-risk infants is still to be demonstrated.

\section{Disclosure of Interest: None.}

\section{References}

1. Braza F, Chesne J, Castagnet S, Magnan A, Brouard S. Regulatory functions of $\mathrm{B}$ cells in allergic diseases. Allergy. 2014; 69, 1454-1463.

2. Bihouée T, Bouchaud G, Chesné J, et al. Food allergy enhances allergic asthma in mice. Respir Res. 2014; 15, 142.

\section{DOHaD AND ECONOMICS: EARLY INTERVENTIONS}

\section{Early-life adversity, environmental enrichment and long-term health}

G. Conti

Department of Applied Health Research, University College London, London, UK

Email: gabriella.conti@ucl.ac.uk

I review recent evidence on the importance of investing early in life based on an economic lifecourse approach to human development. ${ }^{1}$ I discuss the long-term costs caused by early-life adversity, and how early-life experiences affect the biology of the body. In addition, I provide complementary evidence on enrichment interventions, which can, at least partially, compensate for prenatal and perinatal adverse environments.

First, I provide evidence based on a long-running experiment on rhesus monkeys that are randomly allocated at birth across different rearing conditions: mother-reared, peer-reared and surrogate peer-reared. I use data from this experiment to show that the lack of a secure attachment relationship in early life (non-maternal rearing) has long-term negative effects on both physical and mental health ${ }^{2}$; that these effects are not ameliorated by a normal social environment later in life; and that they operate at least, in part, through stress-response pathways and changes in the expression of leucocyte genes related to immune function. These findings provide robust evidence that early-life environments can causally affect the biology of the body, and that at the same time intervention is possible before disease becomes manifest.

Second, I provide evidence from randomized controlled trials in humans that enriching the environment of disadvantaged children promote health and development across the lifecourse. In particular, I show recent evidence from the Abecedarian programme that disadvantaged children randomly assigned to treatment have significantly lower prevalence of risk factors for cardiovascular and metabolic diseases in their mid-30s. ${ }^{3}$ The evidence is especially strong for males. In sum, this 
evidence shows that experiences occurring during critical periods of development can have long-term effects, and that, while children can be permanently damaged, the damage can also be remediated. It makes the case that early-life interventions have the potential for preventing disease and promoting health across the lifecourse.

\section{Disclosure of Interest: None.}

\section{References}

1. Conti G. The developmental origins of health inequality. Res Econ Inequality. 2013; 21, 285-309.

2. Conti G, Hansman C, Heckman JJ, et al. Primate evidence on the late health effects of early-life adversity. Proc Nat Acad Sci. 2012; 109, 8866-8871.

3. Campbell F, Conti G, Heckman JJ, et al. Early childhood investments substantially boost adult health. Science. 2014; 343, 1478-1485.

\section{PATERNAL NUTRITION AND TRANSMISSION}

Transgenerational inheritance of diabetes risk by early paternal malnutrition

J. C. Jimenez-Chillaron

Paediatric Hospital Sant Joan de Déu, Endocrinology, Universitat de Bareclona, Barcelona, Spain

\section{Email: jjimenezc@fsjd.org}

It is well known that nutritional imbalances occurring during early development increase the risk of metabolic dysfunction later in life. Strikingly, such nutritionally induced phenotypes can be transmitted to the following generation(s). This phenomenon has been referred as intergenerational or transgenerational effect. Transgenerational effects can be defined as the transmission of a given phenotype from parent to the offspring, which is not mediated by genetic processes (i.e. inheritance of DNA sequence variants). Potential mechanisms include maternal physiology and behaviour, maintenance of environmental factors and epigenetic mechanisms. Importantly, paternal transmission of nutritionally induced phenotypes strongly suggests epigenetic mechanisms in mediating such effects.

Over the last few years, we have developed mouse models of intrauterine and neonatal malnutrition that show intergenerational inheritance of diabetes risk via the paternal line. Here we will review the experimental evidence that supports the potential role of epigenetic mechanisms in mediating inheritance of diabetes risk in mammals.

Clearly, understanding the molecular mechanisms involved in these effects is of great importance to develop rational nutritional interventions to prevent or delay risk of metabolic disorders across multiple generations.

Disclosure of Interest: None.

\section{SHORT CONFERENCES AND POSTERS PRECONCEPTIONAL PROGRAMMING}

PCP-1 - oral

A short periconceptional maternal hyperglycemia is sufficient to disrupt the feto-placental phenotype in a rabbit model

D. Rousseau-Ralliard ${ }^{1^{*}}$, A. Tarrade ${ }^{1^{*}}$, R. Thieme ${ }^{2}$, R. Brat ${ }^{1}$, M.-C. Aubrière ${ }^{1}$, M. Dahirel ${ }^{1}$, A. Rolland ${ }^{1}$, N. Daniel ${ }^{1}$, N. Fournier ${ }^{3}$, P. Boileau ${ }^{4}$, V. Duranthon ${ }^{1}$, A. NavarretteSantos $^{2}$, B. Fischer ${ }^{2}$ and P. Chavatte-Palmer ${ }^{1}$

${ }^{1}$ INRA, UMR 1198, Biology of Development and Reproduction, Jouy-en-Josas, France; ${ }^{2}$ Faculty of Medicine, Halle, Germany; ${ }^{3}$ Univ Paris-Sud, EA 4529, UFR de Pharmacie, ChâtenayMalabry, France; AP-HP (Assistance Publique-Hôpitaux de Paris), Hôpital européen Georges Pompidou, Service de Biochimie, Paris, France; ${ }^{4}$ UVSQ, Médecine néonatale-CHIPS, Poissy, France

*Equal contribution

Email: pascale.chavatte@jouy.inra.fr

Pre-gestational type 1 diabetes (T1D) increases the risk of miscarriage and congenital malformations and programs the offspring to develop metabolic syndrome at adulthood. ${ }^{1}$ Management of maternal diabetes is essential during the gestation but could also be highly important around the conception. Using a rabbit model, ${ }^{2}$ the effects of maternal T1D during the periconceptional period on preimplantation blastocysts has been well documented, ${ }^{3-5}$ but the effects on feto-placental phenotype at $28 \mathrm{dpc}$ (term $=31$ days) need to be explored.

Diabetes was induced by alloxan in dams 7 days before mating. Glycemia was maintained at $15-20 \mathrm{mmol} / \mathrm{l}$ with exogenous insulin injections. At $4 \mathrm{dpc}$, embryos were collected and transferred into non-diabetic recipients. ${ }^{3}$ At $28 \mathrm{dpc}$, control (C) and diabetic (D) fetuses were collected for biometric records, placental analyses including stereology and gene expression, and lipid profiles of feto-placental tissues by gas chromatography. Lipid data were analyzed by principal component analysis.

D-fetuses were growth-retarded, hyperglycemic and dyslipidemic compared with C. Moreover, placental efficiency ${ }^{6}$ was much higher in D-fetuses than in C-fetuses. The volume density of fetal vessels was significantly decreased in D-placentas compared with C-placentas, whereas the volume density of trophoblast tended to increase $(P=0.051)$. This morphometric disruption was associated with a deregulation of the expression of genes related to nutrient supply and lipid metabolism.

In fetal plasma, a specific fatty-acid signature was observed in D- and C-groups. Moreover, the composition of placental and fetal liver membranes differed according to maternal status and fetal sex. Tissues from D-fetuses contained significantly more omega- 6 polyunsaturated fatty acids compared with C-fetuses. Docosahexaenoic acid decreased, whereas linoleic acid increased in the cardiac membranes of D-fetuses, indicating a higher risk of ischemia. 
This study demonstrates that an exposure to high-plasma glucose during the short periconceptional period is sufficient to adversely program fetal phenotype by reducing fetal growth, altering placental function and lipid profiles in all fetal tissues.

\section{Disclosure of Interest: None.}

\section{References}

1. Chia YT, Chua S, Thai AC, Kek LP, Ratnam SS. Congenital abnormalities and pregestational diabetes mellitus in pregnancy. Singapore Med J. 1996; 37, 380-383.

2. Fischer B, Chavatte-Palmer P, Viebahn C, Navarrete Santos A, Duranthon V. Rabbit as a reproductive model for human health. Reproduction. 2012; 144, 1-10.

3. Ramin N, Thieme R, Fischer S, et al. Maternal diabetes impairs gastrulation and insulin and IGF-I receptor expression in rabbit blastocysts. Endocrinology. 2010; 151, 4158-4167.

4. Thieme R, Schindler M, Ramin N, et al. Insulin growth factor adjustment in preimplantation rabbit blastocysts and uterine tissues in response to maternal type 1 diabetes. Mol Cell Endocrinol. 2012; 358, 96-103.

5. Thieme R, Ramin N, Fischer S, Puschel B, Fischer B, Santos AN. Gastrulation in rabbit blastocysts depends on insulin and insulin-like-growth-factor 1. Mol Cell Endocrinol. 2012; 348, 112-119.

6. Fowden AL, Sferruzzi-Perri AN, Coan PM, Constancia M, Burton GJ. Placental efficiency and adaptation: endocrine regulation. J Physiol. 2009; 587, 3459-3472.

\section{PCP-2 - oral}

Maternal weight status before and during pregnancy and offspring's adiposity at 5-6 years of age in the EDEN mother-child cohort

M. Jacota, A. Forhan, M.-A. Charles, B. Heude and the EDEN Mother-Child Cohort Study Group

INSERM Unit 1018-CESP, Team 10 'Épidémiologie du diabète, de l'obésité et des maladies rénales: approche vie entière', Hôpital Paul Brousse, Villejuif, France

Email: madalina.jacota@inserm.fr

Both maternal pre-pregnancy body mass index $(\mathrm{BMI})^{1}$ and gestational weight gain ${ }^{2,3}$ have been related in the literature to birth size and child obesity. We found previously that prepregnancy weight loss in normal-weight mothers was associated to offspring's low birthweight. ${ }^{4}$ Little is known on the role of periconceptional weight status on postnatal growth and adiposity development. Therefore, we studied the relationship of mothers' weight change and status before and during pregnancy with children's growth and fat mass parameters at 5-6 years.

In 950 mother-child pairs from the EDEN Mother-Child Cohort Study, child's $Z$-scores of height and BMI at 5-6 years, fat mass per cent ${ }^{5}$ (FM\%) and indexes of adiposity distribution were related by linear regression to annual pre-pregnancy weight change since the age of 20 (WCBP), maternal pre- pregnancy BMI and specific gestational weight gain (SGWG). We adjusted on pertinent variables of maternal socio-economic status and health, additionally on child's birth size.

Regarding the relation with pre-pregnancy BMI, children born to thinner mothers, although shorter at 5-6 years, had lower BMIs, but also lower FM\% and a less central adiposity distribution. Between -22 and $35 \mathrm{~kg} / \mathrm{m}^{2}$, we noticed no association between maternal BMI and either child outcomes.

Once adjusted for maternal BMI, no association was found between SGWG and any outcome.

After adjustment for BMI and SGWG, WCBP was negatively associated with child's height $Z$-score; similar trends were noted with BMI $Z$-score and FM\%; additional adjustment on child's birth size reinforced these associations.

Pre-pregnancy weight loss seems associated with a postnatal catch-up growth by age 5 years following foetal growth restriction, but we did not find a definite effect on child's adiposity, as hypothesized before. ${ }^{6-8}$ Studies at other ages and with larger ranges of maternal BMI and weight change may bring further evidence on the role of the periconceptional period in adiposity programming.

\section{Disclosure of Interest: None.}

\section{References}

1. Yu Z, Han S, Zhu J, Sun X, Ji C, Guo X. Pre-pregnancy body mass index in relation to infant birth weight and offspring overweight/obesity: a systematic review and meta-analysis. PLoS One. 2013; 8, e61627, doi:10.1371/journal.pone.0061627.

2. Tie HT, Xia YY, Zeng YS, et al. Risk of childhood overweight or obesity associated with excessive weight gain during pregnancy: a meta-analysis. Arch Gynecol Obstet. 2014; 289, 247-257.

3. Mamun AA, Mannan M, Doi SA. Gestational weight gain in relation to offspring obesity over the life course: a systematic review and bias-adjusted meta-analysis. Obes Rev. 2014; 15, 338-347.

4. Diouf I, Charles MA, Thiebaugeorges O, Forhan A, Kaminski M, Heude B; EDEN Mother-Child Cohort Study Group. Maternal weight change before pregnancy in relation to birthweight and risks of adverse pregnancy outcomes. Eur $J$ Epidemiol. 2011; 26, 789-796.

5. Goran MI, et al. Estimating body composition of young children by using bioelectrical resistance. J Appl Physiol. 1993; 75, 1776-1780.

6. Zhang S, Rattanatray L, Morrison JL, Nicholas LM, Lie S, McMillen IC. Maternal obesity and the early origins of childhood obesity: weighing up the benefits and costs of maternal weight loss in the periconceptional period for the offspring. Exp Diabetes Res. 2011; 2011, 585749, doi: 10.1155/2011/585749.

7. Smith J, Cianflone K, Biron S, et al. Effects of maternal surgical weight loss in mothers on intergenerational transmission of obesity. J Clin Endocrinol Metab. 2009; 94, 4275-4283. 8. Matusiak K, Barrett HL, Callaway LK, Nitert MD. Periconception weight loss: common sense for mothers, but what about for babies? J Obes. 2014; 2014, 204295, doi: $10.1155 / 2014 / 204295$. 


\section{PCP-3}

\section{Effects of maternal preconception weight trajectory on offspring health}

M. Lemaire, M. Jouin, P. Panchenko, A. Baklanov, C. Junien and A. Gabory

BDR Biologie du Développement, Reproduction Developmental Biology and Reproduction, UMR INRA-ENVA-CNRS 1198, Jouy en Josas, France

\section{Email: Marion.lemaire@jouy.inra.fr}

An increasing number of childbearing age women are overweight or obese. Current recommendations include a preconceptional weight loss (WL) of $5-10 \%$ to reach a normal pre-pregnancy body mass index. ${ }^{1}$ Although there is evidence that preconceptional WL reduces pregnancy complications but can induce growth retardation ${ }^{2}$ or preterm delivery, ${ }^{3}$ the long-term consequences on offspring health remain unknown. ${ }^{4}$ In the light of the Developmental Origins of Health and Disease hypothesis, maternal pre-pregnancy weight trajectories could have beneficial, neutral or detrimental long-term effects on offspring. ${ }^{5-7}$ Our aim was to investigate the outcomes of preconception WL in obese C57BL/6J female mice on offspring susceptibility to an obesogenic diet in later life. Female mice of the WL group were fed a high-fat diet (HFD) for 2 months and a control diet (CD) for the following 2 months. Two control groups consisted of: lean and obese control (LC and OC), receiving either the CD or HFD diet for 4 months and during gestation/lactation. At weaning, offspring were fed either an HFD or a CD. Weight, caloric intake, glucose metabolism and body composition were followed until sacrifice at 6 months. No significant differences were observed pre-weaning between LC and WL offspring for weight and glycemia. As for OC offspring, they had a higher body weight and fasting hyperglycemia. Sexual dimorphism was observed after weaning for all parameters studied, and as adults all HFD-fed offspring had an increased body weight, adiposity and fasting hyperglycemia, independently of maternal group. In our model, the offspring phenotype relies mainly on the postweaning diet. Despite abundant literature on in utero exposure to an $\mathrm{HFD},{ }^{8}$ one paper reported the absence of association between offspring parameters and preconception HFD. ${ }^{9}$ More investigations are needed to complete this phenotyping and at epigenetic levels to draw conclusions about maternal preconception trajectory effects on offspring health.

\section{Disclosure of Interest: None.}

\section{References}

1. Haute Autorité de Santé. Surpoids et obésité de l'adulte: prise en charge médicale de premier recours. Recommandation debonne pratique, 2011. Haute Autorité de Santé, Saint-Denis-LaPlaine (F), 133pp.

2. Diouf I, Charles MA, Thiebaugeorges O, Forhan A, Kaminski M, Heude B; EDEN Mother-Child Cohort Study Group. Maternal weight change before pregnancy in relation to birthweight and risks of adverse pregnancy outcomes. Eur $J$ Epidemiol. 2011; 26, 789-796.

3. Grieger JA, Grzeskowiak LE, Clifton VL. Preconception dietary patterns in human pregnancies are associated with preterm delivery. J Nutr. 2014; 144, 1075-1080.

4. Attig L, Vigé A, Gabory A, et al. Dietary alleviation of maternal obesity and diabetes: increased resistance to dietinduced obesity transcriptional and epigenetic signatures. PLoS One. 2013; 8, e66816, doi:10.1371/journal.pone.0066816.

5. Forsum E, Brantsaeter AL, Olafsdottir AS, Olsen SF, Thorsdottir I. Weight loss before conception: a systematic literature review. Food Nutr Res. 2013; 57, doi: 10.3402/fnr.v57i0.20522.

6. Zambrano E, Martinez-Samayoa PM, Rodriguez-Gonzalez GL, Nathanielsz PW. Dietary intervention prior to pregnancy reverses metabolic programming in male offspring of obese rats. J Physiol. 2010; 588, 1791-1799.

7. Zhang S, Rattanatray L, Morrison JL, Nicholas LM, Lie S, McMillen IC. Maternal obesity and the early origins of childhood obesity: weighing up the benefits and costs of maternal weight loss in the periconceptional period for the offspring. Exp Diabetes Res. 2011, doi: 10.1155/2011/585749.

8. Williams L, Seki Y, Vuguin PM, Charron MJ. Animal models of in utero exposure to a high fat diet: a review. Biochim Biophys Acta. 2014; 1842, 507-519.

9. Platt KM, Charnigo RJ, Pearson KJ. Adult offspring of high-fat diet-fed dams can have normal glucose tolerance and body composition. J Dev Orig Health Dis. 2014; 5, 229-239.

\section{PCP-4}

\section{A mice model of preconceptional maternal weight loss}

M. Jouin, P. Panchenko, M. Lemaire, A. Gabory and C. Junien

BDR Biologie du Développement, Reproduction Developmental Biology and Reproduction, UMR INRA-ENVA-CNRS 1198, Jouy en Josas, France

Email: melanie.jouin@jouy.inra.fr

More and more women of childbearing age are overweight or obese. To reduce infertility and obstetric complications, weight loss (WL) is recommended. ${ }^{1,2}$ However, whether this WL has positive or deleterious consequences on fetal growth and the long-term health of the children remains to be clarified. ${ }^{3-5}$

Our aim was to develop a mice model of preconceptional maternal WL for further studies within the framework of the $\mathrm{DOHaD}$ field, with relevance to humans.

C57BL/6J female mice received a high-fat diet (HFD) for 2 months, and then a control diet (CD) for 2 months. Body weight and food intake were recorded twice a week. At 2 and 4 months, fasting glycemia, insulin and cholesterol were measured, and glucose metabolism determined with oral glucose tolerance test. Mice were mated with males under a CD and their weight gain was followed during gestation. Control mothers received a CD (lean control) or HFD (obese control) 
during preconceptional/gestation/lactation period. After offspring weaning, the maternal adipose tissues, liver, kidneys and heart were weighed to evaluate maternal body composition and adiposity.

After 2 months on an HFD, females showed a significant weight gain compared with CD-fed mice, were hyperglycemic, glucose-intolerant and hypercholesterolemic. After 2 months on a CD, normalization of weight, carbohydrate and lipid metabolism were observed. At the end of lactation, WL females' body composition was not distinguishable from lean control.

A switch from HFD to a CD induce a massive WL with normalization of metabolic state and body composition in obese females. This model is therefore suitable to investigate effects of maternal ponderal trajectories or massive preconceptional loss, such as that induced by bariatric surgery in human obese patients on offspring development and their long-term health and the underlying molecular mechanisms. ${ }^{6-8}$

\section{Disclosure of Interest: None.}

\section{References}

1. Grieger JA, Grzeskowiak LE, Clifton VL. Preconception dietary patterns in human pregnancies are associated with preterm delivery. J Nutr. 2014; 144, 1075-1080.

2. Forsum E, Brantsaeter AL, Olafsdottir AS, Olsen SF, Thorsdottir I. Weight loss before conception: a systematic literature review. Food Nutr Res. 2013: 10.3402/fnr. v57i0.20522. Epub 2013 Mar 13.

3. Diouf I, Charles MA, Thiebaugeorges O, Forhan A, Kaminski M, Heude B; EDEN Mother-Child Cohort Study Group. Maternal weight change before pregnancy in relation to birthweight and risks of adverse pregnancy outcomes. Eur $J$ Epidemiol. 2011; 26, 789-796.

4. Attig L, Vigé A, Gabory A, et al. Dietary alleviation of maternal obesity and diabetes: increased resistance to dietinduced obesity transcriptional and epigenetic signatures. PLoS One. 2013; 8, e66816, doi:10.1371/journal.pone.0066816, PONE-D-12-19952 [pii].

5. Zambrano E, Martinez-Samayoa PM, RodriguezGonzalez GL, Nathanielsz PW. Dietary intervention prior to pregnancy reverses metabolic programming in male offspring of obese rats. J Physiol. 2010; 588, 1791-1799.

6. Nicholas LM, Rattanatray L, MacLaughlin SM, et al. Differential effects of maternal obesity and weight loss in the periconceptional period on the epigenetic regulation of hepatic insulin-signaling pathways in the offspring. FASEB J. 2013;27, 3786-3796.

7. Gabory A, Roseboom TJ, Moore T, Moore LG, Junien C. Placental contribution to the origins of sexual dimorphism in health and diseases: sex chromosomes and epigenetics. Biol Sex Differ. 2013; 4, 5 [Epub ahead of print].

8. Zhang S, Rattanatray L, Morrison JL, Nicholas LM, Lie S, McMillen IC. Maternal obesity and the early origins of childhood obesity: weighing up the benefits and costs of maternal weight loss in the periconceptional period for the offspring. Exp Diabetes Res. 2011, 585749, doi:10.1155/2011/585749.

\section{MICROBIOTA AND PROGRAMMING}

MP-1

Long-term modulation of gut mast cell- and tryptasemediated gut permeability alterations by neonatal probiotic Lactobacillus amylovorus administration and late high-fat diet in pig offspring born to peripartum antibiotic-treated mothers

J.-P. Lallès ${ }^{1}$, A. Taekema ${ }^{1}$, D. Bertacchini ${ }^{1}$ and H. Smidt ${ }^{2}$

${ }^{1} A D N C$ Food and Digestive, Central and Behavioral Adaptation, INRA, Saint-Gilles, France; ${ }^{2}$ Laboratory of Microbiology,

Wageningen University, Wageningen, The Netherlands

Email: Jean-Paul.lalles@rennes.inra.fr

Mast cells (MC) are key players in long-lasting, stress-induced gut permeability disorders, and probiotics can counteract these alterations in rats. ${ }^{1,2}$ Early-life antibiotic administration disturbs gut barrier transcriptome and increases tissue MC density and proteases in rats. ${ }^{3,4}$ Intestinal fat absorption activates $\mathrm{MC}$ in rats, ${ }^{5}$ whereas maternal provision of linseed (rich in polyunsaturated fatty acids) modulates MC-dependent permeability in pig offspring. ${ }^{6}$ In pigs, maternal antibiotic administration alters gut physiology in adult offspring, ${ }^{7,8}$ but little is known on the ability of probiotics to modulate MC-mediated permeability. We tested the hypothesis that offspring postnatal probiotic administration modulates gut permeability through MC and tryptase in this model. Gestating sows received amoxicillin orally around parturition. Offspring from 12 litters received orally Lactobacillus amylovorus (PROB) every 2-3 days until day 21 . Offspring from 11 litters received sterile culture medium (Control). All offspring were reared similarly until 5 months of age when they continued to be fed the growing diet (low fat, LF) or received LF plus 11\% palm oil (high fat, HF) for 4 weeks. Pig pairs (LF-HF, $n=10$ / treatment) within litters were slaughtered. Gut tissue paracellular (PCP) and transcellular (TCP) permeabilities were investigated in Ussing chambers without/with MC degranulator 48/80 and MC tryptase was assayed (ELISA). Data were analysed with SASMIXED models. Basal gut permeabilities were unaffected. Under 48/80, ileal PCP tended to be reduced for PROB pigs fed LF diet, but ileal TCP was higher in PROB pigs than in controls. Colonic PCP was unaffected, but TCP increased in PROB pigs fed the LF diet. Ileal tryptase was higher in PROB and correlated positively with ileal TCP. In conclusion, early probiotic supplementation to offspring born to mothers treated with amoxicillin around parturition increased stress-induced ileal TCP and MCT in young adult offspring. Colonic TCP also increased following MC degranulation, but tryptase was not modified, suggesting other MC mediators to operate.

\section{Disclosure of Interest: None.}

\section{References}

1. Konturek PC, Brzozowski T, Konturek SJ. Stress and the gut: pathophysiology, clinical consequences, diagnostic approach and treatment options. J Physiol Pharmacol. 2011; 62, 591-599. 
2. Eutamene H, Lamine F, Chabo C, et al. Synergy between Lactobacillus paracasei and its bacterial products to counteract stress-induced gut permeability and sensitivity increase in rats. J Nutr. 2007; 137, 1901-1907.

3. Schumann A, Nutten S, Donnicola D, et al. Neonatal antibiotic treatment alters gastrointestinal tract developmental gene expression and intestinal barrier transcriptome. Physiol Genomics. 2005; 23, 235-245.

4. Nutten S, Schumann A, Donnicola D, et al. Antibiotic administration early in life impairs specific humoral responses to an oral antigen and increases intestinal mast cell numbers and mediator concentrations. Clin Vaccine Immunol. 2007; 14, 190-197.

5. Ji Y, Sakata Y, Yang Q, et al. Activation of rat intestinal mucosal mast cells by fat absorption. Am J Physiol Gastrointest Liver Physiol. 2012; 302, G1292-G1300.

6. Boudry G, Douard V, Mourot J, Lallès JP, Le HuërouLuron I. Linseed oil in the maternal diet during gestation and lactation modifies fatty acid composition, mucosal architecture, and mast cell regulation of the ileal barrier in piglets. $J$ Nutr. 2009; 139, 1110-1117.

7. Boudry G, Perrier C, Savary G, Lallès JP, Le HuërouLuron I. Peripartum antibiotic alters pig ileal barrier function development and modifies ileal response to a high fat diet later in life. European Society for Paediatric Gastroenterology, Hepatology and Nutrition (ESPGHAN), Sorrento, Italy, 25-28 May 2011. 8. Arnal ME, Zhang J, Messori S, Bosi P, Smidt H, Lallés JP. Early changes in microbial colonization selectively modulate intestinal enzymes, but not inducible heat shock proteins in young adult swine. PLoS One. 2014; 4, e87967.

\section{MP-2 - oral}

Long-term modulation of gut-inducible heat-shock proteins and resistance to oxidative stress by neonatal probiotic Lactobacillus amylovorus administration and late high-fat diet in pig offspring born to peripartum antibiotic-treated mothers

M.-E. Arnal ${ }^{1}$, H. Smidt ${ }^{2}$ and J.-P. Lallès ${ }^{1}$

${ }^{1} A D N C$ Food and Digestive, Central and Behavioral Adaptation, INRA, Saint-Gilles, France; ${ }^{2}$ Laboratory of Microbiology,

Wageningen University, Wageningen, The Netherlands

\section{Email: Jean-Paul.lalles@rennes.inra.fr}

Inducible heat-shock proteins (HSP27, HSP70) protect the gut epithelium from stress, owing to anti-oxidant and anti-inflammatory properties. ${ }^{1}$ iHSP levels are stimulated by nutrients, gut microbial components and their metabolites. ${ }^{1,2}$ Early antibiotic-induced microbiota disturbances have immediate and distant effects on gut transcriptome, barrier and inflammation in rodents. ${ }^{3,4}$ Gut-barrier defects are causally involved in lipopolysaccharide-induced metabolic inflammation and obesity in mice. ${ }^{5}$ However, little is known on early programming of gut function. ${ }^{6}$ We showed in a swine model of maternal administration of antibiotic peripartum that long-term alterations in offspring gut microbiota, iHSPs and enzymes are selective, site- and diet-dependent. ${ }^{7}$ Here, we tested the hypothesis that offspring postnatal probiotic administration modulates gut iHSPs and resistance to oxidative stress. Gestating sows received amoxicillin orally around parturition. Offspring from 12 litters were given orally Lactobacillus amylovorus DSM16698 (PROB) every 2-3 days until day 21. Offspring from 11 litters received sterile culture medium (Control). All offspring were reared similarly until 5 months of age when they were continuously fed the growing diet (low fat, LF) or received LF plus $11 \%$ palm oil (high fat) for 4 weeks. Pairs of pigs ( $n=10 /$ treatment) within litters were slaughtered. Gut tissues were analysed for iHSPs, and for transcellular and paracellular permeability and responses to oxidant monochloramine in Ussing chambers. ${ }^{2,7}$ Data were analysed with SAS-MIXED models. Growth and food intake were unaffected. Ileal iHSPs were unchanged, but colonic HSP27 was lower in PROB. Ileal basal electrophysiology was unaffected, but Na-glucose absorption was higher in PROB, and PROB-diet interactions were observed for electrophysiology parameters (Isc, PD) under oxidative stress. Colonic electrophysiology was unaffected, but transcellular permeability was higher in PROB. In conclusion, gut defence systems and mineral movements are complexly modulated by early probiotic administration and late diet in young adult offspring born to antibiotic-treated mothers. Microbiota role and underlying mechanisms is being investigated.

\section{Disclosure of Interest: None.}

\section{References}

1. Petrof EO, Ciancio MJ, Chang EB. Role and regulation of intestinal epithelial heat shock proteins in health and disease. Chin J Dig Dis. 2004; 5, 45-50.

2. Arvans DL, Vavricka SR, Ren H, et al. Luminal bacterial flora determines physiological expression of intestinal epithelial cytoprotective heat shock proteins 25 and 72 . Am J Physiol Gastrointest Liver Physiol. 2005; 288, G696-G704.

3. Schumann A, Nutten S, Donnicola D, et al. Neonatal antibiotic treatment alters gastrointestinal tract developmental gene expression and intestinal barrier transcriptome. Physiol Genomics. 2005; 23, 235-245.

4. Fåk F, Ahrné S, Molin G, Jeppsson B, Weström B.. Microbial manipulation of the rat dam changes bacterial colonization and alters properties of the gut in her offspring. Am J Physiol Gastrointest Liver Physiol. 2008; 294, G148-G154.

5. Cani PD, Delzenne NM. The role of the gut microbiota in energy metabolism and metabolic disease. Curr Pharm Des. 2009; 15, 1546-1558.

6. Lallès JP. Long term effects of pre- and early postnatal nutrition and environment on the gut. J Anim Sci. 2012; 90 (Suppl. 4), 421-429. 
7. Arnal ME, Zhang J, Messori S, Bosi P, Smidt H, Lallès JP. Early changes in microbial colonization selectively modulate intestinal enzymes, but not inducible heat shock proteins in young adult swine. PLoS One. 2014; 4, e87967.

\section{MP-3 - oral}

Neonatal microbiota diversity and structure modulate further resistance to post-weaning diarrhea in pigs

S. Dou ${ }^{1}$, P. Gadonna-Widehem ${ }^{1}$, D. Hamoudi ${ }^{1}$, N. Bahi-Jaber ${ }^{1}$, L. Rhazi ${ }^{2}$, L. Lakhal ${ }^{2}$, M. Dauplay ${ }^{5}$, A. Piñón Quintana ${ }^{3}$, A. Guyonvarch ${ }^{3}$, I. Le Huërou-Luron ${ }^{4}$ and L. Abdennebi-Najar ${ }^{1}$

${ }^{1} U P$ 2012.10.101, EGEAL, Institut Polytechnique LaSalle Beauvais, Beauvais, France; ${ }^{2}$ Institut polytechnique LaSalle Beauvais, Research direction, Beauvais, France; ${ }^{3}$ InVivo NSA, Départment Scientifique, Technique et Innovation, Saint Nolff, France; ${ }^{4}$ INRA UR1341 ADNC, Saint-Gilles, France; ${ }^{5}$ Institut Polytechnique LaSalle Beauvais, France

Email: samir.dou@lasalle-beauvais.fr

Gut resistance to pathogen colonization is ensured by stable microbial ecosystem and represents an important challenge in human and animal health. ${ }^{1}$ This study aimed to explore the impact of early characteristics of the intestinal microbiota on resistance to post-weaning diarrhea ${ }^{2,3}$ in pigs.

Two farms were selected based on their current hygiene status, optimal hygienic conditions $(\mathrm{OHC})$ and poor hygienic conditions (PHC). At 21 days old, four animals from each litter were selected according to their birth weight (1348.2 \pm $333.8 \mathrm{~g})$, colostrum intake $(330.2 \pm 58.8 \mathrm{~g})$ and rank parity, and were weaned in a third independent and dirty experimental environment to challenge their resistance to post-weaning diarrhea. Diversity and composition of sows $(n=5 /$ farm $)$ and their piglets ( $n=4 /$ litters) at $2,7,14$ and 21 days of age were characterized by culture-independent CE-SSCP.

Of piglets from OHC, 13 have contracted Enterobacteriaceae associated post-weaning diarrhea (D-OHC) and seven were resistant (RE-OHC). At 7 days of age, PHC piglets did not show any sign of diarrhea. PHC animals showed a higher bacterial diversity $(4.4 \pm 0.3 v .4 .0 \pm 0.4, P$-value $<0.05)$ and greater stability over age than $\mathrm{OHC}$ piglets. Bacterial diversity of $\mathrm{PHC}$ and RE-OHC piglets was similar ( $4.4 \pm 0.3 v .4 .3 \pm 0.5$, $P$-value $>0.05$, respectively) and these diversity levels were higher than D-OHC $(3.8 \pm 0.3, P$-value $<0.05)$. RE-OHC microbiota structure differed from that of the $\mathrm{D}-\mathrm{OHC}$ group ( $R=0.37, P$-value $<0.001$ ), while a stronger litter (or sow) effect was observed (ANOSIM-R $=0.49, P$-value $<0.001$ ). Litters including $>75 \%$ RE-OHC piglets were very similar in terms of bacterial composition (ANOSIM-R $=0.09$, $P$-value $>0.05$ ) but strongly distinguishable from litters with $<25 \%$ of RE-OHC piglets (ANOSIM-R $=0.62 \pm 0.21, P$-value $>0.05$ ). Early microbiota diversity and structure and thus the resistance to post-weaning diarrhea are environmental and litter-dependent. Exposure to PHC during neonatal period is associated with early high bacterial diversity, stability and resistance to digestive disorders. This suggests a microbiota-mediated programming of pig health.

Disclosure of Interest: The salary of S.D. is funded by InVivo NSA.

\section{References}

1. Manichanh C, Varela E, Martinez C, et al. The gut microbiota predispose to the pathophysiology of acute postradiotherapy diarrhea. Am J Gastroenterol. 2008; 103, 1754-1761. 2. Meurens F, Summerfield A, Nauwynck H, Saif L, Gerdts V. The pig: a model for human infectious diseases. Trends Microbiol. 2012; 20, 50-57.

3. De La Cochetière MF, Montassier E, Hardouin JB, et al. Human intestinal microbiota gene risk factors for antibioticassociated diarrhea: perspectives for prevention. Risk factors for antibiotic-associated diarrhea. Microb Ecol. 2010; 59, 830-837.

\section{MP-4}

Chronic stress triggers sex-specific divergent trajectories of gene expression in mouse adipose depots

A. Désir-Vigné, H. Eutamène, L. Ferrier and I. Olivier

INRA, UMR 1331 TOXALIM, Neuro-Gastroenterology and Nutrition Group, Toulouse, France

Email: axel.desir@gmail.com

Irritable bowel syndrome (IBS) is a functional gastrointestinal disorder characterized by a visceral hypersensitivity, increased intestinal permeability and a low-grade inflammation. ${ }^{1}$ Etiology includes early traumatic events, ${ }^{2,3}$ restricted fetal growth ${ }^{4}$ and stresses. ${ }^{5}$ These events could induce an accumulation of the abdominal adipose tissue (AAT) in infants, ${ }^{6-8}$ which in turn may contribute to metabolic diseases in further stages of life. ${ }^{9}$ The involvement of the visceral adipose tissue on IBS physiopathology is unknown so far. The aims of our study were (i) to characterize the various adipose depots developed by mice submitted to chronic stress either in the neonatal period (maternal deprivation) or in adulthood (water avoidance stress) showing a IBS-like symptomatology; (ii) to examine the impact of mediators of this tissue on gut permeability; and (iii) to investigate the Corticotropinreleasing hormone receptor (CRHr) expression profile.

$\mathrm{C} 3 \mathrm{H} / \mathrm{HeN}$ mice pups were stressed by separating them from dam $3 \mathrm{~h}$ daily between postnatal days 2 and 15 (maternal deprivation). In the case of water and avoiding stress, adult mice were placed on block affixed to a tank filled with cold water for a period of $1 \mathrm{~h}$ daily for 5 consecutive days. Adipose tissue depots were harvested to assess mRNA expression. Gut permeability was determined in Ussing chambers in the presence of conditioned medium from the adipose tissue cultures of neo-stressed mice.

Stresses affected AAT mRNA expression of pro-inflammatory markers, Pref- 1 and CRH-1 receptor in location and sex-dependent manners. In contrast to male mice, deposits coming from female 
mice were characterized by an anti-inflammatory profile. Mediators secreted from the male mesenteric adipose tissue decreased jejunal and colonic permeability, contrary to what would be expected.

Our results suggest that neonatal stress could play a role in IBS through AAT development. Other studies are required to define the role of AAT-secreted factors in IBS, especially in the context of micro-inflammation and post-infection.

\section{Disclosure of Interest: None.}

\section{References}

1. Longstreth GF, Thompson WG, Chey WD, Houghton LA, Mearin F, Spiller RC. Functional bowel disorders. Gastroenterology. 2006; 130, 1480-1491.

2. Hislop IG. Childhood deprivation: an antecedent of the irritable bowel syndrome. Med J Aust. 1979; 1, 372-374.

3. Bradford K, Shih W, Videlock EJ, et al. Association between early adverse life events and irritable bowel syndrome. Clin Gastroenterol Hepatol. 2012; 10, 385-390.

4. Bengtson MB, Rønning T, Vatn MH, Harris JR. Irritable bowel syndrome in twins: genes and environment. Gut. 2006; 55, 1754-1759.

5. Chang L. The role of stress on physiologic responses and clinical symptoms in irritable bowel syndrome. Gastroenterology. 2011; 140, 761-765.

6. Uthaya S, Thomas EL, Hamilton G, Doré CJ, Bell J, Modi N. Altered adiposity after extremely preterm birth. Pediatr Res. 2005; 57, 211-215.

7. Fowden AL, Forhead AJ. Endocrine mechanisms of intrauterine programming. Reproduction. 2004; 127, 515-526.

8. Barker DJ, Shiell AW, Barker ME, Law CM. Growth in utero and blood pressure levels in the next generation. J Hypertens. 2000; 18, 843-846.

9. Lam YY, Ha CW, Campbell CR, et al. Increased gut permeability and microbiota change associated with mesenteric fat inflammation and metabolic dysfunction in diet-induced obese mice. PLoS One. 2012; 7, e34233.

\section{MP-5}

Does early oligosaccharides consumption affect pancreas maturation?

S. Blat ${ }^{1}$, G. Le Dréan ${ }^{2}$, G. Randuineau ${ }^{1}$, P. Theulier ${ }^{2}$, I. Nogret ${ }^{1}$, B. Castellano ${ }^{2}$, A. David-Sochard ${ }^{2}$, G. Poupeau ${ }^{2}$, P. Parnet ${ }^{2}$ and C. Michel $^{2}$

${ }^{1}$ INRA UR1341 ADNC, St-Gilles, France; ${ }^{2}$ INRA-Université de Nantes, UMR1280 PhAN, Nantes, France

\section{Email: Catherine.Michel@univ-nantes.fr}

Oligosaccharides (OS) are commonly added to infant formulae to better mimic maternal milk. However, their delayed impacts on adult health are poorly characterized. As OS are known to stimulate colonic fermentation and GLP-1 production by L-cells in adult animals, ${ }^{1,2}$ we hypothesized that early OS consumption could modulate endocrine pancreas maturation through the action of GLP-1 on neogenesis and proliferation of $\beta$-cells ${ }^{3}$ with possible consequence on adult metabolism.

Suckling rat pups were supplemented with FOS or GOS/inulin $\operatorname{mix}(2.5 \mathrm{~g} / \mathrm{kg})$, or control solution from days 5 to 14 . Pups were either sacrificed at PND8 or at PND14 or weaned at PND21 to standard chow and followed up until adulthood. Caecocolonic concentration of fermentation products, plasma concentration of total GLP-1, density of colonic GLP-1 producing L-cells, endocrine pancreas anatomy were characterized during supplementation, whereas oral glucose tolerance test was investigated at adulthood.

At PND8 and PND14, OS supplementation increased caecocolonic concentration of fermentation products but did not significantly affect the plasma concentration of GLP-1, although the density of GLP-1-positive L-cells tended to be increased at PND8 in pups supplemented with FOS [117 $\pm 11 v$. $94 \pm 11$ cells $/ \mathrm{mm}^{2}$ in cytotoxic T-lymphocyte (CTL)]. The diameter of endocrine pancreatic islets tend to be decreased at PND8 in pups supplemented with FOS $(59.0 \pm 2.9 v .63 .8 \pm 3.4 \mu \mathrm{m}$ in CTL), but this was no longer true at PND14. GOS/In supplementation was devoid of any significant impact on endocrine pancreas anatomy. None of the treatments significantly altered the metabolic response to oral glucose load in adulthood.

We concluded that very early OS supplementation, yet impacting caecocolonic fermentation, did not modify endocrine pancreas maturation and adult response to glucose load in rat. Subject to the fact that this holds true for humans, this is reassuring considering that the current study investigated type and doses of OS mimicking those commonly prescribed in infants.

\section{Disclosure of Interest: None.}

\section{References}

1. Delzenne N, Cani PD, Neyrinck AM. Modulation of glucagon-like peptide 1 and energy metabolism by inulin and oligofructose: experimental. J Nutr. 2007; 137, 2547 S.

2. Overduin J, Schoterman MH, Calame W, Schonewille AJ, Ten Bruggencate SJ. Dietary galacto-oligosaccharides and calcium: effects on energy intake, fat-pad weight and satiety-related, gastrointestinal hormones in rats. Br J Nut. 2013; 109, 1338.

3. Kieffer TJ, Habener JF. The glucagon-like peptides. Endocr Rev. 1999; 20, 876.

\section{MP-6}

Prevention of gut leakiness in pups exposed to chronic maternal separation prevents long-term emotional disturbances in adulthood

M. Darnaudéry ${ }^{1}$, A. Minni ${ }^{1}$, L. Xia ${ }^{1}$, A. Lépinay ${ }^{1}$, L. Ferrier ${ }^{2}$, S. Layé ${ }^{1}$ and V. Théodorou ${ }^{2}$

${ }^{1}$ Lab NutriNeurO, UMR INRA 1286, University of Bordeaux, Bordeaux, France; ${ }^{2}$ Neurogastroenterology \& Nutrition, INRA, Toxalim, Toulouse, France

Email: muriel.darnaudery@u-bordeaux.fr 
Depression and anxiety disorders are often comorbid with functional intestinal disorders including irritable bowel syndrome. ${ }^{1}$ In rodents, maternal separation (MS) induces enhanced anxiety-like behaviors, hyper-responsiveness of the hypothalamicpituitary adrenal axis (HPA) to stress but also long-lasting gastrointestinal dysfunctions in adulthood. ${ }^{2}$ Recent studies indicate that MS produces an increase of the gastrointestinal barrier permeability and bacterial translocation. ${ }^{3,4}$ The present study aims to determine whether the restoration of a normal intestinal permeability in stressed pups with a myosin light-chain kinase (MLCK) inhibitor (ML-7) during neonatal period will protect against the long-term effects of early stress. Our results show that neonatal inhibition of the intestinal permeability in stressed pups reversed some of the long-term emotional disturbances and HPA axis alterations induced by early stress. Moreover, we demonstrate that transgenic mice with permanent increase in intestinal permeability display emotional disturbances resembling early stress effects. In conclusion, our study suggests that modifications of gut function play a critical role in the long-lasting effects of early stress.

\section{Disclosure of Interest: None.}

\section{References}

1. Chaloner A, Greenwood-Van Meerveld B. Early life adversity as a risk factor for visceral pain in later life: importance of sex differences. Front Neurosci. 2013; 7, 13.

2. O'Mahony SM, Hyland NP, Dinan TG, Cryan JF. Maternal separation as a model of brain-gut axis dysfunction. Psychopharmacology (Berl). 2011; 214, 71-88.

3. Gareau MG, Jury J, Yang PC, MacQueen G, Perdue MH. Neonatal maternal separation causes colonic dysfunction in rat pups including impaired host resistance. Pediatr Res. 2006; 59, 83-88.

4. Moussaoui N, Braniste V, Ait-Belgnaoui A, et al. Changes in intestinal glucocorticoid sensitivity in early life shape the risk of epithelial barrier defect in maternal-deprived rats. PLoS One. 2014; 9, e88382.

\section{EPIGENETICS}

\section{EPGN-1}

\section{Placenta and endometrium imprinting related to piglet maturity}

A. Bonnet ${ }^{1}$, P. Chavatte-Palmer ${ }^{2}$, A. Tarrade ${ }^{2}$, J. Riquet ${ }^{1}$, L. Canario ${ }^{1}$, V. Voillet ${ }^{1}$, M. San-Cristobal ${ }^{1}$, S. Maman ${ }^{3}$, C. Donnadieu ${ }^{4}$, S. Valière ${ }^{4}$ and L. Liaubet ${ }^{1}$

${ }^{1} I N R A$, GenPhySE (Génétique, Physiologie et Systèmes d'Elevage), UMR 1388, INRA-ENSAT-ENVT, Castanet-Tolosan, France; ${ }^{2} I N R A, B D R$ Biologie du Développement et de la Reproduction, UMR INRA-ENVA-CNRS 1198, Jouy en Josas, France; ${ }^{3} I N R A$, SIGENAE, UMR1388 GenPhySE, Castanet-Tolosan, France;

${ }^{4}$ GeT-PlaGe, Genotoul, INRA Auzeville Castanet-Tolosan, France

Email: Agnes.bonnet@toulouse.inra.fr
During the last decade, pig selection focused on prolificacy and merit carcass improvement. The non-expected consequence observed is a substantial increase in piglet mortality before weaning partially owing to less piglet maturity at birth. ${ }^{1}$ Maturity is defined as the complete development allowing survival at birth. The process of maturity acquisition occurred at the end of the gestation, and its possible variation in relation to genetic and maternal uterine environment play a key role in the early piglet mortality. The piglet survival is positively correlated to placenta efficiency. ${ }^{2}$ Placenta regulates the distribution of available resources by adaptating its phenotype (size, morphology, metabolism, transport, etc.) via essential epigenetic mechanisms. ${ }^{3,4}$ Placenta genomic imprinting evolves in the function of developmental stages, sex, cell types and species, ${ }^{5}$ and have important roles in determining life expectancy ${ }^{6}$ and quantitative traits. ${ }^{7}$

We will take advantage of a genetic protocol producing pure and reciprocal crossed fetus using two extreme breeds for fetal maturity: Large White and Meishan (MS) showing, respectively, important and little neonatal death (PORCINET, ANR-09-GENM-005) and a better placental efficiency in MS environment. ${ }^{8}$ A first transcriptomic analysis in the fetal muscle tissue of reciprocal fetuses identified 472 genes expression influenced by one of the parental genomes. Some of these genes are known to be imprinted, for example, IGF2 and MAGEL2. In this context, our objective is to establish relationship between the placenta and endometrium epigenomes with newborn pigs survival at birth. First, we propose to evaluate the imprinting plasticity related to genetic environment at the end of the pig fetal development (90 out of 110 days post coïtum) simultaneously in the two adjacent tissues.

These results will clarify the effect of genetic environment for a subset of imprinted genes in pig and progress in the identification of new maturity markers able to estimate and improve the survival potential and robustness.

\section{Disclosure of Interest: None.}

\section{References}

1. Canario L, Père MC, Tribout $\mathrm{T}$, et al. Estimation of genetic trends from 1977 to 1998 of body composition and physiological state of Large White pigs at birth. Animal. 2007; 1, 1409-1413.

2. Leenhouwers JI, Knol EF, de Groot PN, Vos H, van der Lende T. Fetal development in the pig in relation to genetic merit for piglet survival. J Anim Sci. 2002; 80, 1759-1770.

3. Fowden AL, Coan PM, Angiolini E, Burton GJ, Constancia M. Imprinted genes and the epigenetic regulation of placental phenotype. Prog Biophys Mol Biol. 2011; 106, $281-288$.

4. Tunster SJ, Jensen AB, John RM. Imprinted genes in mouse placental development and the regulation of fetal energy stores. Reproduction. 2013; 145, 117-137.

5. Frost JM, Moore GE. The importance of imprinting genes in the human placenta. PLoS Genet. 2010; 6, e1001015. 
6. Thornburg KL, Shannon J, Thuillier P, Turker MS. In utero life and epigenetic predisposition for disease. Adv Genet. 2010; 71, 57-78.

7. Jammes H, Junien C, Chavatte-Palmer P. Epigenetic control of development and expression of quantitative traits. Reprod Fertil Dev. 2011; 23, 64-74.

8. Ford SP. Embryonic and fetal development in different genotypes in pigs. J Reprod Fertil Suppl. 1997; 52, 165-176.

\section{EPGN-2}

\section{Excess of methyl donors in maternal diet affects postnatal downregulation of Igf2, Igf2r and $\mathrm{H} 19$ genes in liver}

\author{
V. Amarger, F. Giudicelli, A. Pagniez and P. Parnet \\ INRA-Nantes University, UMR1280 PhAN, Nantes, France
}

Email: valerie.amarger@unv-nantes.fr

Fetal and early postnatal growth is a complex phenomenon submitted to genetic, hormonal and environmental factors. ${ }^{1}$ Alterations in fetal nutrition may result in developmental adaptations, possibly through modifications of the epigenetic regulation of the genome expression. Imprinted genes, on which expression depends on a strict epigenetic regulation, have received a special interest as possible mediators of developmental programming effects. ${ }^{2,3}$

This study examined the joint influence of protein restriction (PR) and methyl donor (MD) supplementation in maternal diet during preconception, gestation and lactation on the expression in the liver of imprinted genes involved in fetal growth and postnatal metabolic adaptation. Several imprinted genes were influenced either by maternal PR or by MD supplementation or by the combination of both conditions. The most striking effect was a significant increase in Igf2 (average 20-fold) and H19 (four-fold) expression at weaning in the offspring of MD-supplemented dams, whereas these genes are normally strongly downregulated after birth. A significant but lower effect was measured in the offspring exposed to PR only. On the other hand, the Igf2r gene was overexpressed in response to maternal $\mathrm{PR}$, independently of $\mathrm{MD}$ supplementation. An extensive DNA methylation study was conducted by pyrosequencing on offspring liver DNA at 21 days of age on a total of 120 CpG sites distributed in Igf2 DMRO, DMR1, DMR2, the imprinting control region situated upstream of $H 19$ and H19 promoter. This analysis revealed very heterogenous methylation profiles through these genomic regions. We did not observe any massive effect of maternal nutrition on the methylation level of any of the analyzed regions but rather moderate effect on the specific $\mathrm{CpG}$ sites. These observations suggest that DMRs are most probably resistant to strong epigenetic changes, which highlight the high complexity of the epigenetic regulation of imprinted genes and their response to environmental factors such as nutrition. ${ }^{4}$

Disclosure of Interest: None.

\section{References}

1. Gicquel C, Le Bouc Y. Hormonal regulation of fetal growth. Horm Res. 2006; 65(Suppl. 3), 28-33.

2. Curley JP, Mashoodh R. Parent-of-origin and transgenerational germline influences on behavioral development: the interacting roles of mothers, fathers, and grandparents. Dev Psychobiol. 2010; 52, 312-330.

3. Junien C, Nathanielsz P. Report on the IASO Stock Conference 2006: early and lifelong environmental epigenomic programming of metabolic syndrome, obesity and type II diabetes. Obes Rev. 2007; 8, 487-502.

4. Ivanova E, Chen JH, Segonds-Pichon A, Ozanne SE, Kelsey G. DNA methylation at differentially methylated regions of imprinted genes are resistant to developmental programming by maternal nutrition. Epigenetics. 2012; 7, 1200-1210.

\section{EPGN-3 - oral \\ RNA-mediated paternal heredity of diet-induced obesity and diabetes}

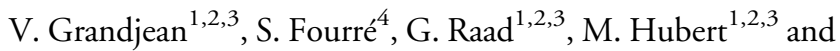
M. Rassoulzadegan ${ }^{1,2,3}$

${ }^{1}$ INSERM, U1091, Nice, France; ${ }^{2}$ CNRS, UMR7277, Nantes, France; ${ }^{3}$ University of Nice-Sophia Antipolis, UFR Sciences, Nice, France; ${ }^{4}$ Institut de Pharmacologie Moléculaire et Cellulaire (IPMC), UMR 6079 CNRS-UNSA, Sophia Antipolis, France

Email: grandjea@unice.fr

Epidemiological surveys have previously indicated that obesity and type II diabetes generated by lipid-rich diets are efficiently inherited, both paternally and maternally. ${ }^{1-4}$ This apparent exception to the fundamental law of non-heritability of acquired characteristics was recently documented in laboratory organisms, but the transgenerational signal remained a matter of speculation. ${ }^{5}$ In this study, we show that experimental transfer of testis RNA from males raised on high-fat diets to healthy one-cell embryos results in adult development of the entire pathology, including obesity, high blood glucose level, and resistance to insulin and glucose intolerance. Transgenerational maintenance of the syndrome thus appears as one instance of the RNA-mediated heredity of epigenetic traits recently documented in experimental systems from the worm to the mouse. ${ }^{6-10}$ To identify putative inducers of metabolic syndrome, we first developed a comparative microarray hybridization analysis of the inducing and control testis RNAs, but we did not detect the differential expression of known regulatory loci. Deep sequencing of the small non-coding fraction of the inducer and control RNAs then showed variations in copy numbers of a series of pi- and mi-RNAs. Tested by microinjection into healthy one-cell embryos, one of the upregulated microRNAs induced obesity and metabolic alterations similar to the diet-induced pathology but no overt diabetes. The phenotype was inherited by the male and female offspring in crosses with healthy partners. 
Questions of interest for future studies include the relationship between a lipid-rich diet and changes in testicular RNAs and the nature of the mark imprinted on the one-cell embryo by RNA transfer that lead to pathological developments in later stages of life.

Disclosure of Interest: None.

\section{References}

1. Chen L, Magliano DJ, Zimmet PZ. The worldwide epidemiology of type 2 diabetes mellitus - present and future perspectives. Nat Rev Endocrinol. 2012; 8, 228-236.

2. Kaati G, Bygren LO, Pembrey M, Sjostrom M. Transgenerational response to nutrition, early life circumstances and longevity. Eur J Hum Genet. 2007; 15, 784-790.

3. Painter RC, Osmond C, Gluckman P, Hanson M, Phillips DI, Roseboom TJ. Transgenerational effects of prenatal exposure to the Dutch famine on neonatal adiposity and health in later life. BJOG. 2008; 115, 1243-1249.

4. Veenendaal MV, Painter RC, de Rooij SR, et al. Transgenerational effects of prenatal exposure to the 1944-45 Dutch famine. BJOG. 2013; 120, 548-553.

5. Carone BR, Fauquier L, Habib N, et al. Paternally induced transgenerational environmental reprogramming of metabolic gene expression in mammals. Cell. 2010; 143, 1084-1096.

6. de Vanssay A, Bouge AL, Boivin A, et al. Paramutation in Drosophila linked to emergence of a piRNA-producing locus. Nature. 2012; 490, 112-115.

7. Gapp K, Jawaid A, Sarkies P, et al. Implication of sperm RNAs in transgenerational inheritance of the effects of early trauma in mice. Nat Neurosci. 2014; 17, 667-669.

8. Grandjean V, Gounon P, Wagner N, et al. The miR-124Sox9 paramutation: RNA-mediated epigenetic control of embryonic and adult growth. Development. 2009; 136, 3647-3655.

9. Rassoulzadegan M, Grandjean V, Gounon P, Vincent S, Gillot I, Cuzin F. RNA-mediated non-Mendelian inheritance of an epigenetic change in the mouse. Nature. 2006; 441, 469-474.

10. Shirayama M, Seth M, Lee HC, et al. piRNAs initiate an epigenetic memory of nonself RNA in the $C$. elegans germline. Cell. 2012; 150, 65-77.

\section{EPGN-4}

Research of microRNA biomarkers of gestational diabetes in bloods of umbilical cords

S. Doubi-Kadmiri ${ }^{1}$, A. Baroin-Tourancheau ${ }^{1}$, M.-A. Charles, B. Heude ${ }^{2}$, L. Amar ${ }^{1}$ and the EDEN Mother-Child Cohort Study Group

${ }^{1}$ Centre de Neurosciences de Paris-Sud (CNPS)/UMR 8195, Equipe Neuroendocrinologie Moléculaire de la Prise Alimentaire (NMPA), IBAIC, Orsay, France; ${ }^{2}$ Epidémiologie du diabète, de l'obésité et des maladies rénales: approche 'vie entire', Villejuif, France.

Email: barbara.heude@inserm.fr
MicroRNAs (miRNAs) are RNAs of 18-24 bases that have been known to regulate gene expression in mammals. MiRNAs are essential during spermatogenesis, in post-implantation development and adult somatic tissues. MiRNAs mediate post-transcriptional regulation of messenger RNA. Different prediction programmes and bioinformatic analyses provide lists of candidate targets for each miRNA. Quantitative mass spectrometry analysis following introduction or depletion of some miRNAs has shown an effective control of the tested miRNAs over $-50 \%$ of their predicted targets. Thus, each miRNA may modulate the expression of a very large set of genes.

In the EDEN mother-child cohort fasting blood samples have been collected from the mother at 24-28 weeks of amenorrhoea before the screening test for gestational diabetes. Cord blood was collected at birth. Plasma and serum samples from maternal venous blood and cord blood have been stored at $-80^{\circ} \mathrm{C}$. Gestational diabetes was diagnosed in $125 \mathrm{EDEN}$ women based on the screening test, according to the Carpenter and Coustan criteria, or retrieved from the obstetrical file if diagnosed later in pregnancy. Both maternal and cord plasma are available for 94 of these women.

This project, of which preliminary results will be presented, aims at studying transmission of circulating miRNA from mothers to foetus. We will first analyse the profiles of circulating miRNAs in the plasma of healthy mothers and in the umbilical cord of their offspring to investigate the transmission of maternal circulating miRNAs to the foetus. We will then compare these patterns of transmission to those of the mother-child pairs of mothers having developed gestational diabetes. The profile of miRNA circulating in maternal blood and transmitted to the foetus will also be studied in relation to maternal food intake patterns characterized by principal component analysis from the food frequency questionnaires self-administered during pregnancy and after delivery.

Disclosure of Interest: None.

\section{EPGN-5}

Genome-wide analysis of DNA methylation and gene expression in liver in response to maternal proteinrestriction or methyl donor deficiency reveal a set of genes that might drive the nutritional programming of metabolic disorders irrespective of the nutritional insult

G. Chen ${ }^{1}$, J. Broséus ${ }^{1,2^{*}}$, S. Hergalant ${ }^{1 *}$, A. Donnart ${ }^{3}$,

C. Chevalier ${ }^{3}$, J.-L. Guéant ${ }^{1,2}$, F. Bolaños-Jiménez ${ }^{4}$ and

R. Houlgatte ${ }^{1,2}$

${ }^{1}$ INSERM U954, Nancy, France; ${ }^{2} \mathrm{CHU}$ de Nancy, Nancy, France; ${ }^{3}$ Plateforme de Génomique Intégrative de Nantes, Nantes, France; ${ }^{4} U M R 1280$ Physiologie des Adaptations Nutritionnelles, INRA-Université de Nantes, Nantes, France

* These authors contributed equally to this work

Email: gailichen0203@gmail.com

One of the most striking features of metabolic programming is that a common physiopathological output at adulthood is obtained 
irrespective of the nutritional insult during early life. This has led to suggest that the metabolic alterations due to early nutritional stress might result from the programming of only a small number of genes, which act as gatekeepers of a fundamental gene network or signalling pathway. ${ }^{1}$ Here we aimed to test this hypothesis through the combined analysis of the transcriptome and methylome in rat liver samples derived from animals born to dams fed either a lowprotein diet (protein restriction, PR) or a diet without vitamin $B_{12}$ and folate (methyl donor deficiency, MDD) through gestation and lactation. At weaning, the offspring born to MDD dams were killed, whereas the pups from the low-protein-fed (LP) group were fed standard chow until the age of 6 months. The genome-wide expression and DNA metylation results obtained using these models were crossed-linked to previous methylome and transcriptome data obtained using liver from LP pups killed at birth. ${ }^{2}$ This analysis revealed a common set of 46 genes that were upregulated in the three models of metabolic programming compared with control animals. A similar number of genes (42) were commonly downregulated by maternal MDD and maternal PR. Most of the upregulated genes are involved in the regulation of mitochondrial function, whereas the downregulated genes are mainly involved in the regulation of cell proliferation and gene expression. We identified also a set of 122 genes whose methylation levels were changed in the same direction by methyl donor deficiency and protein restriction. Of them, 29 genes exhibited concomitant changes in gene expression and DNA methtylation in response to maternal PR or MDD. These observations sustain the hypothesis that a small set of core genes underlies the programming of metabolic disorders irrespective of the nutritional insult.

\section{Disclosure of Interest: None.}

\section{References}

1. McMullen S, Langley-Evans SC, Gambling L, et al. A common cause for a common phenotype: the gatekeeper hypothesis in fetal programming. Med Hypotheses. 2012; 78, 88-94.

2. Altobelli G, Bogdarina IG, Stupka E, Clark AJ, LangleyEvans S. Genome-wide methylation and gene expression changes in newborn rats following maternal protein restriction and reversal by folic acid. PLoS One. 2013; 8, e82989, doi: 10.1371/journal.pone.0082989.

\section{EPGN-6 - oral \\ Impact on epigenetic machinery gene expression and on feto-placental development of preconceptional maternal weight loss}

P. Panchenko, L. Jouneau, M. Jouin, M. Lemaire, C. Junien and A. Gabory

BDR Biologie du Développement et Reproduction Developmental Biology and Reproduction, UMR INRA-ENVA-CNRS 1198, Jouy en Josas, France

Email: polina.panchenko@jouy.inra.fr
Whether the currently recommended preconceptional weight loss (WL) for obese women is beneficial/detrimental for fetoplacental development remains poorly explored ${ }^{1-3}$ and even less on the long term. ${ }^{4,5}$ Obesity, even if corrected before conception, and the WL processes could be 'memorized' via epigenetic mechanisms perturbing expression of the key developmental genes leading to altered fetal programming. ${ }^{6-8}$ Our aim was to investigate the effects of maternal WL after diet-induced obesity on feto-placental development and on gene expression in male and female mice offspring. During the preconception period, female $\mathrm{C} 57 \mathrm{Bl} / 6 \mathrm{~J}$ mice were fed a high-fat diet (HFD) for 2 months, leading to obesity and then a control diet (CD) for 2 months, leading to a complete WL. In parallel, the obese control group (OC) was fed an HFD and the lean control group (LC) a CD throughout the preconceptional period and gestation. At embryonic day 18 (E18.5), OC fetuses presented with intrauterine growth retardation (IUGR), whereas WL fetuses, despite maternal weight normalization before conception, showed a significantly decreased weight at term that was intermediate between the OC and LC fetuses. Placental weight was not affected by diet. The gene expression of 60 epigenetic machinery and 30 key developmental genes was analyzed in the placental labyrinth and fetal liver using RTq-PCR Taqman custom array card. The expression of several epigenetic machinery genes was altered in the OC fetuses. In the WL fetuses the level of expression of some genes was restored to the level of the LC fetuses, whereas other genes showed similar profiles as in the OC fetuses. Thus, correction of maternal obesity by nutritional intervention in the preconceptional period only partially protects the offspring from IUGR. We show that modulation of the histone acetylation-deacetylation switch could play a role in fetal programming. ${ }^{9}$ Further studies at the genome-wide level will elucidate the epigenetic targets and mechanisms of placental/fetal programming triggered by maternal ponderal trajectories.

\section{Disclosure of Interest: None.}

\section{References}

1. Diouf I, Charles MA, Thiebaugeorges O, Forhan A, Kaminski M, Heude B; EDEN Mother-Child Cohort Study Group. Maternal weight change before pregnancy in relation to birthweight and risks of adverse pregnancy outcomes. Eur $J$ Epidemiol. 2011; 26, 789-796.

2. Grieger JA, Grzeskowiak LE, Clifton VL. Preconception dietary patterns in human pregnancies are associated with preterm delivery. J Nutr. 2014; 144, 1075-1080.

3. Forsum E, Brantsaeter AL, Olafsdottir AS, Olsen SF, Thorsdottir I. Weight loss before conception: a systematic literature review. Food Nutr Res. 2013; 57.

4. Attig L, Vigé A, Gabory A, et al. Dietary alleviation of maternal obesity and diabetes: increased resistance to dietinduced obesity transcriptional and epigenetic signatures. PLoS One. 2013; 8, e66816.

5. Zambrano E, Martinez-Samayoa PM, RodriguezGonzalez GL, Nathanielsz PW. Dietary intervention prior to 
pregnancy reverses metabolic programming in male offspring of obese rats. J Physiol. 2010; 588, 1791-1799.

6. Nicholas LM, Rattanatray L, MacLaughlin SM, et al. Differential effects of maternal obesity and weight loss in the periconceptional period on the epigenetic regulation of hepatic insulin-signaling pathways in the offspring. Faseb J. 2013; 27, 3786-3796.

7. Gabory A, Roseboom TJ, Moore T, Moore LG, Junien C. Placental contribution to the origins of sexual dimorphism in health and diseases: sex chromosomes and epigenetics. Biol Sex Differ. 2013; 4, 5.

8. Zhang S, Rattanatray L, Morrison JL, Nicholas LM, Lie S, McMillen IC. Maternal obesity and the early origins of childhood obesity: weighing up the benefits and costs of maternal weight loss in the periconceptional period for the offspring. Exp Diabetes Res. 2011; 2011, 585749.

9. Sookoian S, Gianotti TF, Burgueno AL, Pirola CJ. Fetal metabolic programming and epigenetic modifications: a systems biology approach. Pediatr Res. 2013; 73, 531-542.

\section{EPGN-7}

Placental contribution to nutritional programming of health and diseases: ontogenesis epigenetics and sexual dimorphism

A. Gabory, P. Panchenko, L. Ferry and C. Junien

BDR Biologie du Développement et Reproduction Developmental Biology and Reproduction, UMR INRA-ENVA-CNRS 1198,

Jouy en Josas, France

Email: anne.gabory@jouy.inra.fr

The recent and rapid increase worldwide in non-communicable diseases challenges the assumption that genetic factors are the primary contributors to such diseases. A new dimension, that of the 'Developmental Origins of Health and Disease' (DOHaD), is at stake and therefore requires a paradigm shift. Maternal obesity and malnutrition predispose the offspring to develop metabolic syndrome, a vicious cycle leading to transmission to subsequent generation(s), with differences in response and susceptibility according to the sex of the individual. Placenta is a programming agent of adult health and diseases. ${ }^{1,2}$ Adaptation in placental phenotype in response to maternal diet and body composition alter fetal nutrient provision. This implies important epigenetic changes that are, however, still poorly documented in $\mathrm{DOHaD}$ studies, particularly concerning overnutrition. Our objective was to investigate the effects of a high-fat diet (HFD) on mouse placental development. We used transcriptomic and epigenetic techniques and showed for the first time that not only the gene sets but also the biological functions affected by the HFD differed markedly between the two sexes. ${ }^{3,4}$ Moreover, the expression of genes coding for epigenetic machinery enzymes, as well as global DNA methylation, were highly dynamic during the fetal period (three stages), clearly differed between the two layers of placenta (labyrinth and junctional zone) and showed conspicuous ontogenetic sexual dimorphism for epigenetic modifiers. ${ }^{5,6}$ These findings demonstrate a striking sexual dimorphism of programming trajectories in response to the same environmental challenge. Explaining the sex-specific causal variables and how males $v$. females respond and adapt to environmental perturbations should help physicians and patients anticipate disease susceptibility. Thus, explorations of changes in sexual dimorphism are potentially useful to identify sex-specific disease mechanisms for use in the development of different, more appropriate prevention and treatment strategies for males and females.

Disclosure of Interest: None.

\section{References}

1. Thornburg KL, O'Tierney PF, Louey S. Review: the placenta is a programming agent for cardiovascular disease. Placenta. 2010; 31(Suppl), S54-S59.

2. Gabory A, Roseboom TJ, Moore T, Moore LG, Junien C. Placental contribution to the origins of sexual dimorphism in health and diseases: sex chromosomes and epigenetics. Biol Sex Differ. 2013; 4, 5 [Epub ahead of print].

3. Gabory A, Ferry L, Fajardy I, et al. Maternal diets trigger sex-specific divergent trajectories of gene expression and epigenetic systems in mouse placenta. PLoS One. 2012; 7, e47986, doi:10.1371/journal.pone.0047986, PONE-D-12-16453 [pii].

4. Gallou-Kabani C, Gabory A, Tost J, et al. Sex- and dietspecific changes of imprinted gene expression and DNA methylation in mouse placenta under a high-fat diet. PLoS One. 2010; 5, e14398, doi:10.1371/journal.pone.0014398.

5. Mank JE, Nam K, Brunstrom B, Ellegren H. Ontogenetic complexity of sexual dimorphism and sex-specific selection. Mol Biol Evol. 2010; 27, 1570-1578.

6. Lu H, et al. Hepatic ontogeny and tissue distribution of mRNAs of epigenetic modifiers in mice using RNAsequencing. Epigenetics. 2012; 7, 914-929.

\section{EPGN8}

Epigenetic basis for adaptive phenotype in the human parasite Schistosoma mansoni

S. Fneich, C. Cosseau, A. Théron, G. Mitta and C. Grunau

Laboratoire Ecologie et Evolution des Interactions (2EI), UMR 5244 CNRS UPVD, Perpignan, France

Email: sara.fneich@univ-perp.fr

Schistosoma mansoni is a human parasite responsible for intestinal schistosomiasis. It has a complex life cycle with two hosts: a freshwater snail as an intermediate host; and a definitive vertebrate host (human or rodent) in which sexual reproduction occurs. The disease is widely distributed in tropical regions; ${ }^{1}$ however, in the past few months, 12 cases of endemic schistosomiasis were observed in Corsica. ${ }^{2}$ Compatible mollusk hosts of the parasite are present in several areas of continental Europe, meaning that they are at risk. It is therefore essential to characterize the evolutionary interactions between the parasite and their hosts. $S$. mansoni displays phenotypic variability based on epigenetic mechanisms. More precisely, it 
regulates the expression of SmPoMuc (Schistosoma mansoni Polymorphic Mucins) in the larval stages. SmPoMuc are molecular markers for the infection success in the intermediate host. ${ }^{3,4}$ To provide a better understanding on the role of epigenetics in the heritability of this adaptive phenotype, we studied the impact of environmental stress on the infectivity of the parasite. We show that following a hybridization event between different $S$. mansoni strains, infection success increases drastically in parasite offsprings. Furthermore, using pharmacological induction of epimutations (with Trichostatin A, TSA), we also observed an increase in infection success. In both cases, new SmPoMuc variants were generated by the parasite. We demonstrate that strain hybridization and TSA treatment lead to changes in the epigenetic information that establish novel developmental trajectories, leading to additional and novel phenotypic variants in the population. Our findings fit perfectly into theoretical models that predict such a function for the epigenetic information, ${ }^{5,6}$ but are, to the best of our knowledge, the first experimental evidence of an epigenetic-based mechanism of adaptive evolution.

\section{Disclosure of Interest: None.}

\section{References}

1. World Health Organisation (WHO). Schistosomiasis. Fact Sheet No 115, 2014. WHO Media Centre: Geneva.

2. Berry A, Moné H, Iriart X, et al. Schistosomiasis haematobium, Corsica, France. Emerg Infect Dis. 2014; 20, 1595-1597.

3. Cosseau C, Azzi A, Rognon A, et al. Epigenetic and phenotypic variability in populations of Schistosoma mansoni-a possible kick-off for adaptive host/parasite evolution. Oikos. 2010; 119, 669-678.

4. Perrin C, Lepesant JM, Roger E, et al. Schistosoma mansoni mucin gene (SmPoMuc) expression: epigenetic control to shape adaptation to a new host. PLOS Pathog. 2013; 9, e1003571.

5. Pal C, Miklos I. Epigenetic inheritance, genetic assimilation and speciation. J Theor Biol. 1999; 200, 19-37.

6. Klironomos FD, Berg J, Collins S. How epigenetic mutations can affect genetic evolution: model and mechanism. Bioessays. 2013; 35, 571-578.

\section{LATER HEALTH OF PREMATURE AND SMALL FOR GESTATIONAL AGE BABIES}

\section{IUGR-1}

Synchronization capacity of fibroblast primary cultures established from mother and first-generation offspring in a model of protein restriction

A. Oliveira Sa Braga ${ }^{3}$, P. Martimiano de $\mathrm{Melo}^{3}, \mathrm{~A}$ Pagniez ${ }^{1,2}$, E. Nascimento ${ }^{3}$, S. Lopès de Souza ${ }^{3}$, R. Manhães-de-Castro ${ }^{3}$, F. Bolaños-Jiménez ${ }^{1,2}$ and Bertrand Kaeffer ${ }^{1,2}$

${ }^{1}$ INRA-Nantes University, UMR1280 PhAN, Nantes, France;

${ }^{2}$ CHU Hôtel Dieu, Nantes, France; ${ }^{3}$ Departamento de Nutrição, Universidade Federal de Pernambuco, Recife, Pernambuco, Brazil

Email: Bertrand.Kaeffer@univ-nantes.fr
Fibroblasts are proposed as a reference cellular material to study clock gene expression under different physiopathological conditions. Our hypothesis was that fetal calf serum synchronization can be used to reinduce major clock genes from rat mothers and their offspring (embryos and young adult male rats), revealing circadian rhythm alterations related to perinatal protein restriction.

Expression of three clock genes (bmal1, period 1 and 2) have been explored by qPCR on 60 fibroblast cell lines established from rats fed on low-protein or control diets.

Synchronization was obtained on 23 and 22 cell lines established from 30 rats fed on low-protein or control diets, respectively. The synchronization index of low-protein mothers and offspring groups was better than corresponding controls. Strong disruptions of period 1 and 2 mRNA have been found in cell lines derived from 17-day embryos of the low-protein group corresponding to an altered expression of period 1 protein in parallel experiments conducted on 13-day and 20-day embryos of the low-protein group. On the expression of bmall mRNA, a period of $24 \mathrm{~h}$ has been found on cell lines selected from control rats but not with low-protein cell lines. Interestingly, we have shown that at 35 days of life, cell lines derived from low-protein group were found to display a severe disruption of bmall gene expression.

Protein restriction during the perinatal period acts as a major selective pressure on the capacity of synchronization of in vitro propagated fibroblasts. Our work illustrates the theory of Noguchi et al. ${ }^{1}$ by suggesting that fibroblasts of the low-protein group have been selected on their tuning capacity. In addition, we expand our previous work ${ }^{2}$ on the effects of early correction of metabolic syndrome by tryptophan.

Disclosure of Interest: None.

\section{References}

1. Noguchi T, Wang LL, Welsh DK. Fibroblast PER2 circadian rhythmicity depends on cell density. Biol Rhythms. 2013; 28, 183-192.

2. Nascimento E, Guzman-Quevedo O, Delacourt N, et al. Long-lasting effect of perinatal exposure to l-tryptophan on circadian clock of primary cell lines established from male offspring born from mothers fed on dietary protein restriction. PLoS One. 2013; 8, e56231.

\section{IUGR-2}

Rats born with intrauterine growth retardation are resistant to cholecystokinin-induced inhibition of food intake.

C. Poinsignon and G. Le Dréan

UMR1280 'Physiologie des Adaptations Nutritionnelles', INRAUniversité de Nantes, CHU Hôtel Dieu, Nantes, France; Institut des Maladies de l'Appareil Digestif (IMAD), Centre Régional de Nutrition Humaine du Grand Ouest (CRNH), Nantes, France

Email: Gwenola.LeDrean@univ-nantes.fr 
Intrauterine growth retardation (IUGR) is associated with an increased risk of metabolic disorders later in life. ${ }^{1}$ In rodents, nutritional programming alters food-intake behavior (hyperphagia), particularly during the first 2 months of life. ${ }^{2,3}$ Cholecystokinin (CCK) is a key gastrointestinal peptide-regulating satiety via vagal afferent nerve (VAN). ${ }^{4}$ We hypothesized that IUGR alters CCK-induced satiety, leading to hyperphagia. The effect of IUGR was studied on CCK secretion, CCK-1 receptor (CCK-1R) expression on VAN and short-term food intake. IUGR male rats $(\mathrm{R})$ were obtained from protein-restricted mothers $(8 \%$ protein) and control rats (C) from unrestricted mothers (20\% protein). After weaning, both groups received a standard diet until 60 days. Rats were food-deprived $3 \mathrm{~h}$ and received an i.p. injection of vehicle $(\mathrm{NaCl} 0.9 \%)$ or CCK8S at three different doses $(0.25$, 2.5 and $7.5 \mathrm{nmol} / \mathrm{kg}$ ) prior refeeding. Food consumption was measured every 30 min during $90 \mathrm{~min}$. Plasma concentration of CCK8NS was assayed (ELISA) at different pre- and postprandial time points. Expression of CCK-1R was analyzed on nodose ganglia by immunohistochemistry. In the $\mathrm{C}$ group, CCK dose dependently reduced food intake $(30 \mathrm{~min})$, whereas in the $\mathrm{R}$ group only the highest dose significantly decreased food consumption (32\% as compared with vehicle). In the $\mathrm{C}$ group, $2.5 \mathrm{nmol} / \mathrm{kg}$ of CCK significantly reduced food intake (35\%) but had no effect in the R group, suggesting a very low sensitivity to CCK in this group. Basal and postprandial plasma concentration of CCK8NS evolved similarly between groups, showing no alteration of CCK intestinal production by IUGR at 60 days. Vagal expression of CCK-1R tended to be higher in the $\mathrm{R}$ group as compared with the $\mathrm{C}$ group, but the difference was not significant $(P=0.14)$. Our results suggest that at 2 months old, IUGR rats are resistant to satiety effect of CCK, independently of CCK production and vagal CCK-1R expression.

Disclosure of Interest: None.

\section{References}

1. Barker DJ. The fetal and infant origins of adult disease. BMJ. 1990; 301, 1111.

2. Coupé B, Grit I, Darmaun D, Parnet P. The timing of 'catch-up growth' affects metabolism and appetite regulation in male rats born with intrauterine growth restriction. $A m$ J Physiol Regul Integr Comp Physiol. 2009; 297, 813-824.

3. Orozco-Sólis R, Lopes de Souza S, Barbosa Matos RJ, et al. Perinatal undernutrition-induced obesity is independent of the developmental programming of feeding. Physiol Behav. 2009; 96, 481-492.

4. Dockray GJ. Gastrointestinal hormones and the dialogue between gut and brain. J Physiol. 2014; 592, 2927-2941.

IUGR-3 - oral

Maternal exposure to diesel exhaust during pregnancy affects postnatal health of the offspring in a rabbit model

D. Rousseau-Ralliard ${ }^{1}$, P. Hoarau ${ }^{1}$, C. Richard ${ }^{1}$, M. Guinot ${ }^{1}$, M.-S. Lallemand ${ }^{1}$, M. Dahirel ${ }^{1}$, N. Fournier ${ }^{2}$, S. Valentino ${ }^{1}$,
M. Albert ${ }^{3}$, G. Morin ${ }^{3}$, J. Aioun ${ }^{1}$, E. Mourier ${ }^{1}$, J.-L. Paul ${ }^{2}$, M.-C. Aubrière ${ }^{1}$, S. Camous ${ }^{1}$, F. Cassee ${ }^{4}$, A. Tarrade ${ }^{1}$ and P. Chavatte-Palmer ${ }^{1}$

${ }^{1}$ INRA, UMR 1198, Biology of Development and Reproduction, Jouy-en-Josas, France; ${ }^{2}$ Univ Paris-Sud, EA 4529, UFR de Pharmacie, Châtenay-Malabry; AP-HP (Assistance PubliqueHôpitaux de Paris), Hôpital Européen Georges Pompidou, Service de Biochimie, Paris, France; ${ }^{3}$ INRA, UCEA, Jouy-en-Josas, France; ${ }^{4}$ National Institute of Public Health and the Environment (RIVM), Bilthoven, The Netherlands

Email: pascale.chavatte@jouy.inra.fr

Recent events related to pollution peaks have shown that we are continuously and insidiously submitted to air pollution. Epidemiological ${ }^{1}$ and experimental studies ${ }^{2}$ on rodents describe direct consequences on health with increasing respiratory and cardiovascular diseases ${ }^{3}$ and high susceptibility for metabolic diseases. ${ }^{4}$ Indirect consequences due to in utero exposure also induce intrauterine growth retardation in humans. ${ }^{5,6}$ The goal of this study was to study the effects of in utero exposure to diesel exhausts, in rabbit, ${ }^{7}$ focusing on the characterization of F1 offspring's phenotype at adulthood.

The phenotype of offspring animals has been studied from puberty to adulthood (7.5 months) to evaluate the occurrence of cardiometabolic disorders, by animal tracking (measurement of food intake, weight change) as well as cardiometabolic functional tests (fasting blood analyses of lipid metabolism, analyses of body composition by iDXA, assessment of insulinemic and glycemic response to a bolus of glucose during glucose tolerance test, blood pressure and heart rate measurements). After this in vivo experiment, the animals were euthanized, and the insulinsensitive tissues were collected for biometry records.

In utero exposure to polluted air modified the adult offspring's phenotype, after puberty, in a sex-specific manner. Polluted males exhibited a metabolic syndrome ${ }^{8}$ with hyperglycemia, more abdominal fat and rise in blood pressure with age compared with the control males. The polluted males presented with symptoms of hepatic steatosis (higher transaminase ALAT, heavier liver) and atherosclerosis (lower HDL-cholesterol). The polluted females presented with hypertriglyceridemia and a decrease in bone mass and density compared with the control females, indicating a higher susceptibility to bone pathologies.

In conclusion, an indirect in utero exposure to air pollution was sufficient to affect durably the phenotype of animals that developed signs of insulin resistance with higher risk of cardiovascular morbidity, involving sex-specific pathways.

Disclosure of Interest: None.

\section{References}

1. Kelishadi R, Poursafa P, Keramatian K. Overweight, air and noise pollution: universal risk factors for pediatric prehypertension. J Res Med Sci. 2011; 16, 1234-1250. 
2. Shimada A, Kawamura N, Okajima M, et al. Translocation pathway of the intratracheally instilled ultrafine particles from the lung into the blood circulation in the mouse. Toxicol Pathol. 2006; 34, 949-957.

3. Chen H, Goldberg MS, Burnett RT, et al. Long-term exposure to traffic-related air pollution and cardiovascular mortality. Epidemiology. 2013; 24, 35-43.

4. Nalbone G, Cicolella A, Laot-Cabon S. Endocrine disruptors and metabolic diseases: a major public health challenge. Santé Publique. 2013; 25, 45-49.

5. Dadvand P, Parker J, Bell ML, et al. Maternal exposure to particulate air pollution and term birth weight: a multi country evaluation of effect and heterogeneity. Environ Health Perspect. 2013; 121, 367-373.

6. Slama R, Gräbsch C, Lepeule J, et al. Maternal fine particulate matter exposure, polymorphism in xenobioticmetabolizing genes and offspring birth weight. Reprod Toxicol. 2010; 30, 600-612.

7. Fischer B, Chavatte-Palmer P, Viebahn C, et al. Rabbit as a reproductive model for human health. Reproduction. 2012; 144, 1-10.

8. Alberti KG, Zimmer P, Shaw J. Metabolic syndrome - a new world-wide definition. A consensus statement from the International Diabetes Federation. Diabet Med. 2006; 23, 469-480.

\section{IUGR-4 - oral}

Anabolic effect of citrulline and arginine in a model of intrauterine growth restriction: role of hormones and placental amino-acid transporters

E. Misbert ${ }^{1,2}$, A. Bourdon ${ }^{1,2}$, J. Hannigsberg ${ }^{1,2}$, T. Nhat Tran $^{1,2}$, P. Parnet ${ }^{1,2}$, V. Amarger ${ }^{1,2}$, N. Winer ${ }^{1,2}$ and D. Darmaun ${ }^{1,2}$

${ }^{1}$ INRA-Nantes University, UMR1280 PhAN, Nantes, France;

${ }^{2}$ Department of Obstetrics, CHU de Nantes, Nantes, France

\section{Email: emilie.misbert@etu.univ-nantes.fr}

Nitric oxide (NO) is known to regulate placental vascular placental blood flow, ${ }^{1}$ and in earlier work we found that the antenatal administration of arginine or citrulline, two aminoacid precursors of $\mathrm{NO}$, attenuates the intrauterine growth restriction (IUGR) induced by dietary protein restriction in gestating rats. ${ }^{2,3}$ We hypothesized that such supplementation might enhance the secretion of the anabolic hormones insulin and insulin-like growth factors (IGF), and upregulate placental amino-acid transporters, as maternal-fetal amino-acid transport plays a key role in the regulation of fetal growth. ${ }^{4,5}$

From the first day of gestation, four groups of eight pregnant rats received either an adequate protein (AP, 20\% protein) or a low-protein (LP, 4\% protein) diet as such, or with $\mathrm{L}$-arginine $(\mathrm{LP}+\mathrm{Arg}, 1.4 \mathrm{~g} / \mathrm{kg} / \mathrm{day})$ or L-citrulline $(\mathrm{LP}+\mathrm{Cit}, 2 \mathrm{~g} / \mathrm{kg} /$ day $)$ supplementation in drinking water. Fetuses and placentas were extracted by cesarean section at day 21 of gestation. Fetal weight was $\approx 27 \%$ lower in the LP group $v$. the AP group $(P<0.001)$. Supplementation with citrulline and arginine was associated with an $\approx 4$ and $9 \%$ rise in fetal weight, compared with the LP group $(P<0.05)$. Placental gene expression and plasma hormone concentrations were assessed using qPCR and ELISA, respectively. In the LP group, insulin was decreased in maternal plasma, and IGF1 decreased in both maternal and fetal plasma. Arginine supplementation tended to increase maternal insulin (LP + Arg $v$ LP, $P=0.067$ and LP + Arg $v$. LP + Cit, $P=0.0095)$, and both supplementations significantly upregulated placental IGF2 expression $(P<0.0083)$. The gene expression of Slc38a4 $(P=0.0215)$ and Slc7a5 $(P=0.0370)$ was decreased in IUGR without supplementation, whereas Slc38al $(P<0.0001)$ and Slc7a8 $(P<0.0083)$ were upregulated in the same group. In contrast, in the supplemented groups, the mRNA of all placental amino-acid transporters assessed was increased: Slc38a2 (LP + Arg v. $P<0.0102$ with a greater effect of arginine $v$. citrulline, $P=0.0136)$, Slc38a4 $(\mathrm{LP}+$ Arg, $P<0.0001 ; \mathrm{LP}+\mathrm{Cit}, P<0.0083)$, Slc7a5 (LP + Arg, $P=0.0222$; LP + Cit, $P=0.0001)$, Slc7a8 $(P<0.0083)$, Slc3a2 (LP + Arg, $P<0.0001 ; \mathrm{LP}+$ Cit, $P=0.0002)$.

These findings suggest that: (1) IUGR is associated with a reduction in maternal anabolic hormone secretion; (2) placental amino-acid transport is regulated both by maternal nutritional status and fetal demand; and (3) enhanced maternal secretion of insulin and IGF2, as well as upregulation of placental amino-acid transport contribute to the anabolic effect of arginine and citrulline on fetal growth in this model of IUGR.

\section{Disclosure of Interest: None.}

\section{References}

1. Tsatsaris V, Fournier T, Winer N. Pathophysiology of preeclampsia. J Gynecol Obstet Biol Reprod (Paris). 2008; 37, 16-23.

2. Bourdon A, Nowak C, Naël C, et al. Citrulline enhances fetal growth and protein synthesis in a model of intrauterine growth restriction. Clin Nutr. 2011; 30(Suppl. 6.1), 8 (abstract).

3. Hannigsberg J, Bourdon A, Tran T, et al. Effets de la supplementation orale en citrulline sur la croissance foetale dans un modele animal de retard de croissance intrauterin. Nutr Clin Metabol. 2013; 27(Suppl. 1), S36-S37 (abstract).

4. Jansson N, Petterson J, Haafiz A, et al. 2006. Downregulation on placental transport of amino acids precedes the development of intrauterine growth restriction in rats fed a low protein diet. J Physiol. 2006; 576, 935-946.

5. Rosario FJ, Jansson N, Kanay Y, et al. Maternal protein restriction in the rat inhibits placental insulin, mTOR, and STAT3 signaling and down-regulates placental amino acid transporters. Endocrinology . 2011; 152, 1119-1129. 
IUGR-5 - oral

The complex relationships of birth weight and early growth on blood pressure at 5 years: overcoming the reversal paradox in the EDEN cohort

M. Taine, S. Carles, J. Botton, A. Forhan, M.-A. Charles, B. Stengel, B. Heude and the EDEN Mother-Child Cohort Study Group

INSERM, Center for Research in Epidemiology and Population Health (CESP), U1018, Epidemiology of Diabetes, Obesity and Renal Diseases: Lifelong Approach Team, Villejuif, France

Email: mariontaine@gmail.com

The respective contributions of birth weight and postnatal growth on blood pressure level are important to distinguish, but may be confounded by the so-called reversal paradox. ${ }^{1,2}$

We aimed to study the association between birth weight (BW) and systolic blood pressure (SBP) at 5 years, avoiding the reversal paradox. We also investigated interactions between $\mathrm{BW}$ and weight growth velocities in their relation with SBP at 5 years.

The EDEN mother-child cohort is a prospective study that started in 2003 and followed up on 1120 children (54\% boys) from the second pregnancy trimester until 5 years. From birth to 5 years, on average, 17.2 weights per child (2-32) were collected or measured, allowing for the estimation of predicted weights and weight growth velocities at any age. Standardized blood pressure measurements were recorded at 5 years. A BW $Z$-score for gestational age and sex was used. To avoid the reversal paradox, a SBP S.D. score preadjusted for age, sex, body mass index and height was built. Multiple linear regression model was used to study the association between BW and SBP S.D. score. Interactions between BW categories (small for gestational age, appropriate for gestational age, large for gestational age) and weight growth velocities were tested at different ages.

Mean BW was $3285 \pm 510 \mathrm{~g}$. At 5 years, mean SBP was $101.5 \pm 0.3$ in boys and $102.7 \pm 0.3 \mathrm{mmHg}$ in girls. BW $Z$-score was negatively and significantly associated with SBP S.D. score ( $\beta=-0.06 \pm 0.03, P=0.03$ ) after adjusting for several maternal and pregnancy risk factors. Interactions were found between BW categories and weight growth velocities from 2 to 4 months ( $P$ from 0.009 to 0.09$)$ but not at older ages $(P>0.20)$.

Children who were born SGA and presented accelerated weight growth in their first few months of life had higher SBP at 5 years. They may deserve specific attention and monitoring for cardiovascular risk.

\section{Disclosure of Interest: None.}

\section{References}

1. Lucas A, Fewtrell MS, Cole TJ. Fetal origins of adult disease - the hypothesis revisited. BMJ. 1999; 319, 245-249.

2. Tu Y, Gilthorpe M. Is reversal paradox a paradox? In Statistical Thinking in Epidemiology (ed. CRC Press), 2012; pp. 97-117. Taylor \& Francis Group: Boca Raton, FL.

\section{IUGR-6}

Is there a negative direct effect of birth weight on blood pressure? A causal mediation analyses

A. Chiolero ${ }^{1}$, G. Paradis ${ }^{2}$ and J. Kaufman ${ }^{2}$

${ }^{1}$ Institute of Social and Preventive Medicine, Lausanne University Hospital, Lausanne, Switzerland; '2 Department of Epidemiology, Biostatistics, and Occupational Health, McGill University, Montreal, Canada

Email: arnaud.chiolero@chuv.ch

Numerous studies have shown a negative association between birth weight and blood pressure later in life. ${ }^{1}$ These observations are at the foundation of the fetal programming theory. ${ }^{2}$ Because birth weight is associated with current weight, and current weight is a strong determinant of blood pressure, ${ }^{3}$ adjustment for current weight - considered as a mediator - is a common statistical procedure to estimate the direct effect of birth weight on blood pressure. ${ }^{4,5}$ However, such adjustment on a mediator can induce bias, namely, a collider stratification bias. ${ }^{6,7}$ In this study, we used new sensitivity analysis methods to assess the effect of the adjustment for current weight on the estimate of the direct effect of birth weight on blood pressure in children. ${ }^{7,8} \mathrm{We}$ used data from a school-based study conducted in Switzerland in 2005-2006. ${ }^{3}$ Data were available on 3762 children with a mean age of 12.3 years. Directed acyclic graphs were drawn to show explicitly causal relationships, notably to help specify total, direct and indirect effect of birth weight on blood pressure. Several potential confounders of the association between birth and blood pressure and of the association between current weight and blood pressure were accounted for in the analyses. There was a small negative association between birth weight and systolic blood pressure, which was strengthened upon adjustment for current weight. Sensitivity analyses suggested that the negative association between birth weight and blood pressure was not simply because of a collider stratification bias induced by the adjustment on current weight. Therefore, our results are compatible with the existence of a direct negative causal effect of birth weight on blood pressure in children. ${ }^{8}$ Nevertheless, further studies are needed to estimate the total and direct effect on blood pressure of specific interventions aiming at changing birth weight.

\section{Disclosure of Interest: None.}

\section{References}

1. Huxley R, Neil A, Collins R. Unravelling the fetal origins hypothesis: is there really an inverse association between birthweight and subsequent blood pressure? Lancet. 2002; 360, 659-665.

2. Barker DJ, Bagby SP, Hanson MA. Mechanisms of disease: in utero programming in the pathogenesis of hypertension. Nat Clin Pract Nephrol. 2006; 2, 700-707.

3. Chiolero A, Cachat F, Burnier M, et al. Prevalence of hypertension in schoolchildren based on repeated 
measurements and association with overweight. J Hypertens. 2007; 25, 2209-2217.

4. Lucas A, Fewtrell MS, Cole TJ. Fetal origins of adult disease - the hypothesis revisited. BMJ. 1999; 319, 245-249.

5. Weinberg CR. Barker meets Simpson. Am J Epidemiol. 2005; 161, 33-35.

6. Cole SR, Hernán MA. Fallibility in estimating direct effects. Int J Epidemiol. 2002; 31, 163-165.

7. VanderWeele TJ. Bias formulas for sensitivity analysis for direct and indirect effects. Epidemiology. 2010; 21, 540-551.

8. Chiolero A, Paradis G, Kaufman JS. Assessing the possible direct effect of birth weight on childhood blood pressure: a sensitivity analysis. Am J Epidemiol. 2014; 179, 4-11.

\section{IUGR-7 - oral}

SGA children with moderate catch-up growth are showing impaired insulin secretion at the age of 4

I. Milovanovic ${ }^{1}$, F. Njuieyon ${ }^{1}$, S. Deghmoun ${ }^{1}$, D. Chevenne ${ }^{2}$, C. Levy-Marchal ${ }^{1}$ and J. Beltrand ${ }^{3,4,5}$

${ }^{1}$ INSERM CIE 05 - Unité d'épidémiologie clinique, Hôpital

Robert Debré, Paris, France; ${ }^{2}$ Service de biochimie et

hormonologie, Hôpital Robert Debré, Paris, France;

${ }^{3}$ Endocrinologie et diabétologie pédiatrique, Hôpital Necker,

Paris, France; ${ }^{4}$ Université Paris 5, René Descartes, Paris, France;

${ }^{5}$ INSERM U845, Imagine Affliated, Paris, France

Email: jacques.beltrand@nck.aphp.fr

Being born small for gestational age (SGA) is a risk factor for later development of type 2 diabetes. ${ }^{1}$ The development of glucose tolerance disorders in adults involves insulin resistance and impaired insulin secretion. ${ }^{2,3}$

The objective was to evaluate insulin secretion and insulin sensitivity in a 4-year-old cohort of SGA.

A total of 85 children were prospectively followed up from mid-gestation to 4 years of age. Fetal growth velocity was measured using ultrasound measurements. Body composition and hormonal profile were measured at birth, 1 and 4 years.

A total of 23 SGA babies had lower birth weight compared with 62 appropriate for gestational age (AGA) $(-1.9 \pm 0.3 v$. $-0.6 \pm 0.8 Z$-score; $P<0.0001)$ and they were thinner at birth (ponderal index $24.8 \pm 1.8 v .26 .3 \pm 3.1 \mathrm{~kg} / \mathrm{m}^{3} ; P=0.01$ and fat mass $11 \pm 2.6 v$. $12.9 \pm 3.1 \% ; P=0.01)$. No significant differences in other measured metabolic and hormonal parameters were observed between two groups at birth. SGA infants experienced an early catch-up growth in weight (mean gain of $1.1 \pm 0.6$ S.D.) during the 1 st year of life. At 4 years, SGA children remain lighter than AGA, but with weight $Z$-score in the normal range $(-0.1 \pm 1.3 v .0 .5 \pm 1.3 Z$-score; $P=0.05)$. No excess of fat mass was observed $(19 \pm 4.8 v .19 .7 \pm 4.1 \%$; $P=0.45) ; 120$-min plasma glucose was significantly higher $(6.2 \pm 1.1 v .5 .6 \pm 0.9 \mathrm{mmol} / \mathrm{l} ; P=0.006)$, and insulinogenic index was significantly lower $(0.28 \pm 0.15 \quad v$. $0.40 \pm 2.4$; $P=0.02)$ in the SGA group at 4 years of life contrasting with a preserved insulin sensitivity (QUICKI $0.47 \pm 0.09 v$. $0.43 \pm 0.05 ; P=0.06$ ).

SGA children with compensatory catch-up growth in the 1st year of life show mild disturbances of glucose tolerance associated with a lower insulinogenic index at 4 years of age, suggesting impairment of $\beta$-cell function.

Disclosure of Interest: None.

\section{References}

1. Hales CN, Barker DJ, Clark PM, et al. Fetal and infant growth and impaired glucose tolerance at age 64. BMJ. 1991; 303, 1019-1022.

2. Jaquet D, Gaboriau A, Czernichow P, Levy-Marchal C. Insulin resistance early in adulthood in subjects born with intrauterine growth retardation. J Clin Endocrinol Metab. 2000; 85, 1401-1406.

3. Jaquet D, Deghmoun S, Chevenne D, et al. Dynamic change in adiposity from fetal to postnatal life is involved in the metabolic syndrome associated with reduced fetal growth. Diabetologia. 2005; 48, 849-855.

\section{IUGR-8}

UCP 1 is present in porcine adipose tissue and is responsive to postnatal leptin

A. Mostyn ${ }^{1}$, S. Dou ${ }^{2}$, L. Attig ${ }^{2}$, T. Larcher ${ }^{3}$, P. ChavattePalmer $^{4}$, M. Boukthir ${ }^{5}$, A. Gertler ${ }^{6}$, J. Djiane ${ }^{7}$, M. E. Symonds ${ }^{8^{*}}$ and L. Abdennebi-Najar ${ }^{2 *}$

${ }^{1}$ School of Veterinary Medicine and Science, Sutton Bonington Campus, University of Nottingham, Nottingham, UK; ${ }^{2} U P$ 2012.10.101, EGEAL, Institut Polytechnique LaSalle, Beauvais, France; ${ }^{3} I N R A$ UMR 703, Ecole Nationale Vétérinaire, Nantes, France; ${ }^{4} I N R A$, UMR1198, BDR Biologie du Développement et Reproduction, Jouy en Josas, France; ${ }^{5}$ Unité de Recherche 04UR08/03 Faculté de Médecine, Tunis, Tunisia; ${ }^{6}$ The Hebrew University of Jerusalem, Rehovot, Israel, ${ }^{7}$ Unité NOPA, INRA, Centre de recherché, Jouy en Josas, France; ${ }^{8}$ Early Life Research Unit, Academic Child Health, School of Medicine, University Hospital, The University of Nottingham, Nottingham, UK

*Equal contribution

Email: Samir.dou@lasalle-beauvais.fr

Intrauterine growth restriction (IUGR) may be accompanied by inadequate thermoregulation, especially in piglets that are not considered to possess any brown adipose tissue (BAT), and are thus entirely dependent on shivering thermogenesis to maintain body temperature after birth. ${ }^{1}$ This is due to an openreading frame on the BAT-specific uncoupling protein (UCP) 1 gene in the porcine species, meaning that UCP1 is not expressed. ${ }^{2}$ The onset of non-shivering thermogenesis in BAT 
at birth is dependent on the rapid appearance of endocrine stimulatory factors, including leptin. ${ }^{3,4}$ Leptin can stimulate heat production by promoting non-shivering thermogenesis in BAT, but whether this response occurs in piglets is unknown. Newborn female piglets that were characterized as showing IUGR (mean birth weight of $-0.98 \pm 0.26 \mathrm{~kg} ; n=48$ ) were therefore injected with either saline or leptin once a day for the first 5 days of neonatal life. The dose of leptin was $0.5 \mathrm{mg} / \mathrm{kg}$ which is sufficient, as previously shown, ${ }^{5}$ to increase plasma leptin $\sim 10$-fold and on the day of birth induced a rapid increase in body temperature to values comparable with normal-sized 'control' piglets (mean birth weight of $-1.47 \pm 0.37 \mathrm{~kg}$; $n=26$ ). The perirenal adipose tissue was then sampled from all offspring at 21 days of age, and the presence of the BATspecific UCP1 was determined by immunohistochemistry and immunoblotting. UCP1 was clearly detectable in all samples analysed and its abundance was significantly reduced in the IUGR piglets administered saline compared with controls, but was raised to the same amount as controls in those IUGR females administered leptin. There were no differences in gene expression between primary markers of the brown and white adipose tissue between groups. In conclusion, piglets possess BAT that when stimulated exogenously by leptin can promote body temperature.

\section{Disclosure of Interest: None.}

\section{References}

1. Trayhurn P, Temple NJ, Van Aerde J. Evidence from immunoblotting studies on uncoupling protein that brown adipose tissue is not present in the domestic pig. Can J Physiol Pharmacol. 1989; 67, 1480-1485.

2. Berg F, Gustafson U, Andersson L. The uncoupling protein 1 gene (UCP1) is disrupted in the pig lineage: a genetic explanation for poor thermoregulation in piglets. PLoS Genet. 2006; 2, e129.

3. Mostyn A, Keisler DH, Webb R, Stephenson T, Symonds ME. The role of leptin in the transition from fetus to neonate. Proc Nutr Soc. 2001; 60, 187-194.

4. Symonds ME. Brown adipose tissue growth and development. Scientifica. 2013; 2013, 305763.

5. Attig L, Brisard D, Larcher T, et al. Postnatal leptin promotes organ maturation and development in IUGR piglets. PLoS One. 2013; 8, e64616.

\section{IUGR-9}

Developmental programming of hypertension in IUGR rat model: implication of arginase pathway and eNOS uncoupling

C. Yzydorczyk ${ }^{1,2}$, I. Grandvuillemin ${ }^{1,3}$, C. Buffat ${ }^{3}$,

F. Boubred ${ }^{1,3}$, E. Lamy ${ }^{1}$, S. Simoncini ${ }^{1}$, F. Sabatier ${ }^{1,4}$,

F. Dignat-George ${ }^{1,5}$ and U. Simeoni ${ }^{1,2,3}$

${ }^{1}$ Aix-Marseille Université, INSERM, VRCM, UMR S 1076,

Marseille, France; ${ }^{2}$ Division of Pediatrics \& DOHaD Laboratory,
CHUV University Hospital and UNIL, Lausanne, Switzerland; ${ }^{3} A P H M, C H U$ de la Conception, Department of Neonatology, France; ${ }^{4} A P H M, C H U$ de la Conception, Laboratory of Cell Therapy, Marseille, France; ${ }^{5}$ APHM, CHU de la Conception, Laboratory of Hematology, Marseille, France

Email: cyzydorczyk@yahoo.fr

Epidemiological studies have shown that low birth weight is associated with an increased risk of cardiovascular diseases, notably, hypertension (HT) later in life. These findings in humans have been reproduced using animal models of intrauterine growth restriction (IUGR) characterized by an increased blood pressure, ${ }^{1}$ an impaired vasodilatory capacities ${ }^{2}$ in adulthood. However, it is still unknown whether the alteration of vasodilatory capacities is a consequence or a cause of HT and which mechanisms are involved; $22 \%$ (CTRL) or $9 \%$ casein (low protein, LP) was administrated to pregnant rats during whole gestation. On the offsprings, systolic blood pressure (SBP) was measured (tail-cuff) at 5 and 8 weeks of age. At 5 weeks, we measured: aortic vascular reactivity to acetylcholine (Ach) \pm preincubation with L-arginine (L-Arg, substrate for $\mathrm{eNOS}$ ) and \pm S-(2-boronoethyl)-L-cysteine (BEC, arginase inhibitor); arginase activity (spectrophotometry); aortic NO production using the NO-specific fluorescent dye, 4,5-diaminofluorescein diacetate \pm Ach with \pm L-Arg preincubation; eNOS expression (western blot); aortic superoxide anion (SA) production using hydroethidine \pm pretreatment with N-nitro-L-arginine (L-NNA, NOS inhibitor). In LP $v$. CTRL groups SBP is increased only at 8 weeks of age. At 5 weeks vasodilation response to Ach is impaired $(P<0.001)$. Preincubation with L-Arg and BEC restores the impaired endothelium vasodilation to the CTRL group; arginase activity is increased $(P<0.05)$; NO production in basal condition and after Ach stimulation is decreased $(P<0.001)$, but is restored with L-Arg pretreatment to the CTRL group. Total eNOS protein expression is increased $(P<0.05)$; SA level is increased $(P<0.001)$, and pretreatment with L-NNA normalized it to the CTRL group. These data suggest that upregulation of the arginase activity and eNOS uncoupling can lead to impaired endothelium-dependent vasodilation observed in IUGR rat model and could pave the way to the developmental programming of HT observed in adulthood.

\section{Disclosure of Interest: None.}

\section{References}

1. Boubred F, Daniel L, Buffat C, et al. Early postnatal overfeeding induces early chronic renal dysfunction in adult male rats. Am J Physiol Renal Physiol. 2009; 297, F943-F951.

2. Yzydorczyk C, Gobeil F Jr, Cambonie G, et al. Exaggerated vasomotor response to ANG II in rats with fetal programming of hypertension associated with exposure to a low-protein diet during gestation. Am J Physiol Regul Integr Comp Physiol. 2006; 291, R1060-R1068. 


\section{IUGR-10}

Modulation of oxidative stress via SIRT1 expression: a role in the developmental programming of endothelial dysfunction in preterm infants

C. Yzydorczyk ${ }^{1,2}$, S. Simoncini ${ }^{1}$, A. L. Chateau ${ }^{1}$, J. Mengin ${ }^{1}$, I. Ligi ${ }^{3}$, F. Boubred ${ }^{1,3}$, F. Sabatier ${ }^{1,4}$, U. Simeoni ${ }^{1,2,3}$ and F. Dignat-George ${ }^{1,5}$

${ }^{1}$ Aix-Marseille Université, INSERM, VRCM, UMR_S 1076, Marseille, France; ${ }^{2}$ Division of Pediatrics \& DOHaD Laboratory, CHUV University Hospital and UNIL, Lausanne, Switzerland; ${ }^{3}$ APHM, CHU de la Conception, Department of Neonatology, Marseille, France; ${ }^{4}$ APHM, CHU de la Conception, Laboratory of Cell Therapy, Marseille, France; ${ }^{5}$ APHM, CHU de la Conception, Laboratory of Hematology, Marseille, France

Email: cyzydorczyk@yahoo.fr

Cardiovascular diseases (CVD) are the leading cause of death worldwide. Low birth weight (LBW) is now considered as a major independent risk factor for $\mathrm{CVD}$, according to $\mathrm{DOHaD}$ paradigm. LBW infants, notably preterm infants (PT), display vascular tree impairment and may pave the way to later hypertension. We have recently shown that endothelial colony-forming cells [ECFCs, biomarker to assess endothelial dysfunction (ED)] from PT present an accelerated stress-induced senescence, via a decreased expression of SIRT1, leading to an altered expression of key cell cycle markers and a deficit in their angiogenic properties. ${ }^{1,2}$ SIRT1 has been demonstrated to regulate cellular protection against oxidative stress (OS) in CVD. OS plays a key role in many vascular pathologies of PT as retinopathy and dysplasia bronchopulmonary. We therefore hypothesized that OS could be involved in premature senescence of ECFCs from PT. Venous umbilical cord blood was collected from 18 term neonates (CTRL) and 29 PTs. ECFCs were obtained after mononuclear cell culture. On ECFCs from PT $v$. CTRL neonates, we measured: expression of antioxidant defenses (superoxide dismutase $\mathrm{Cu} / \mathrm{Zn}, \mathrm{SOD} 1$ ), catalase $(\mathrm{CAT})$ by western blot \pm pretreatment with resveratrol $(\mathrm{R})$ and \pm transient SIRT1 overexpression; superoxide anion (SA) production using hydroethidine \pm pretreatment with $\mathrm{N}$-nitro-L-arginine (L-NNA), $\mathrm{R}$, tempol (T), apocynin (Apo, NADPH inhibitor) and transient SIRT1 overexpression. In ECFCs from PT $v$. CTRL: the expression of CAT and SOD1 was decreased $(P<0.01)$. Transient SIRT1 overexpression and R pretreatment restore the expression of these enzymes to CTRL levels. SA production was increased $(P<0.001)$. Pretreatment with L-NNA, T, Apo and transient SIRT1 overexpression normalized the exaggerated SA production, mediated via eNOS uncoupling and NADPH oxidase, to CTRL group. Therefore, manipulating SIRT1 expression using antioxidant therapeutical approach, consistent with a protective role against OS, may open a new key in deprogramming ED observed in PT infants.

\section{References}

1. Ligi I, Simoncini S, Tellier E, et al. A switch toward angiostatic gene expression impairs the angiogenic properties of endothelial progenitor cells in low birth weight preterm infants. Blood. 2011; 118, 1699-1709.

2. Vassallo PF, Simoncini S, Ligi I, et al. Accelerated senescence of cord blood endothelial progenitor cells in premature neonates is driven by SIRT1 decreased expression. Blood. 2014; 23, 2116-2126.

\section{IUGR-11}

Is high-fat diet-induced hypothalamic plasticity modified by intrauterine growth restriction?

N. Dellschaft, I. Grit and P. Parnet

INRA-Nantes University, UMR1280 PhAN, Nantes, France

Email: neele.dellschaft@univ-nantes.fr

Introduction of a high-fat diet (HFD) has recently been found to modify the anorexigenic tone in the arcuate nucleus by reducing the number of excitatory synapses onto orexigenic primary neurons and by reducing inhibitory synapses onto anorexigenic neurons in the arcuate nucleus of rats resistant to diet-induced obesity. ${ }^{1}$ This is consistent with the observation that rats reduce the intake of a HFD within days of its introduction. Leptin signaling is crucial for synaptic plasticity involved in appetite regulation. ${ }^{2}$ As leptin resistance and overweight has been observed in intraruterine growth restriction offspring, ${ }^{3}$ we proposed that their capacity for synaptic plasticity may be changed.

Female Sprague-Dawley rats were fed a low-fat diet ad libitum $(n=18)$ or were subjected to a restriction to $50 \%$ of the control group intake during pregnancy $(n=16)$, with ad libitum intake after parturition. Male offspring either stayed on chow throughout (100\% chow, $n=34 ; 50 \%$ chow, $n=33$ ) or were changed to a HFD (100\% HFD, $n=52 ; 50 \% \mathrm{HFD}, n=50)$ on 28 days postnatal. Tissues were collected at 29, 33, 36 and 119 days of age. Hypothalami are examined by the evaluation of presynaptic and postsynaptic markers.

Of the offspring, $50 \%$ were smaller at birth ( $84 \%$ of control) and remained smaller until 70 days, after which all offspring had similar weight until dissection at 120 days. Introduction of HFD led to a persistently higher food intake and adiposity, not affected by maternal diet. During the 1st week, HFD caused an increase in plasma leptin. Hypothalamic expression of anorexigenic neurotransmitter POMC and of genes involved in leptin resistance, PTP1B and SOCS3, were increased in 100\%, but POMC was decreased without changes in PTP1B and SOCS3 in $50 \%$ offspring, suggesting a difference in hypothalamic reaction to HFD. We will present further data on hypothalamic synaptic plasticity as observed by immunohistochemistry and western blot.

Disclosure of Interest: None.

\section{Disclosure of Interest: None.}




\section{References}

1. Benani A, Hryhorczuk C, Gouazé A, et al. Food intake adaptation to dietary fat involves PSA-dependent rewiring of the arcuate melanocortin system in mice. J Neurosci. 2012; 32, 11970-11979.

2. Pinto $S$. Rapid rewiring of arcuate nucleus feeding circuits by leptin. Science. 2004; 304, 110-115.

3. Desai M, Gayle D, Han G, Ross MG. Programmed hyperphagia due to reduced anorexigenic mechanisms in intrauterine growth-restricted offspring. Reprod Sci. 2007; 14, 329-337.

\section{IUGR-12}

\section{Preterm delivery and low fetal birth weight: preliminary result at hôpital Privé Natecia (Lyon)}

P. Mirakian, M. de Ciantis, V. Bied, M. Donadieu and

C. Ozanon

\section{Private Hospital Natecia, Service AMP Natecia, Lyon, France}

The use of assisted reproduction technology (ART) is increasing. ${ }^{1}$ However, in France, the follow-up of pregnancies after ART is poorly evaluated. The aim of this study is to observe pregnancy terms and fetal weight after ART pregnancies.

Our retrospective study included 1377 patients after ART pregnancy (UII, IVF, ICSI, FET) between 2009 and 2013. Data were collected from Médifirst software. The primary endpoint was prematurity induced by ART. Multiple pregnancies were secondarily excluded from the results to eliminate the confounding factor of twins. The results were compared with the epidemiologic values found in the literature. ${ }^{2}$

Distribution for all pregnancies, $n=1377$ (unique: $n=1155$; twin: $n=216$; triple: $n=6$ ).

Outcome for all pregnancies: $32 \%$ prematurity.

Outcome after singleton pregnancies: $25 \%$ prematurity.

(Normal term >37 SA: $n=870$; prematurity between 33 and 37 SA: $n=234$; severe prematurity between 32 and 28 SA: $n=35$; very severe prematurity $<28$ SA: $n=16$ ).

There were no significant differences when comparing ART procedures.

After exclusion of multiple pregnancies, the preterm pregnancy effect remains $25 v .6 .3 \%$ in the general population. There were $9 \%$ fetal weight $<2500 \mathrm{~g}$ after ART pregnancy $v$. $5 \%$ in the general population. In addition, we observed $5 \%$ low fetal weight after a normal term of ART pregnancy.

Our data suggest that preterm ART pregnancy and the incidence of weight $<2500 \mathrm{~g}$ children born after ART pregnancy are related.

We are already waiting for more information from this cohort to assess the causes of increased prematurity incidence in ART: indeed, in this study, we have not taken into account the various factors related to the prematurity. We also suggest an adverse hormonal effect exposure ${ }^{3}$ during ART pregnancy and/or stress during these special pregnancies after a long time of infertility.

Disclosure of Interest: None.

\section{References}

1. Ban Frangez H, Korosec S, Verdenik I, et al. Preterm delivery risk factors in singletons born after in vitro fertilization procedures. Eur J Obstet Gynecol Reprod Biol. 2014; 176, 183-186. 2. Stojnic J, Radunovic N, Jeremic K, Kotlica BK, Mitrovic M. Perinatal outcome of singleton pregnancies following in vitro fertilization. Tulic I Clin Exp Obstet Gynecol. 2013; 40, 277-283.

3. Kadhel P, Monfort C, Costet N, et al. Chlordecone exposure, length of gestation, and risk of preterm birth. Am J Epidemiol. 2014; 179, 536-544.

IUGR-13 - oral

Intrauterine growth restriction is associated with altered expression patterns of sirtuins and key metabolic genes in pig skeletal muscle

S. Chriett ${ }^{1}$, I. Le Huërou-Luron ${ }^{2}, \mathrm{H}$. Vidal $^{1}$ and L. Pirola ${ }^{1}$

${ }^{1}$ Carmen (Cardiology, Metabolism and Nutrition) Laboratory,

INSERM U1060, Lyon-1 University, South Lyon Medical

Faculty, Oullins, France; ${ }^{2}$ INRA-UMR 1341 ADNC

('Alimentation, Adaptations Digestives, Nerveuses et

Comportementales'), Saint-Gilles, France

Email: sabrina.chriett@universite-lyon.fr

Intrauterine growth restriction (IUGR) and associated low birth weight might lead to the development of metabolic disturbances including insulin resistance and type 2 diabetes through mechanisms largely unknown. ${ }^{1}$ Prenatal and early postnatal lives are important determinants of future health. IUGR might be associated with gene expression changes driving to metabolic diseases. ${ }^{1-3}$

Using a Sus scrofa (pig) model of spontaneous IUGR, we investigated skeletal muscle gene expression of sirtuins and metabolic genes during fetal life (71 and 112 days postconception) and 2 days after birth. The aim of the study was to investigate whether the same regulations take place in IUGR and are associated with sirtuins and metabolic genes alterations.

We focused on the longissimus dorsi muscle. mRNA levels of the insulin pathway genes, Irs1 and Glut4, metabolic genes, Hk2 and Gadph, and Sirtuins (1-7) were analyzed. Protein levels were also investigated.

mRNA expression of several sirtuin isoforms (SIRT1, 5, 6, 7) exhibited significant correlations with gestational age or fetus/ newborn weights. Significant correlations were similarly observed for insulin signaling and the metabolic genes IRS1, Glut4 and HK2.

Comparing the control $v$. IUGR samples, our study revealed the existence of transcriptional differences. Whereas Sirt1 and $\mathrm{Hk} 2$ displayed an age- and weight-dependent downregulation in controls, such feature was lost in IUGR pigs. Similarly, Sirt2 and Glut4 were upregulated in IUGR pigs as compared with controls. The protein level showed a significant upregulation of 
Glut4 at 2 days after birth. These IUGR-dependent gene alterations were, in part, linked to protein post-translational modifications on histone $\mathrm{H} 3$.

We demonstrated that, in pig skeletal muscle, several sirtuins isoforms and metabolic genes display specific gene expression trajectories during fetal and early postnatal life. Such gene expression patterns were altered in the IUGR condition. Given the importance of sirtuins and insulin-signaling genes in the control of metabolism, ${ }^{4,5}$ the transcriptional changes we observed might contribute to the predisposition to metabolic disease in adulthood. ${ }^{6}$

\section{Disclosure of Interest: None.}

\section{References}

1. Barker DJ. Fetal origins of coronary heart disease. BMJ. 1995; 311, 171-174.

2. Junien C. Early determinants of health and disease: epigenetics and environment. Epigenetics and child health: basic principles. Epigenetic mechanisms for nutrition determinants of later health outcomes. Bull Acad Natl Med. 2011; 195, 511-526; discussion 526-527.

3. Martin-Gronert MS, Tarry-Adkins JL, Cripps RL, Chen JH, Ozanne SE. Maternal protein restriction leads to early life alterations in the expression of key molecules involved in the aging process in rat offspring. Am J Physiol Regul Integr Comp Physiol. 2008; 294, R494-R500.

4. Dong XC. Sirtuin biology and relevance to diabetes treatment. Diabetes Manag (Lond). 2012; 2, 243-257.

5. Yu J, Auwerx J. The role of sirtuins in the control of metabolic homeostasis. Ann NY Acad Sci. 2009; 1173(Suppl. 1): E10-E19.

6. Simmons RA. Developmental origins of diabetes: the role of epigenetic mechanisms. Curr Opin Endocrinol Diabetes Obes. 2007; 14, 13-16.

\section{MOTHER AND INFANT NUTRITION}

\section{MIN-1 - oral}

Exercise before and during an obese mouse pregnancy restores some placental gene expression and transport function

G. Gascoin ${ }^{1,2}$, H. Blackmore ${ }^{1}$, B. Musial ${ }^{1}$, S. Barnes ${ }^{1}$, D. Duque ${ }^{1}$, S. E. Ozanne ${ }^{1}$ and D. Fernandez-Twinn ${ }^{1}$

${ }^{1}$ Institute of Metabolic Sciences, University of Cambridge, Cambridge, UK; ${ }^{2}$ Department of Neonatal Medicine, Angers University Hospital, Angers, France

\section{Email: GeGascoin@chu-angers.fr}

Overweight or obesity prevalence in pregnant women has increased in line with the global obesity epidemic: up to $50 \%$ of women of reproductive age and 20-25\% of pregnant women at first antenatal visits in Europe and the United States. Epidemiological and animal data suggest that maternal obesity during pregnancy adversely affects offspring health. ${ }^{1-4}$ The underlying mechanisms may involve maternal and foetal dysregulation of glucose, insulin, lipid and amino-acid metabolism. The placenta develops to support foetal growth, and therefore plays a key role in the aetiology of developmental programming by impacting on nutrient transfer.

The objective of this study was to analyse the effect of exercise on placenta in obesogenic diet-exposed mouse dams.

The study consisted of three groups: control $(n=5)$, obese $(n=5)$ and obese + exercise $(n=5)$. The obesogenic diet was for 6 weeks before first mating in the two obese groups. After weaning, the obese + exercise group commenced training for a week ( $20 \mathrm{~min} /$ day, 5 days/week) before mating for second pregnancy and exercised until day 17 of gestation. The two other groups were also mated for second pregnancies. Placentas were collected at day 19 for morphometry/lipid staining and frozen for protein and gene-expression analyses.

Exercise intervention reduced placenta lipid storage and transfer to the foetal trophoblast. It also normalized the expression of some insulin-signalling components that were dysregulated in the placentas of unexercised obese dams.

Exercise starting before and maintained during pregnancy may improve foetal outcome by restoring placental nutrient transfer.

Disclosure of Interest: None.

\section{References}

1. Alfaradhi MZ, Fernandez-Twinn DS, Martin-Gronert MS, et al. Oxidative stress and altered lipid homeostasis in the programming of offspring fatty liver by maternal obesity. Am J Physiol Regul Integr Comp Physiol. 2014; 307, R26-34.

2. Ingvorsen $\mathrm{C}$, Thysen $\mathrm{AH}$, Fernandez-Twinn D, et al. Effects of pregnancy on obesity-induced inflammation in a mouse model of fetal programming. Int J Obes (Lond). 2014; 38, 1282-1289.

3. Fernandez-Twinn DS, Blackmore HL, Siggens L, et al. The programming of cardiac hypertrophy in the offspring by maternal obesity is associated with hyperinsulinemia, AKT, ERK, and mTOR activation. Endocrinology. 2012; 153, 5961-5971.

4. Fernandez-Twinn DS, Alfaradhi MZ, Martin-Gronert MS, et al. Downregulation of IRS-1 in adipose tissue of offspring of obese mice is programmed cell-autonomously through posttranscriptional mechanisms. Mol Metab. 2014; 3, 325-333.

MIN-2 - oral

Perinatal protein restriction effect on maternal milk composition throughout the lactation period and its potential role on metabolic trajectories of the offspring and their outcome at adulthood

A. M. Agnoux ${ }^{1,2}$, J.-P. Antignac ${ }^{3}$, G. Simard ${ }^{4,5,6}$, C.-Y. Boquien ${ }^{1,2}$, A. David ${ }^{1,2}$, E. Desnots ${ }^{1,2}$, V. Ferchaud-Roucher ${ }^{1,2}$, D. Darmaun ${ }^{1,2}$, P. Parnet ${ }^{1,2}$ and M.-C. Alexandre-Gouabau ${ }^{1,2}$

${ }^{1}$ INRA, UMR1280, Physiologie des Adaptations Nutritionnelles, Institut des Maladies de l'Appareil Digestif (IMAD), Centre de 
Recherche en Nutrition Humaine Ouest (CRNH), Nantes, France; ${ }^{2} L U N A M$, Centre de Recherche en Nutrition Humaine Ouest (CRNH), Institut des Maladies de l'Appareil Digestif (IMAD), Nantes, France; ${ }^{3}$ LUNAM, Oniris, Laboratoire d'Etude des Résidus et Contaminants dans les Aliments (LABERCA), USC INRA 1329, Nantes, France; ${ }^{4}$ LUNAM Université, Angers, France; ${ }^{5}$ INSERM U1063, Angers, France; ${ }^{6}$ Université d'Angers, CHU Angers, Department of Biochemistry, Angers, France

Email: Marie-Cecile.Alexandre-Gouabau@univ-nantes.fr

A major gap in understanding the impact of perinatal nutrition on birth and later health outcomes in the concept of metabolic programming $^{1}$ concerns the effect of maternal nutrition on breast milk composition. We investigated in a rat programming model the effects of maternal isocaloric low-protein diet during gestation and lactation on milk composition of the dams, on the metabolomics trajectories of male suckled offspring and their outcome at adulthood. We addressed this issue by using an integrated methodology that combined targeted milk analyses of free amino-acid and fatty-acid content throughout lactation, targeted plasmatic acylcarnitines profiling with an untargeted milk and plasmatic mass spectrometric-based metabolomics phenotyping. ${ }^{2}$ The assessment of insulin sensitivity in weaned rats exposed to 10 -week western diet at adulthood was performed by a hyperinsulinemic-euglycemic clamp. $^{3}$

The metabolomic trajectories of male suckled offspring showed an adaptive step (PND0-PND16) followed by a second step (PND20-PND25) corresponding to the first earlier metabolic disorders statement. The specific inflexion kinetic point in the short-term metabolomics trajectories could be explained at least, in part, by the specific milk composition provided by protein-restricted dams. Finally, these changes occurred earlier before the insulin secretion impairment and/or insulin sensitivity loss observed at adulthood along with permanent changes in several biomarkers involved in substrate oxidation inflexibility dependent on the time window of perinatal dietary manipulation. Interestingly, a decrease of several insulinemic-glycemic amino acids in milk provided by proteinrestricted dams suggested that a maternal protein restriction during the perinatal period induces a modulation in the insulinotrophic status of dams milk that may contribute greatly for the lower growth of the suckled male offspring, and possibly later in insulin deregulation. Altogether, our results show that milk composition is clearly influenced by diet and may be a key determinant of offspring growth and metabolic programming at adulthood.

\section{Disclosure of Interest: None.}

\section{References}

1. Barker DJ, Osmond C, Forsén TJ, Kajantie E, Eriksson JG. Trajectories of growth among children who have coronary events as adults. N Engl J Med. 2005; 353, 1802-1809.
2. Nicholson JK, Lindon JC, Holmes E. 'Metabonomics': understanding the metabolic responses of living systems to pathophysiological stimuli via multivariate statistical analysis of biological NMR spectroscopic data. Xenobiotica. 1999; 29, 1181-1189.

3. Martin Agnoux A, Antignac J-P, Simard G, et al. Timewindow dependent effect of perinatal maternal protein restriction on insulin sensitivity and energy substrate oxidation in adult male offspring. Am J Physiol-Regul Integr Comp Physiol. 2014; 307, R184-197.

\section{MIN-3}

Formula milk is involved in programming of oxidative stress and inflammation in kidney of IUGR piglets

G. Elmhiri ${ }^{1}$, D. Mahmood ${ }^{2}$, C. Leridon ${ }^{1}$, P. Jacolot ${ }^{1}$, S. Firmin ${ }^{1}$, A. Chango ${ }^{1}$, L. Guigand ${ }^{3}$, F. J. Tessier ${ }^{1}$, T. Larcher ${ }^{3}$ and L. Abdennebi-Najar ${ }^{1}$

${ }^{1}$ UP-EGEAL 2012.10.101, Institut Polytechnique LaSalle Beauvais, Beauvais, France; ${ }^{2}$ UMR 8256, UPMC Université Paris 6, CNRS, INSERM Department of Adaptation and Ageing Biology (UMR 8256/ERL-1164), Paris, France; ${ }^{3}$ INRA, UMR 703 APEX, Ecole Nationale Vétérinaire Agroalimentaire et de l'Alimentation Nantes-Atlantique (Oniris), Nantes, France

Email: ghada.el-mhiri@lasalle-beauvais.fr

Dietary advanced glycation end products (AGEs) are known to promote several chronic diseases, one of them being kidney failure. ${ }^{1-3}$ This study aims to test whether AGEs-derived formula enhances programming of inflammation and oxidative stress in the kidney of intrauterine growth restriction (IUGR) piglets. A total of 16 animals were administered either a low heated formula (LHF: $37^{\circ} \mathrm{C}$ for $5 \mathrm{~min}, n=8$ ) or a high heated formula (HHF: $120^{\circ} \mathrm{C}$ for $20 \mathrm{~min}, n=8$ ) during 3 weeks. They were euthanized at postnatal day 54 (PND54). N ( $\varepsilon$ )carboxymethyllysine (CML), a major marker of AGEs, was measured in plasma, feces and formula by HPLC/MS-MS. CML and sRAGE were detected by immunofluorescence in the kidney cells at PND54. Target renin-angiotensin, apoptotic, proinflammatory genes, p62 NFKB and sRAGE levels were quantified using different approaches. Free CML $(P<0.05)$ and plasma urea/creatinine ratio $(P<0.05)$ increased only in the HHF-fed group at PND36. CML was detected in the nucleus of renal tubular cell-fed formula piglets but not in suckled ones. AT1, AT2, Angiotensin 1, caspase 3, caspace 8, $\mathrm{NF \kappa B}, \mathrm{p} 62 \mathrm{NF \kappa B}$ and total protein oxidation were higher in the HHF-fed group as compared with the LHF-fed group $(P<0.05)$. In addition, glomerular diameter decreased $(P<0.05)$. MDA level increased in the liver of the HHF-fed animals $(P<0.05)$. The present study provides in vivo evidence in IUGR piglets that were fed AGEs-derived formula, by reaching the nucleus of the kidney cell, brings an additional insult to enhance programming of inflammation and oxidative 
stress in the kidney. This experimental model with piglets shed light on the importance of considering AGEs-derived formula as a contributor of kidney damage in IUGR infants later in life.

\section{Disclosure of Interest: None.}

\section{References}

1. Lucas A. Programming by early nutrition: an experimental approach. J Nutr. 1998; 128(Suppl.), 401S-406S.

2. Barker DJ. The fetal and infant origins of adult disease. BMJ. 1990; 301, 1111.

3. Baumann M, Stehouwer C, Scheijen J, et al. N epsilon(carboxymethyl)lysine during the early development of hypertension. Ann NY, 2008; 1126, 201-204.

\section{MIN-4}

Risk factors for overweight and obesity in 8-9-year-old children in the district of Constantine (Algeria)

A. Sayed, H. Daoudi, A. Rouabah and L. Rouabah

Laboratory of Biology Cellular \& Molecular, University of Constantine, Constantine, Algeria

Email: mirasayed0411@gmail.com

The prevalence of childhood obesity has nearly tripled since $1970 ;^{1}$ the highest rate of childhood obesity has been observed in the developed countries. Its prevalence is increasing in the developing countries too ${ }^{2}$ and emerging as a major health problem. ${ }^{3}$ Obesity persists from childhood to adulthood through adolescence. ${ }^{1}$

The aim was to assess the incidence of obesity and overweight among primary school children (8-9 years), and to find the possible association between obesity/overweight, dietary habits and activity physical of these children.

A cross-sectional descriptive study was conducted in 2011 to estimate the prevalence of overweight and obesity and to emphasize the risk factors. We included 599 school children in the 3 th and 4th grades in public primary schools in the district of Constantine (Algeria). We studied anthropometric measurements (overweight and body mass index), calculated on the basis of WHO 2007 criteria, followed by dietary habits, socio-demographic data through a parental questionnaire. Data analysis were performed using the SPSS 20 software. Pearson correlation analyses were also performed.

The prevalence of overweight among the subjects was $16.9 \%$, whereas that of obesity was $10.2 \%$, the incidence of low birth weight $(<2.5 \mathrm{~kg})$ was $32.2 \%$ for all the children (31.6\% for overweight and $28.6 \%$ for obese children). The incidence of macrosomia (birth weight $\geqslant 4 \mathrm{~kg}$ ) was $25.5 \%$ for all the children (41.1\% for overweight and $44.2 \%$ for obese children) with $P<0.001$ and $r=0.19$. Breakfast and a practice of sport were predictors of obesity and overweight among the school children studied.
The prevalence of overweight and obesity among the school children is increasing. Birth weight, less healthy dietary habits and less physical activity may be responsible for this high prevalence.

\section{Disclosure of Interest: None.}

\section{References}

1. Nader PR, O'Brien M, Houts R, et al. Identifying risk for obesity in early childhood. Pediatrics. 2006; 118, 594-601.

2. Amin TT, Al-Sultan AI, Ali A. Overweight and obesity and their association with dietary habits, and sociodemographic characteristics among male primary school children in Al-Hassa, Kingdom of Saudi Arabia. Indian I Community Med Off Publ Indian Assoc Prev Soc Med. 2008; 33, 172-181. 3. Vogels N, Posthumus DL, Mariman EC, et al. Determinants of overweight in a cohort of Dutch children. Am J Clin Nutr. 2006; 84, 717-724.

\section{MIN-5}

Breastfeeding and adult body fat: the missing confounding factor

S. Péneau $^{1}$, S. Hercberg ${ }^{1,2,3}$ and M.-F. Rolland-Cachera ${ }^{1}$

${ }^{1}$ Université Paris 13, Sorbonne Paris Cité, Equipe de Recherche en Epidémiologie Nutritionnelle, Centre de Recherche en Epidémiologies et Biostatistiques, INSERM (U1153), INRA, CNAM, Université Paris 5, Université Paris 7, Bobigny, France; ${ }^{2}$ Université Paris 13, Sorbonne Paris Cité, USEN (Unité de surveillance et d'épidémiologie nutritionnelle), Bobigny, France; InVS, Bobigny, France; ${ }^{3}$ Département de Santé Publique, Hôpital Avicenne, Bobigny, France

Email: s.peneau@eren.smbh.univ-paris13.fr

Many studies show that breastfeeding is protective against overweight and obesity; ${ }^{1}$ however, others do not support this effect. $^{2}$ Early nutrition is an important factor that may play a role in the association between breastfeeding and later body fatness and is generally characterized by high-protein-low-fat intakes in industrialized countries. ${ }^{3,4}$ However, this factor is generally missing. We therefore investigated whether breastfeeding relates to body fat in adulthood, taking into account early nutritional factors. Nutritional intakes of 73 healthy infants born in 1984, participating in the two-decade-long ELANCE study were estimated at the ages of 10 months and 2 years. Breastfeeding was defined as any kind of breastfeeding, including partial breastfeeding, regardless of the duration. At 20 years, weight, height, subscapular skinfold (SF) and fat mass assessed via bioelectrical impedance analysis were measured. In this sample, $64 \%$ of the children had been breastfed. In linear regression models adjusted for mother's body mass index and father's profession, breastfeeding was not associated with any of the body fat measurements at 20 years (all $P>0.05$ ). 
After adding nutritional intake variables to the models (total energy and \% energy from nutrients), breastfeeding became significantly associated with lower SF thickness at 20 years. In particular, breastfed subjects had significantly lower $\% \mathrm{SF}$ at 20 years after adjustment for energy and $\%$ fat intakes at 2 years $(\beta=-28.25 \%$ SF, 95\% CI $=-50.28$ to $-6.21, P=0.013)$ or when adjusting for energy and \% carbohydrates at 2 years $(-28.27 \%$ SF, 95\% CI $=-50.64$ to $-5.90, P=0.014)$. Breastfeeding was not associated with adult body fatness, taking into account the usual confounding factors. However, after additionally adjusting for nutritional intake covariates, a protective effect of breastfeeding emerged. Early nutrition needs to be taken into account when examining the long-term health effects of breastfeeding.

\section{Disclosure of Interest: None.}

\section{References}

1. Owen CG, Martin RM, Whincup PH, Smith GD, Cook DG. Effect of infant feeding on the risk of obesity across the life course: a quantitative review of published evidence. Pediatrics. 2005; 115, 1367-1377.

2. Casazza $\mathrm{K}$, et al. Myths, presumptions, and facts about obesity. N Engl J Med. 2013; 368, 446-454.

3. Rolland-Cachera MF, Maillot M, Deheeger M, et al. Association of nutrition in early life with body fat and serum leptin at adult age. Int J Obes (Lond). 2013; 37, 1116-1122.

4. Hoppe C, Molgaard C, Thomsen BL, Juul A, Michaelsen KF. Protein intake at 9 mo of age is associated with body size but not with body fat in 10-y-old Danish children. Am J Clin Nutr. 2004; 79, 494-501.

\section{MIN-6}

\section{Barley supplementation at mid-gestation in broodmares does not affect fetal development and is accompanied with minimal placental adaptations}

M. Robles ${ }^{1}$, P. Peugnet ${ }^{1}$, C. Dubois ${ }^{2}$, L. Wimel ${ }^{2}$, A. Tarrade ${ }^{1}$ and P. Chavatte-Palmer ${ }^{1}$

${ }^{1}$ INRA, UMR 1198, Biologie du Développement et Reproduction, Jouy-en-Josas, France; ${ }^{2} I F C E$, Station Expérimentale de la Valade, Chamberet, France

\section{Email: mrobles@jouy.inra.fr}

Modifications of maternal environment could alter fetal growth and development through the placenta and thus health in adulthood. ${ }^{1-3}$ Osteochondrosis is an osteoarticular pathology which affects young horses and strongly impacts the equine industry. ${ }^{4}$ It has been shown that breeding practices, especially feeding pregnant mares with concentrate in the last part of gestation, could play a role in the development of this disease. ${ }^{5}$ To understand the effect of feeding practices during gestation, 24 saddlebred mares were allocated to one of two groups: group B was supplemented twice a day with barley (B), and group F was fed only with fodder (F) between the 7th month of gestation and foaling. B mares maintained an optimal body condition score through gestation, with an increase in glycemia and insulinemia after each meal and an insulin resistance in the 9th month of gestation. F mares lost condition as assessed by body condition score in the last part of gestation, leading to a moderate undernutrition and a transitional increase in non-esterified fatty-acid plasma concentrations. Diets had no effect on feto-placental biometry, nor on placental structure. In contrast, an increase in microcotyledonary vessel volume was observed in $\mathrm{F}$ placentas, indicating placental adaptation, possibly to increase feto-maternal exchanges. ${ }^{6}$ There was no overall difference in the expression of genes involved in vascularization, nutrient transfer, growth and development between placentas from B and F mares. Nevertheless, as seen by others, ${ }^{7-9}$ sex-specific effects of maternal nutrition were observed in placentas from female foals, with differences in the expression of endogline, kinase insert domain receptor, insulinlike growth factor 2 and insulin-like growth factor 1 receptor genes. This study demonstrates that breeding practices, that is, supplementation in concentrate at mid-gestation, do not seem to affect fetal development.

\section{Disclosure of Interest: None.}

\section{References}

1. Painter RC, Roseboom TJ, Bleker OP. Prenatal exposure to the Dutch famine and disease in later life: an overview. Reprod Toxicol. 2005; 20, 345-352.

2. Fowden AL, Forhead AJ, Coan PM, Burton GJ. The placenta and intrauterine programming. I Neuroendocrinol. 2008; 20, 439-450.

3. Redmer DA, Wallace JM, Reynolds LP. Effect of nutrient intake during pregnancy on fetal and placental growth and vascular development. Domest Anim Endocrinol. 2004; 27, 199-217.

4. Ytrehus B, Carlson CS, Ekman S. Etiology and pathogenesis of osteochondrosis. Vet Pathol Online. 2007; 44, 429-448.

5. Vander Heyden L, Lejeune JP, Caudron I, et al. Association of breeding conditions with prevalence of osteochondrosis in foals. Vet Rec. 2013; 172, 68-68.

6. Coan PM, Vaughan OR, Sekita Y, et al. Adaptations in placental phenotype support fetal growth during undernutrition of pregnant mice. J Physiol. 2010; 588, 527-538.

7. Gallou-Kabani C, Gabory A, Tost J, et al. Sex- and dietspecific changes of imprinted gene expression and DNA methylation in mouse placenta under a high-fat diet. PLoS One. 2010; 5, e14398.

8. Mao J, Zhang X, Sieli PT, Falduto MT, Torres KE, Rosenfeld CS. Contrasting effects of different maternal diets on sexually dimorphic gene expression in the murine placenta. Proc Natl Acad Sci. 2010; 107, 5557-5562.

9. Tarrade A, Rousseau-Ralliard D, Aubrière MC, et al. Sexual dimorphism of the feto-placental phenotype in response to a high fat and control maternal diets in a rabbit model. PLoS One. 2013; 8, e83458. 


\section{MIN-7}

Early nutrition: transcriptomic profiling of exfoliated cells, microvesicles and exosomes from breast milk and corresponding gastric fluid aspirate of preterm infant

B. Kaeffer, H. Billard, C.-Y. Boquien, E. Gauvard, A. Drouard, V. Gournay, J.-C. Rozé and I. Floris

INRA-Nantes University, UMR1280 PhAN, Nantes, France; Hospital of Mother and Child, Nantes, France

\section{Email: Bertrand.Kaeffer@univ-nantes.fr}

Exfoliated epithelial cells can be isolated from breast milk and gastric fluid along with microvesicles and exosomes. By quantifying the degree of exfoliation, that is, by assessing the loss of epithelial cells or of their specific molecular compounds (microRNA, mRNA) along with microvesicles and exosomes, it is possible to evaluate the molecular exchange between mother and child.

Samples from two cohorts were used: Triocapi (NCT01630278; gastric aspirates of preterm infant: 16) and Lactacol (NCT01493063; breast milk: four, one per week; gastric aspirates of preterm infant: four, one per week). Microvesicles and exosomes have been purified by ultracentrifugation ${ }^{1}$ and characterized by Zetasizer (Malvern). Exfoliated cells have been characterized by microscopic observation, quantified by DNA assay. A major microRNA (hsa-miR-146b-5P) and period 1 mRNA have been detected by qPCR.

Morphological identification of epithelial cells by confocal imaging $^{2}$ and quantification by purification of genomic DNA have shown that samples contained between 2000 and 20,000 cells. Size distributions were around $1 \mu \mathrm{m}$ for microvesicles and $100 \mathrm{~nm}$ for exosomes. Coding and non-coding RNAs were extracted to perform qPCR analysis. ${ }^{3}$ On cellular preparation recovered from breast milk and gastric aspirate of the baby sampled $3 \mathrm{~h}$ later, we focused on the detection of hsa-miR-146b-5P and period 1 mRNA.

The hsa-miR-146b-5P is among the most abundant microRNAs of breast milk and has been linked to immune function. ${ }^{4}$ Future studies will concentrate on its putative target mRNAs, involved in taurine metabolism, or the regulation of clock genes (period 1) as well as to the microvesicles/exosomes containing microRNA/mRNA related to mTORC1/microRNA-21 signaling and targeted to infant's mucosa. ${ }^{5}$

\section{Disclosure of Interest: None.}

\section{References}

1. Lässer C, Alikhani VS, Ekström K, et al. Human saliva, plasma and breast milk exosomes contain RNA: uptake by macrophages. J Transl Med. 2011; 9, 9.

2. Kaeffer B, Legrand A, Moyon $\mathrm{T}$, et al. Non-invasive exploration of neonatal gastric epithelium by using exfoliated epithelial cells. PloS One. 2011; 6, e25562.

3. Kaeffer B, Des Robert C, Alexandre-Gouabau MC, et al.

Recovery of exfoliated cells from the gastro-intestinal tract of premature infants: a new tool to obtain 'non-invasive biopsies'? Pediatr Res. 2007; 62, 564-569.

4. Kosaka N, Izumi H, Sekine K, Ochiya T. microRNA as a new immune-regulatory agent in breast milk. Silence. 2010; 1, 7. 5. Melnik BC, John SM, Schmitz G. Milk is not just food but most likely a genetic transfection system activating mTORC1 signaling for postnatal growth. Nutrition Journal. 2013; 12, 103.

\section{MIN-8 - oral \\ Adherence to French nutritional guidelines among pregnant women from the Elfe survey}

M. Kadawathagedara ${ }^{1,3}$, C. Kersuzan ${ }^{2}$, C. Tichit $^{2}$, S. Gojard ${ }^{2}$, M.-A. Charles ${ }^{1,3}$, S. Lioret ${ }^{1,3}$ and B. de Lauzon-Guillain ${ }^{1,3}$

${ }^{1}$ INSERM, Centre de Recherche en Epidémiologie et Santé des Populations, Villejuif, France; ${ }^{2}$ INRA, UR1303-Alimentation et Sciences Sociales (ALISS), Ivry-Sur-Seine, France; ${ }^{3}$ Université Paris-Sud, UMR-S 1018, Villejuif, France

Email: manik.kadawathagedara@inserm.fr

The National Program of Health and Nutrition (PNNS) has been implemented in France to improve the health status of the whole population. Nine nutritional guidelines were defined, and additional advices have been provided to specific populations groups such as pregnant women. Our study aimed to assess the adherence to nutritional guidelines in French pregnant women.

We used data from the Elfe cohort, in which 18,329 mothers were recruited in 2011 after delivery from a random sample of maternity wards in metropolitan France. Diet in the last trimester of pregnancy was assessed using a validated 122-item food frequency questionnaire. Medical records and a face-to-face interview were used to collect obstetrical and socio-demographic data. We used PNNS-Guideline Score ${ }^{1}$ to evaluate the adherence to the PNNS guidelines. A specific score was also created to evaluate the specific advices provided to pregnant women.

Over the 11 PNNS guidelines, the median score among these pregnant women was $6 \mathrm{IQR}$ [5-7]. The items of the PNNS score not followed by at least $50 \%$ of the women were: 'Fruit and vegetables', 'Bread, cereals, potatoes and legumes', 'Whole-grain food', 'Seafood', 'Sweetened foods', 'Beverages' and 'Salt'. Over the 10 pregnancy guidelines, the median score was 5.7 IQR [4.7-6.7]. The items of the pregnancy score not followed by at least $50 \%$ of the women were: 'Folic acid supplementation', 'Folates', 'Vitamin D', 'Iron' and 'Meal frequency'. In multivariate analysis, higher PNNS and pregnancy scores were observed among women born abroad France, those older and primiparous, higher education level, with lower body mass index, higher social position, higher income, higher attendance to antenatal classes and higher number of antenatal visits.

To improve the adherence to nutritional guidelines among French pregnant women, the prevention messages should be targeted to women with a low socio-economic position. 
Disclosure of Interest: M.K. was supported by a grant SF-Dohad-Bledina.

\section{Reference}

1. Estaquio C, Kesse-Guyot E, Deschamps V, et al. Adherence to the French Programme National Nutrition Santé Guideline Score is associated with better nutrient intake and nutritional status. J Am Diet Assoc. 2009; 109, 1031-1041.

\section{MIN-9}

Maternal nutrition during lactation dictates milk composition and has long-term metabolic consequences in the male rat offspring

J.-S. Wattez, A. Delmont, O. Beseme, S. Goers, F. Delahaye, L.-F. Barella, M. Bouvet, D. Eberlé, C. Laborie, J. Lesage,

B. Foligné, P. Mathias, C. Breton, C. Metges, F. Pinet and D. Vieau

EA4489, Unité Environnement Périnatal et Croissance, Equipe Dénutrition Maternelle Périnatale, Université Lille, Lille, France

Email: js.wattez@hotmail.fr

Several data have established a close link between intrauterine growth restriction (IUGR) and development of chronic adult diseases, such as obesity, diabetes and hypertension both in humans and animals. ${ }^{1-3}$ Moreover, modification of growth velocity during early postnatal period (i.e. lactation) may also sensitize to the development of metabolic syndrome in adulthood. ${ }^{4}$

We have recently shown that a $50 \%$ maternal food restriction during the last week of gestation and throughout lactation (FR50 model) causes short- and long-term metabolic alterations in male rat offspring. Neonates from FR50 mothers exhibit decreased perinatal growth associated with hypoleptinemia, whereas they show hyperphagia, hyperleptinemia, glucose intolerance and mild hypertension in adulthood. Cross-fostering experiments demonstrate that these alterations are also present in normotrophs adopted by undernourished mothers, and markedly attenuated when IUGR are lactated by mothers fed ad libitum during lactation. ${ }^{5}$ In addition, maternal nutrition during lactation controls leptin concentration both in breast milk and in the plasma of pups, suggesting that milk composition may have long-lasting programming/deprogramming metabolic effects in the offspring. Global milk analysis demonstrated that maternal undernutrition decreases lactose concentration and modulates lipid profile at postnatal day (PND) 10, and diminishes serotransferin levels at PND21. The evidence that maternal nutrition specifically modifies some compounds of milk, opens new perspectives to identify molecules that could be used in artificial milk to protect from the subsequent development of metabolic diseases.

\section{Disclosure of Interest: None.}

\section{References}

1. Barker DJ. The developmental origins of chronic adult disease. Acta Paediatr. 2004; 93, 26-33.

2. Gluckman PD, Hanson MA, Spencer HG, Bateson P. Environmental influences during development and their later consequences for health and disease: implications for the interpretation of empirical studies. Proc Biol Sci. 2005; 272, 671-677.

3. Simmons R. Developmental origins of adult metabolic disease. Endocrinol Metab Clin North Am. 2006; 35, 193-204. 4. Gluckman PD, Hanson MA, Cooper C, Thornburg KL. Effect of in utero and early-life conditions on adult health and disease. $N$ Engl J Med. 2008; 359, 61-73.

5. Wattez JS, Delahaye F, Barella LF, et al. Short- and longterm effects of maternal perinatal undernutrition are lowered by cross-fostering during lactation in the male rat. J Dev Orig Health Dis. 2014; 5, 109-120.

\section{MIN-10}

Females from undernourished mothers are predisposed to altered placental function and offspring growth when fed a high-fat diet before and/or during gestation

O. Cisse, I. Fajardy, F. Delahaye, M.-A. Lukaszewski, V. Montel, A. Dickes-Coopman, E. Moitrot, D. Eberlé, C. Breton, D. Vieau and C. Laborie

EA4489, Unité Environnement Périnatal et Croissance, Equipe Dénutrition Maternelle Périnatale, Université Lille, Lille, France

\section{Email: Ouma.cisse@gmail.com}

Maternal malnutrition is harmful to developing fetus and can predispose offspring to diseases later in life. ${ }^{1,2}$ The placenta plays a central role in the interface between the mother and the fetus. Thus, placental adaptations to inadequate maternal nutrition are imperative for optimal fetal growth. ${ }^{3,4}$ We have previously shown that both maternal undernutrition $(70 \%$ food restriction during gestation: FR30 model) and overnutrition (gestational hyperglycemia) alter placental function resulting in abnormal fetal growth in rats. ${ }^{5,6}$ We hypothesized that maternal malnutrition programs the reproductive capacity of female offspring. Therefore, we decided to investigate daughters of FR30 mothers, in particular their pregnancies/placenta and their offspring, once daughters are submitted to a moderate high-fat (HF) diet (containing 23\% kcal lipids) before and/or during gestation.

HF-fed daughters before and during gestation led to hyperleptinemia and hyperinsulinemia, reduced placental weight and fetal growth restriction, especially in male newborns. In addition, we identified a decrease in the mRNA expression levels of genes involved in prostaglandin synthesis, placental growth and angiogenesis in placenta of growth-restricted fetus. In contrast, HF-fed daughters during preconception led to maternal impaired glucose tolerance, increased placental weight and fetal overgrowth (macrosomia), especially in female newborns. These 
changes were associated with increased expression of genes regulating placenta remodeling (such as chemerin and serpine1). Interestingly, these data indicate that the impact of maternal malnutrition on daughters and the growth of their offspring is sex specific. Altogether, our findings suggest that HF-fed females from FR30 mothers may modify placental vasculature development contributing to abnormal fetal growth.

\section{Disclosure of Interest: None.}

\section{References}

1. Barker DJ. The developmental origins of adult disease. J Am Coll Nutr. 2004; 23, 588S-595S.

2. Warner MJ, Ozanne SE. Mechanisms involved in the developmental programming of adulthood disease. Biochem J. 2010; 427, 333-347.

3. Sandovici I, Hoelle K, Angiolini E, Constância M. Placental adaptations to the maternal-fetal environment: implications for fetal growth and developmental programming. Reprod Biomed. 2012; 25, 68-89.

4. Jansson T, Powell TL. Role of placental nutrient sensing in developmental programming. Clin Obstet Gynecol. 2013; 56, 591-601.

5. Mayeur S, Lancel S, Theys N, et al. Maternal calorie restriction modulates placental mitochondrial biogenesis and bioenergetic efficiency: putative involvement in feto-placental growth defects in rats. Am J Physiol Endocrinol Metab. 2013; 304, E14-E22.

6. Cisse O, Fajardy I, Dickes-Coopman A, et al. Mild gestational hyperglycemia in rat induces fetal overgrowth and modulates placental growth factors and nutrient transporters expression. PLoS One. 2013; 8, e47986.

\section{MIN-11 - oral}

Maternal obesity predisposes adult male rat offspring to increased adiposity through induction of lipogenic genes

S. Lecoutre, C. Laborie, D. Eberlé, V. Montel, A. DickesCoopman, E. Denhez, J. Lesage, D. Vieau and C. Breton

EA4489, Unité Environnement Périnatal et Croissance, Equipe Dénutrition Maternelle Périnatale, Université Lille, Lille, France

\section{Email: 23simon.lec@gmail.com}

Increasing evidence indicate that adverse environments during development, either in utero or in the early postnatal period, can program higher risk of metabolic pathologies later in life. ${ }^{1}$ In particular, maternal obesity, excessive nutrition and accelerated growth in neonates have been shown to sensitize offspring to obesity. ${ }^{2,3} \mathrm{We}$ hypothesize that the white adipose tissue is a prime target of metabolic programming induced by maternal obesity. ${ }^{4-6}$ In order to unravel the underlying mechanisms, we have developed a rat model of maternal obesity using a high-fat (HF) diet (containing $60 \mathrm{kcal} \%$ lipids) before and during gestation and lactation. At birth, newborns from obese dams (called HF) were normotrophs. However, HF neonates exhibited a rapid weight gain during lactation, a key period of adipose tissue development in rodents. ${ }^{7}$ At weaning, HF overweight male offspring were fed a chow diet until 9 months of age. Increased body weight at weaning is no more observable from 3 months of age. At 7 months of age, HF adult male offspring were normoglycemic but showed impaired glucose intolerance, hyperinsulinemia and hypercorticosteronemia. Moreover, despite no difference in daily caloric intake, HF male rats exhibited dysregulated light/dark-phase food intake rhythm. Finally, HF adult male offspring did not show overt obesity but were predisposed to fat accumulation with increased white fat pad weights and hyperleptinemia. They also exhibited hypertrophic adipocyte with elevated lipogenic (i.e. SREBP-1c, FAS, leptin) and diminished adipogenic (i.e., PPAR $\gamma$ ) mRNA levels in a depot-specific manner. Thus, accelerated growth during lactation might be a particularly sensitive event for metabolic programming of adiposity by maternal obesity.

Disclosure of Interest: None.

\section{References}

1. Barker DJ. The developmental origins of chronic adult disease. Acta Paediatr. 2004; 93, 26-33.

2. Ravelli AC, van Der Meulen JH, Osmond C, Barker DJ, Bleker OP. Obesity at the age of $50 \mathrm{y}$ in men and women exposed to famine prenatally. Am J Clin Nutr. 1999; 70, 811-816.

3. Gluckman PD, Hanson MA, Beedle AS, Spencer HG. Predictive adaptive responses in perspective. Trends Endocrinol Metab. 2008; 19, 109-110.

4. Breton C. The hypothalamus-adipose axis is a key target of developmental programming by maternal nutritional manipulation. J Endocrinol. 2013; 216, R19-R31.

5. Lukaszewski MA, Eberlé D, Vieau D, Breton C. Nutritional manipulations in the perinatal period program adipose tissue in offspring. Am J Physiol Endocrinol Metab. 2013; 305, E1195-E1207.

6. Lukaszewski MA, Mayeur S, Fajardy I, et al. Maternal prenatal undernutrition programs adipose tissue gene expression in adult male rat offspring under high-fat diet. Am J Physiol Endocrinol Metab. 2011; 301, E548-E559.

7. Muhlhausler B, Smith SR. Early-life origin of metabolic dysfunction: role of the adipocyte. Trends Endocrinol Metab. 2009; 2, 51-57.

\section{MIN-12}

Consequences of early nutrition on the developing sweet/ fatty taste, eating behavior and motivation for palatable foods in the rodent model, from birth to sexual maturity V. Paillé ${ }^{1}$, M.-C. Canivenc ${ }^{2}$, S. Nicklaus ${ }^{2}$ and P. Parnet ${ }^{1}$

${ }^{1}$ INRA-Nantes University, UMR1280 PhAN, Nantes, France; IMAD; ${ }^{2} U M R 1324$ CSGA (Centre des Sciences du Goût et de l'Alimentation), INRA, CNRS, Université de Bourgogne, Dijon, France

Email: vincent.paille@univ-nantes.fr 
Epidemiological and experimental data have shown that malnutrition during pregnancy and the neonatal period increased the risk of developing abnormal eating behaviors, and its associated disorders later in life. Indeed, it is now recognized that the prenatal and postnatal maternal consumption of fatty and sugary foods increases the risk of obesity in children. ${ }^{1}$ However, the underlying mechanisms are still poorly understood. The reward circuits (mesolimbic dopamine) that control the hedonic feeding are a good candidate as dopamine function is altered in dietinduced obesity in both humans ${ }^{2-4}$ and animals. ${ }^{5,6}$ Moreover, dopamine projections develop for a large part postnatally ${ }^{7}$ making them susceptible to the 'organizational effects' of early diet.

What could be the impact of early overnutrition (maternal diet during pregnancy and lactation) on the ontogeny of brain reward circuits and expression of receptors involved in the regulation of food intake?

Pups from 24 pregnant Sprague-Dawley rat dams fed either a normal diet or a western diet (WD) during gestation and lactation were used. Longitudinal behavioral taste preferences were performed using a two-bottle choice test at 25,50 and 100 days after birth on 12 males and 12 females. F1 males from WD mothers have a stable preference for sweet and fat taste over time (25, 50 and 100). Surprisingly, F1 rats developed an early saccharin aversion that decreases with time and is less pronounced in male rats from WD mothers. Repeated presentations decrease the preference for sweet but have no effect for fat. Only male rats from WD mothers lost interest for fat at P50. Following these behavioral tests, the animals were killed for histology and molecular analysis of brain reward pathways and taste receptors to correlate with the behavior. Altogether these data suggest that early malnutrition affect differentially male and female taste preferences over time.

\section{Disclosure of Interest: None.}

\section{References}

1. Levin BE. Metabolic imprinting: critical impact of the perinatal environment on the regulation of energy homeostasis. Philos Trans R Soc Lond B Biol Sci. 2006; 361, 1107-1021.

2. Stice E, Spoor S, Bohon C, Veldhuizen MG, Small DM. Relation of reward from food intake and anticipated food intake to obesity: a functional magnetic resonance imaging study. J Abnorm Psychol. 2008; 117, 924-935.

3. Frank GK, Reynolds JR, Shott ME, et al. Anorexia nervosa and obesity are associated with opposite brain reward response. Neuropsychopharmacology. 2012; 37, 2031-2046.

4. Green E, Jacobson A, Haase L, Murphy C. Reduced nucleus accumbens and caudate nucleus activation to a pleasant taste is associated with obesity in older adults. Brain Res. 2011; 1386, 109-117.

5. Davis JF, Tracy AL, Schurdak JD, et al. Exposure to elevated levels of dietary fat attenuates psychostimulant reward and mesolimbic dopamine turnover in the rat. Behav Neurosci. 2008; 122, 1257-1263.

6. Geiger BM, Haburcak M, Avena NM, Moyer MC, Hoebel BG, Pothos EN. Deficits of mesolimbic dopamine neurotransmission in rat dietary obesity. Neuroscience. 2009; 159, 1193-1199.

7. Antonopoulos J, Dori I, Dinopoulos A, Chiotelli M, Parnavelas JG. Postnatal development of the dopaminergic system of the striatum in the rat. Neuroscience. 2002; 110, 245-256.

\section{MIN-13}

Sociocultural determinants on breastfeeding initiation and duration in France: preliminary results from the Elfe study

S. Wagner ${ }^{1}$, C. Kersuzan ${ }^{2}$, S. Gojard ${ }^{2}$, C. Tichit ${ }^{2}$, S. Nicklaus ${ }^{4}$, B. Geay ${ }^{5}$, P. Humeau ${ }^{2}$, X. Thierry ${ }^{3}$, M.-A. Charles ${ }^{1}$, S. Lioret ${ }^{1}$ and B. de Lauzon-Guillain ${ }^{1}$

${ }^{1}$ INSERM, CESP, U1018, Villejuif, France; ${ }^{2}$ INRA, UR1303-ALISS, Ivry-Sur-Seine, France; ${ }^{3}$ Institut National des Etudes Démographiques (INED), Paris, France; ${ }^{4} I N R A$, UMR1324-CSGA, Dijon, France; CNRS, UMR6265-CSGA, Dijon, France; Université de Bourgogne, UMR-CSGA, Dijon, France; ${ }^{5}$ Centre Universitaire de Recherche sur l'Action Publique et le Politique, UMR-CNRS 7319, Amiens, France

Email: sandra.wagner@inserm.fr

During the beginning of life, human milk is the most adequate feeding source for infants. The World Health Organisation recommends exclusive breastfeeding up to 6 months, with continued breastfeeding along with appropriate complementary foods up to 2 years. ${ }^{1}$ In France, rates of exclusive breastfeeding are very low according to international standards. The last national perinatal survey conducted in 2010 showed that $60 \%$ of the infants were exclusively breastfed at birth. ${ }^{2}$ This rate drops to $35 \%$ at 1-month post partum, as recently reported in the EPIFANE study. ${ }^{3}$ It was shown that demographic and sociocultural factors can affect breastfeeding initiation, such as social status, maternal age and region.,3 However, little is known about the factors influencing breastfeeding duration in France.

Our aim was to investigate the sociocultural factors associated with both the initiation and duration of breastfeeding in the Elfe (Etude Longitudinale Française depuis l'Enfance) study, the first large-scale French birth cohort. This follows up more than 18,000 babies born in a nationally representative sample of maternity patients recruited in 2011. Multivariate logistic and linear regression models were used to assess the associations between breastfeeding and sociocultural factors.

Our results showed that $72 \%$ of the infants were breastfed, exclusively or partially, at birth, and $24 \%$ at 6 months. The analyses indicated that paternal support during delivery and high parental socio-economic status were positively associated with both the initiation and the duration of breastfeeding, whereas maternal body mass index or maternal smoking during pregnancy were negatively associated with both factors. Parental country of birth was strongly related to breastfeeding initiation and duration, with the highest initiation prevalence 
and longest duration of breastfeeding in families where both parents were born abroad. These results will allow us to better target at-risk groups regarding breastfeeding practices.

Disclosure of Interest: None.

\section{References}

1. World Health Organisation. Feeding and Nutrition of Infants and Young Children. Guidelines for the WHO European Region, with Emphasis on the Former Soviet Countries, 2003. WHO: Geneva, pp. 1-288.

2. Bonet M, L'Helias LF, Blondel B. Allaitement maternel exclusif et allaitement partiel en maternité: la situation en France en 2003. Arch Pédiatr. 2008; 15, 1407-1415.

3. Salanave B, de Launay C, Guerrisi C, Castetbon K. Taux d'allaitement maternel à la maternité et au premier mois de l'enfant. Résultats de l'étude Epifane, France, Bulletin épidémiologique hebdomadaire de l'INVS, no. 34, 2012.

\section{MIN-14 - oral}

Maternal high-fat diet prevents the decrease in basilar spine density in the medial prefrontal cortex of pups exposed to chronic maternal separation

M. Rincel, A. Lépinay, L. Xia, A. Aubert, A. Sere, S. Layé and M. Darnaudéry

Lab NutriNeurO-UMR INRA 1286, University of Bordeaux, Bordeaux, France

Email: marion.rincel@etud.u-bordeaux.fr

Early-life adversity is a main risk factor for anxiety disorders and depression in adulthood. In rats, early-life stress (ELS) induced by chronic infant-mother separation during early postnatal life leads to cognitive and emotional alterations ${ }^{1,2}$ as well as increased endocrine responsiveness to subsequent stressors in adult offspring. ${ }^{3}$ ELS also produces altered dendritic morphology and spine density in the hippocampus and the medial prefrontal cortex (mPFC). ${ }^{4-6}$ It has been proposed that abnormal density and organization of the spines may contribute to the behavioral alterations caused by stress exposure. ${ }^{7}$ Recent findings in the laboratory suggest that the behavioral and endocrine effects of maternal separation in adult offspring could be reversed by maternal exposure to high-fat diet (HFD). In the present study, we investigated the effects of maternal HFD (45\% energy from fat) on the consequences of ELS on mPFC pyramidal neuron morphology and spine density during development. For this purpose, we used the Golgi-Cox staining method. Here we report that maternal HFD prevented the decrease in basilar spine density in the mPFC of stressed pups. The combination of maternal separation and maternal HFD, but not separation or maternal HFD alone, increased dendritic length at both apical and basilar levels. Interestingly, HFD was highly palatable and reduced maternal anxiety during separation sessions. Our results demonstrate that maternal HFD could attenuate some mPFC alterations associated with ELS during development. These results reinforce the crucial role of the environmental factors such as stress or nutrition during early life on brain maturation. Whether these effects could participate to amelioration of anxiety-like behavior and cognitive functions after maternal HFD in offspring exposed to ELS remains to be explored.

\section{Disclosure of Interest: None.}

\section{References}

1. Franklin TB, Saab BJ, Mansuy IM. Neural mechanisms of stress resilience and vulnerability. Neuron. 2012; 75, 747-761.

2. Uchida S, Hara K, Kobayashi A, et al. Early life stress enhances behavioral vulnerability to stress through the activation of REST4-mediated gene transcription in the medial prefrontal cortex of rodents. J Neurosci. 2010; 30, 15007-15018.

3. Ladd CO, Huot RL, Thrivikraman KV, Nemeroff CB, Plotsky PM. Long-term adaptations in glucocorticoid receptor and mineralocorticoid receptor mRNA and negative feedback on the hypothalamo-pituitary-adrenal axis following neonatal maternal separation. Biol Psychiatry. 2004; 55, 367-375. 4. Monroy E, Hernández-Torres E, Flores G. Maternal separation disrupts dendritic morphology of neurons in prefrontal cortex, hippocampus, and nucleus accumbens in male rat offspring. J Chem Neuroanat. 2010; 40, 93-101.

5. Leslie AT, Akers KG, Krakowski AD, et al. Impact of early adverse experience on complexity of adult-generated neurons. Transl Psychiatry. 2011; 1, e35.

6. Chocyk A, Bobula B, Dudys D, et al. Early-life stress affects the structural and functional plasticity of the medial prefrontal cortex in adolescent rats. Eur J Neurosci. 2013; 38, 2089-2107.

7. Licznerski P, Duman RS. Remodeling of axo-spinous synapses in the pathophysiology and treatment of depression. Neuroscience. 2013; 251, 33-50.

\section{MIN-15}

Impact of chronic maternal separation on emotion and motivation for food reward in $\mathrm{C} 57 \mathrm{BL} 6 / \mathrm{J}$ and $\mathrm{C} 3 \mathrm{H} / \mathrm{Hen}$ mice

L. Xia, A. Mathou, A. Mini, C. Marion, S. Layé and

M. Darnaudéry

UMR INRA 1286, Laboratoire NutrINeurO-Nutrition et Neurobiologie Intégrée, UFR Pharmacie, Université Bordeaux Segalen, Bordeaux, France

Email: lin.xia@bordeaux.inra.fr

Early-life stress has been implicated in psychiatric diseases in particular mood disorders and addiction. ${ }^{1}$ Maternal separation (MS) in rodents is a well-studied model of early-life stress. In rats, several studies demonstrate that chronic MS leads to an 
exaggerated hypothalamic-pituitary-adrenal axis response to stress and alterations of emotional behavior in adult offspring. ${ }^{2-4}$ In contrast, in mice, inconsistent results have been reported after MS. ${ }^{5}$ The aim of the present study was to explore in two mouse strains $(\mathrm{C} 57 \mathrm{BL} / 6 \mathrm{~J}$ and $\mathrm{C} 3 \mathrm{H} / \mathrm{HeN})$ differing by their initial maternal behavior, ${ }^{6}$ the impact of MS on anxiety-like behavior (elevated plus maze), depressive-like behavior (tail suspension task, TST) and on food motivation (operant conditioning task) in male and female adult offspring. We hypothesized that $\mathrm{C} 3 \mathrm{H}$, a strain with higher maternal behavior, will be more vulnerable to the effects of MS. MS lasted $3 \mathrm{~h} /$ day from postnatal day 2 (PND2) to PND14, and during MS dams were submitted to chronic unpredictable stress. ${ }^{7}$ We found that MS impaired body weight growth in $\mathrm{C} 3 \mathrm{H}$ pups but had no effect in $\mathrm{C} 57$. This effect persisted into adulthood in male $\mathrm{C} 3 \mathrm{H}$ but not in female. MS showed a tendency to increase the immobility time in the TST in female mice $(P=0.07)$, but had no significant effect in anxiety-like behavior. In social preference test, MS had opposite effects on $\mathrm{C} 3 \mathrm{H}$ and $\mathrm{C} 57$ male mice. Indeed, MS increased social preference in $\mathrm{C} 3 \mathrm{H}$ mice but decreased it in C57 $(P=0.003)$. MS induced a marked increase of the motivation for palatable food in male and female $\mathrm{C} 3 \mathrm{H}$ mice. In conclusion, our results demonstrate that MS combined with an unpredictable stress has long-lasting impact on offspring behavior. However, the effects of early-life stress depend both on sex and mouse strain.

Disclosure of Interest: None.

\section{References}

1. Kendler KS, Sheth K, Gardner CO, Prescott CA. Childhood parental loss and risk for first-onset of major depression and alcohol dependence: the time-decay of risk and sex differences. Psychol Med. 2002; 32, 1187-1194.

2. Lee JH, Kim HJ, Kim JG, et al. Depressive behaviors and decreased expression of serotonine reuptake transporter in rats that experienced neonatal maternal seperation. Neurosci Res. 2007; 58, 32-39.

3. Marais L, Van Rensburg SJ, Van Zyl JM, Stein DJ, Daniels WM. Maternal separation of rat pups increases the risk of developing depressive-like behavior after subsequent chronic stress by altering corticosterone and neurotrophin levels in the hippocampus. Neurosci Res. 2008; 61, 106-112.

4. De Kloet ER, Sibug RM, Helmerhorst FM, Schmidt M. Stress, genes and the mechanism of programming the brain for later life. Neurosci Biobehav Rev. 2005; 29, 271-281.

5. Millstein RA, Holmes A. Effects of repeated maternal separation on anxiety- and depression-related phenotypes in different mouse strains. Neurosci Biobehav Rev 2007; 31, 3-17. 6. Shoji H, Kato K. Maternal behavior of primiparous females in inbred strains of mice: a detailed descriptive analysis. Physiol Behav. 2006; 89, 320-328.

7. Franklin TB, Russig H, Weiss IC, et al. Epigenetic transmission of the impact of early stress across generations. Biol Psychiatry. 2010; 68, 408-415.

\section{MIN-16}

Comparison between exogenous and endogenous miRNAs as standards for appropriate normalization of microRNAs quantitative PCR analysis in breast milk to assess their potential role in nutritional programming

I. Floris, H. Billard, C.-Y. Boquien, E. Gauvard, J.-C. Rozé, F. Bolaños-Jiménez and B. Kaeffer

INRA-Nantes University, UMR1280 PhAN, Nantes, France; Hospital of Mother and Child, Nantes, France

Email: Ilaria.floris@univ-nantes.fr

MicroRNAs (miRNAs) are short non-coding RNAs that regulate gene expression by inducing mRNA degradation or inhibiting mRNA translation. ${ }^{1}$ MiRNAs are contained in many biological fluids ${ }^{2}$ including human breast milk $^{2-4}$ and might be involved in nutritional programming because they can survive the stomach acidity, allowing their intestinal absorption by the baby and the exchange of genetic information between the mother and her infant. ${ }^{3}$ Accurate quantification of milk miRNAs is challenging because an invariant reference gene to correct for sample-to-sample variations in miRNAs extraction and qRT-PCR efficiency is lacking. Though synthetic non-human miRNAs have been used to normalize miRNAs levels in human body fluids, these standards normalize for technical but not for biological variability and cannot improve assay precision. ${ }^{5}$ Here we compared the use of a synthetic miRNA from Caenorhabditis elegans (spike-in) with several endogenous miRNAs as suitable reference genes for miRNAs qRT-PCR analysis in milk.

C. elegans miRNA was added to whole human milk or to its cream and whey fractions before RNA extraction and its expression, as well as that of several candidate endogenous controls (miR-16, let-7a, and let-7g), was determined by qRTPCR. The expression of miR-146b, a milk miRNA linked to metabolism ${ }^{6}$ and immune function, ${ }^{3}$ was also determined. Variance and stability were determined using RefFinder, a web tool integrating geNorm, Normfinder, BestKeeper and the comparative $\Delta C_{t}$ method. $^{7-9}$

Important intra-assay variability in spike-in expression was found between whole milk and cream. RefFinder analysis established let- $7 \mathrm{a}$ as the best control for normalization in cream, whey and whole milk. MiR-146b expression was reduced in milk of overweight mothers compared with normal weight mother's milk $(P<0.05, n=6)$, when let-7a, but not spike-in, was used for normalization.

The endogenous miRNA let-7a is a suitable reference for the accurate quantification of miRNAs in human milk.

Disclosure of Interest: None.

\section{References}

1. Bartel DP. MicroRNAs: genomics, biogenesis, mechanism, and function. Cell. 2004; 116, 281-297. 
2. Weber JA, Baxter DH, Zhang S, et al. The microRNA spectrum in 12 body fluids. Clin Chem. 2010; 56: 1733-1741. 3. Kosaka N, Izumi H, Sekine K, Ochiya T. microRNA as a new immune-regulatory agent in breast milk. Silence. 2010; 1, 1-7. 4. Munch EM, Harris RA, Mohammad M, et al. Transcriptome profiling of microRNA by next-gen deep sequencing reveals known and novel miRNA species in the lipid fraction of human breast milk. PLoS One. 2013; 2, e50564.

5. McDonald JS, Milosevic D, Reddi HV, Grebe SK, Algeciras-Schimnich A. Analysis of circulating microRNA: preanalytical and analytical challenges. Clin Chem. 2011; 6, 833-840.

6. Ahn J, Lee H, Jung CH, Jeon TI, Ha TY. MicroRNA-146b promotes adipogenesis by suppressing the SIRT1-FOXO1 cascade. EMBO Mol Med. 2013; 10, 1602-1612.

7. Pfaffl MW, Tichopad A, Prgomet C, Neuvians TP. Determination of stable housekeeping genes, differentially regulated target genes and sample integrity: BestKeeper-Excelbased tool using pair-wise correlations. Biotechnol Lett. 2004; 26, 509-515.

8. Andersen CL, Jensen JL, Orntoft TF. Normalization of real-time quantitative reverse transcription-PCR data: a modelbased variance estimation approach to identify genes suited for normalization, applied to bladder and colon cancer data sets. Cancer Res. 2004; 64, 5245-5250.

9. Silver N, Best S, Jiang J, Thein SL. Selection of housekeeping genes for gene expression studies in human reticulocytes using real-time PCR. BMC Mol Biol. 2006; 7, 33.

\section{MIN-17}

\section{Cytotoxic effect of low doses of a maternal food contaminants mixture on pancreatic cells}

G. Fabricio Sergio ${ }^{1}$, S. Firmin ${ }^{1}$, N. Bahi-Jaber ${ }^{1}$, G. Elmhiri ${ }^{1}$, P. Mathias ${ }^{2}$ and L. Abdennebi-Najar ${ }^{1}$

${ }^{1}$ UP 2012.10.101, EGEAL, Institut Polytechnique LaSalle Beauvais, Beauvais, France; ${ }^{2}$ Laboratorio de Biologia Cellular da Secreçao, Universidade Estadual de Maringá, Maringá, Brazil

\section{Email: Gabriel.Sergio@ext.lasalle-beauvais.fr}

Fetus/infants are exposed to many chemical food contaminants that are suspected to be involved in the epidemic of metabolic disorders such as diabetes. These chemicals are of major concern because they can transfer from mother to the offspring through the placenta during pregnancy and through breastfeeding after birth. ${ }^{1,2}$ Evaluating the effects of food contaminants at doses commonly found in maternal food (as an unique compound or a mixture of different contaminants) on $\beta$-cell viability and functionality is needed to better determine their implication in the programming of diabetes. In this study, the cytotoxicity of a chemical mixture commonly present in maternal food against endocrine pancreas was assessed using insulin-secreting Min 6 cell line. Cells were co-exposed for 24, 48 and $72 \mathrm{~h}$ to increasing concentrations $(0.001 \mu \mathrm{M}-1 \mu \mathrm{M})$ of bisphenol $\mathrm{A}$, diethylhexylphthalate, cadmium, deoxynivalenol, 2,3,7,8-tétrachlorodibenzop-dioxin, aroclor 1254, malathion and malaoxon. Cytotoxic effect of the mixture was monitored using mitochondrial dehydrogenase activity (MDH), as an indicator of the cellular stress response, to the chemical mixture. ${ }^{3}$ A reduced $\mathrm{MDH}$ activity of $20 \%$ was shown in the pancreatic clonal cells exposed to $0.8 \mu \mathrm{M}$ for $24 \mathrm{~h}$ in comparison with the untreated cells. The cytotoxic effect was time dependent and observed at concentrations higher than $0.01 \mu \mathrm{M}$ after 48-h exposure. These preliminary results suggest that this chemical mixture may promote a pancreatic cell death and install a $\beta$-cell mass dysfunction in the offspring. Analysis of oxidative stress parameters and insulin secretory capacity of the pancreatic cells are under investigation to determine the mechanisms involved in the programming of diabetes by food contaminants. In addition, this evaluation will help us to address whether current multi-contamination of maternal food represents a real risk for the development of adult metabolic diseases.

\section{Disclosure of Interest: None.}

\section{References}

1. Heindel JJ, vom Saal FS. Role of nutrition and environmental endocrine disrupting chemicals during the perinatal period on the aetiology of obesity. Mol Cell Endocrinol. 2009; 304, 90-96.

2. Stefanidou M, Maravelias C, Spiliopoulou C. Human exposure to endocrine disruptors and breast milk. Endocr Metab Immune Disord Drug Targets. 2009; 9, 269-276.

3. Cachon BF, Firmin S, Verdin A, et al. Proinflammatory effects and oxidative stress within human bronchial epithelial cells exposed to atmospheric particulate matter $(\operatorname{PM}(2.5)$ and PM(>2.5)) collected from Cotonou, Benin. Environ Pollut. 2014; 185, 340-351.

\section{MIN-18}

Plasma apelin variations during pregnancy in obese mice: role of the placenta

A. Marx-Deseure ${ }^{1,2}$, S. Hanssens ${ }^{1,2}$, L. Butruille ${ }^{2}$, C. Besengez ${ }^{2}$, J. Lesage ${ }^{3}$, L. Storme ${ }^{2,4}$ and Philippe Deruelle ${ }^{1,2}$

${ }^{1}$ CHRU of Lille, Jeanne de Flandre Hospital, GynecologyObstetrics, Lille, France; ${ }^{2}$ University Lille 2, EA 4489, Lille, France; ${ }^{3}$ University Lille 1, EA 4489, Villeneuve d'Ascq, France; ${ }^{4}$ CHRU of Lille, Jeanne de Flandre Hospital, Neonatal Reanimation, Lille, France

Email: marxaurore@gmail.com

Apelin is an adipokine, which plays a role in the regulation of glucose homeostasis and may contribute to obesity-related metabolic disease. ${ }^{1,2}$ Although apelin and its receptor APJ are expressed in fetal tissues, ${ }^{3,4}$ their function and regulation during the pregnancy, especially in pathological situation such as obesity, remain largely unknown. The aim of this study was to examine whether apelin levels are altered in pregnant obese mice. 
A total of 66 female $\mathrm{C} 57 \mathrm{bl} / 6 \mathrm{~J}$ mice were fed a high-fat (HF, $35 \%$ carbohydrate, $45 \%$ fat) or standard-chow (C) diet 10 weeks before conception and through pregnancy. Animals were killed at E6.5, E12.5 and E18.5. Maternal plasma apelin and insulin levels were measured at each point and fetal apelin levels at E18.5. We collected the maternal organs for immunochemistry and placenta to analyze in vitro apelin secretion.

During pregnancy, maternal plasma apelin concentrations rose at E12.5 and dropped at late gestation $(P<0.05)$. In obese and insulin-resistant HF pregnant mice, plasma apelin and insulin concentrations were higher in comparison with the $\mathrm{C}$ group $(P<0.05$ at E6.5, E12.5 and E18.5). At E18.5, fetal plasma apelin levels were six times higher than the maternal levels (C: $5.0 \pm 0.70$ v. 29.2 \pm 6.9 , $P<0.00001$; HF: $8.3 \pm 1.9$ v. $34.3 \pm 7.6, P<0.01)$, but were similar between the two groups $(P>0.05)$. In vitro, placental apelin secretion was severely altered in the HF group (2h: $171.5 \pm 13.8 v$. $40.8 \pm 19.9, \quad P<0.0001 ; \quad 6$ h: $220.5 \pm 13.1 \quad v . \quad 75.4 \pm 13.3$, $P<0.0001 ; 24$ h: $237.4 \pm 23 v$. 136.6 $\pm 17.0, P<0.001)$.

We found that apelin secretion is increased during gestation in obese mice. We hypothesized that these changes might be related to the pregnancy-related insulin resistance. Placental apelin secretion is altered in obese mice, suggesting a link with the placental abnormalities induced by obesity. Further studies in human are needed to confirm these results.

\section{Disclosure of Interest: None.}

\section{References}

1. Dray C, Knauf C, Daviaud D, et al. Apelin stimulates glucose utilization in normal and obese insulin-resistant mice. Cell Metab. 2008; 8, 437-445.

2. Boucher J, Masri B, Daviaud D, et al. Apelin, a newly identified adipokine up-regulated by insulin and obesity. Endocrinology. 2005; 146, 1764-1771.

3. Van Mieghem T, van Bree R, Van Herck E, Pijnenborg R, Deprest J, Verhaeghe J. Maternal apelin physiology during rat pregnancy: the role of the placenta. Placenta. 2010; 31, 725-730. 4. Ivars J, Butruille L, Knauf C, et al. Maternal hypertension induces tissue-specific modulations of the apelinergic system in the fetoplacental unit in rat. Peptides. 2012; 35, 136-138.

MIN-19 - oral

Dietary scFOS supplementation during prenatal and early postnatal life influences metabolic and immunologic responses in adults fed a high-fat diet

C. Le Bourgot ${ }^{1}$, S. Blat ${ }^{1}$, S. Ferret-Bernard ${ }^{1}$, L. Le Normand ${ }^{1}$, A. Cahu ${ }^{1}$, G. Panaget ${ }^{1}$, E. Apper-Bossard ${ }^{2}$, F. Respondek ${ }^{2}$ and I. Le Huërou-Luron ${ }^{1}$

${ }^{1} A D N C$ Food and Digestive, Central and Behavioral Adaptation, INRA, Saint-Gilles, France; ${ }^{2}$ TEREOS-SYRAL, Marckolsheim, France

Email: cindy.lebourgot@rennes.inra.fr
Perinatal nutrition is a very important environmental factor that programmes microbiological, metabolic and immunologic development, which in turn may influence long-term health and disease susceptibility. Dietary supplementation with shortchain fructooligosaccharides (scFOS), soluble fibres defined as prebiotics, modulates intestinal microbiota and influences homeostatic systems (glucose metabolism, immunity). ${ }^{1,2}$ Prebiotics have also been shown to reduce development of high-fat (HF) diet-related disorders. ${ }^{3-5}$

Our study aimed at evaluating effects of early scFOS consumption on later adult metabolic and immunologic status in the context of an adverse nutritional environment.

Sows received a standard diet supplemented with scFOS (Profeed $^{\circledR}$, FOS) or not (CTRL) for the last 4 weeks of gestation and the lactation. At postnatal day (PND) 28, 10 piglets were weaned on a CTRL or an FOS diet until PND77. They were then fed a standard diet until PND180 and a HF diet until PND270. Glucose tolerance was assessed in vivo at PND264 (IVGTT), whereas the other metabolic parameters were measured on tissues and plasma sampled at killing (PND270). Ileal immune responses were analysed in vitro using explants with or without the Peyer's patch (PP) cultured with ConA or lipopolysaccharide (LPS) stimuli.

Growth, food intake and adiposity were not different between groups during HF diet. Insulin response to a glucose challenge was slightly higher in the FOS group, but no other metabolic parameters (basal glycaemia and insulinaemia, pancreatic insulin content, gut and plasma GLP-1) were modified. Reduced proinflammatory IFN $\gamma$ and TNF $\alpha$ secretion by ConA-stimulated explants of ileal PP, and increased IL-10 secretion by LPSstimulated ileal explants in FOS group revealed an effect of early scFOS supplementation on local immunity orientation.

Such results underline the key role of the perinatal nutrition on adult metabolic and intestinal immunity responses to an adverse nutritional challenge. This could involve modulation of gut colonization by prebiotics.

\section{Disclosure of Interest: None.}

\section{References}

1. Roberfroid M, Gibson GR, Hoyles L, et al. Prebiotic effects: metabolic and health benefits. Br J Nutr. 2010; 104 (Suppl. 2), S1-S63.

2. Le Bourgot C, Ferret-Bernard S, Le Normand L, et al. Maternal short-chain fructooligosaccharide supplementation influences intestinal immune system maturation in piglets, 2014; 9, e107508.

3. Respondek F, Myers K, Smith TL, Wagner A, Geor RJ. Dietary supplementation with short-chain fructo-oligosaccharides improves insulin sensitivity in obese horses. J Anim Sci. 2011; 89, 77-83.

4. Neyrinck AM, Van Hée VF, Piront N, et al. Wheatderived arabinoxylan oligosaccharides with prebiotic effect increase satietogenic gut peptides and reduce metabolic endotoxemia in diet-induced obese mice. Nutrition \& Diabetes, 2012; 2, e28. 
5. Jakobsdottir G, Xu J, Molin G, Ahrne S, Nyman M. Highfat diet reduces the formation of butyrate, but increases succinate, inflammation, liver fat and cholesterol in rats, while dietary fibre counteracts these effects. PloS One 2013; 8, e80476.

\section{MIN-20 \\ High-protein diet exposure during gestation but not during lactation modifies female rat pups response to dietary challenge in adulthood}

C. D. de Maredsous ${ }^{1,3}$, C. Delteil ${ }^{1}$, F. Blachier ${ }^{1}$, P. Barbillon ${ }^{2}$, T. Mary-Huard ${ }^{2}$, D. Tomé ${ }^{1}$, R. Oozeer ${ }^{3}$ and A.-M. Davila ${ }^{1}$

${ }^{1}$ UMR 914, Paris, France; ${ }^{2}$ UMR 518, AgroParisTech/INRA, Paris, France; ${ }^{3}$ Nutricia Danone Research, Utrecht, The Netherlands

Email: caroline.descleedemaredsous@agroparistech.fr

Nutrient exposure during early life, starting from gestation, impacts metabolic programming and future health. ${ }^{1}$ Increased dietary protein intake during lactation is believed to enhance obesity risks at adulthood. ${ }^{2}$ This study aims to characterize on a rat model the influence of maternal high-protein (HP) diet during gestation or lactation on female pups' response to dietary challenge. Three groups of Wistar rat dams were fed either a control diet (C, 20\% energy protein; Cgest-Clact) or an HP diet (55\% energy protein) during gestation (HPgest-Clact) or during lactation (CgestHPlact). From weaning to 10 -week-old female pups received a C, $\mathrm{HP}$ or western (W) diet. Data were analyzed using the MIXED procedure in SAS and a Tukey correction for multiple testing. Birth weight was not significantly affected by gestation diet. In this rat model, Cgest-HPlact pups were not different from Cgest-Clact pups; with no difference in the response to $\mathrm{W}$ dietary challenge and a lower body weight $(P<0.0001)$, food intake $(P=0.001)$, adiposity $(P=0.0002)$ and adipocytes size $(P<0.0001)$ in response to HP dietary challenge, compared with $\mathrm{C}$ diet after weaning, respectively. In contrast, HP exposure during gestation predisposes pups to the sensitivity to dietary challenges: (i) feeding HPgest-Clact pups with W diet after weaning induced higher weight gain (gestation diet $\times$ pups diet $\times$ time effect: $P<0.0001$ ), higher energy intake (gestation diet $\times$ pups diet effect: $P=0.02$ ), more visceral adipose tissue (gestation diet $\times$ pups diet effect: $P=0.002$ ); (ii) feeding HPgest-Clact pups with HP diet after weaning induced the same lower body weight $(P=0.0003)$, food intake $(P=0.03)$, adiposity $(P=0.003)$, but a higher plasma glucose basal level and peak after glucose oral challenge $(P<0.0001)$ compared with $\mathrm{C}$ diet; (iii) HPgest-Clact pups had smaller adipocytes size $(P=0.014)$ at 10 weeks. These results strongly suggest that there is a specific metabolic programming effect on female rat pups by maternal HP diet during gestation.

Disclosure of Interest: C.D.M. and R.O. are employed by Danone Nutricia Research.

\section{References}

1. Gluckman PD, Hanson MA, Cooper C, Thornburg KL. Effect of in utero and early-life conditions on adult health and disease. $N$ Engl J Med. 2008; 359, 61-73

2. Weber M, et al. Lower protein content in infant formula reduces BMI and obesity risk at school age: follow-up of a randomized trial. Am J Clin Nutr. 2014; 99, 1041-1051.

\section{PROGRAMMING OF COGNITIVE IMPAIREMENT}

PCI-1 - oral

Is perinatal butyrate intake, through maternal supplementation, able to prevent cognitive impairment due to intrauterine growth restriction in a rat model?

V. Paillé, H. Boudin, I. Grit, C. Bonnet, P. de Coppet, J.-P. Segain and P. Parnet

UMR 1280, INRA-Université de Nantes, IMAD, CHU Hotel Dieu, Nantes, France

Email: patricia.parnet@univ-nantes;fr

Intrauterine growth restriction (IUGR) increases the risk of developing neurodevelopmental, learning and memory alterations. ${ }^{1,2}$ In animals, IUGR is associated with impaired hippocampic neurodevelopment, a reduced number of neurons and dendrites, and altered synapse formation. ${ }^{3,4}$ Molecular mechanisms could involve epigenetic regulation of genes involved in neurogenesis and synaptic plasticity in the hippocampus. ${ }^{5}$ Particularly, memory formation and consolidation involve regulation of histone acetylation, ${ }^{6-8}$ inhibition of histone deacetylase (HDAC), resulting in improved synaptic plasticity. Butyrate, a short-chain fatty acid produced by the bacterial fermentation of non-digestible carbohydrate, is a wellknown inhibitor of HDAC, and thus might be beneficial on hippocampal neurogenesis and synaptic plasticity.

We therefore hypothesize that increasing butyrate availability during perinatal period may enhance neurodevelopment and improve the cognitive functions of the offspring by promoting synaptic plasticity.

Four groups of male rats were obtained after feeding dams either a control diet or a $50 \%$ protein-reduced diet combined or not, with a supplementation of butyrate in drinking water. In vitro, neuronal developmental studies were conducted on the hippocampus cell cultures from 19-day-old embryos. Golgi staining of the hippocampus from 35-postnatal day rats was performed for neuroanatomical studies. Behavioral tests allow the assessment of anxiety (open field), spatial memory (Y maze) and memory consolidation (novel object recognition). Epigenetic modifications of histones (i.e. methylation and acetylation patterns) were investigated on the hippocampus by immunohistochemistry and western blot techniques.

IUGR induces a decrease of the axonal length and the number of dendrites as observed on a 4 days neuronalculture and 
butyrate-treated dams partially restores these alterations. Perinatal administration of butyrate to dams improves performance in the spatial memory test on young rats. The link with neuroanatomical parameters and epigenetic marks will be investigated.

Altogether these results suggest that maternal supplementation of butyrate or prebiotics could improve cognitive performance in IUGR-born infants.

\section{Disclosure of Interest: None.}

\section{References}

1. Fily A, Pierrat V, Delporte V, Breart G, Truffert P; EPIPAGE Nord-Pas-de-Calais Study Group. Factors associated with neurodevelopmental outcome at 2 years after very preterm birth: the population-based Nord-Pas-de-Calais EPIPAGE cohort. Pediatrics. 2006; 117, 357-366.

2. Walker D-M, Marlow N. Neurocognitive outcome following fetal growth restriction. Arch Dis Child Fetal Neonatal Ed. 2008; 93, F322-F325.

3. Mallard C, Loeliger M, Copolov D, Rees S. Reduced number of neurons in the hippocampus and the cerebellum in the postnatal guinea-pig following intrauterine growthrestriction. Neuroscience. 2000; 100, 327-333.

4. Dieni S, Rees S. Dendritic morphology is altered in hippocampal neurons following prenatal compromise. J Neurobiol. 2003; 55, 41-52.

5. Ke X, Lei Q, James SJ, et al. Uteroplacental insufficiency affects epigenetic determinants of chromatin structure in brains of neonatal and juvenile IUGR rats. Physiol Genomics. 2006; $25,16-28$.

6. Levenson JM, O'Riordan KJ, Brown KD, Trinh MA, Molfese DL, Sweatt JD. Regulation of histone acetylation during memory formation in the hippocampus. J Biol Chem. 2004; 279, 40545-40559.

7. Guan J-S, et al. HDAC2 negatively regulates memory formation and synaptic plasticity. Nature. 2009; 459, 55-60.

8. Stefanko DP, Barrett RM, Ly AR, Reolon GK, Wood MA. Modulation of long-term memory for object recognition via HDAC inhibition. Proc Natl Acad Sci USA. 2009; 106, 9447-9452.

\section{PCI-2}

High-fat high-sugar maternal diet has consequences on milk composition and offspring's microbiota activity, metabolism and behavioural responses in Yucatan pigs

M. Besson ${ }^{1}$, S. Blat ${ }^{1}$, S. Guérin ${ }^{1}$, G. Randuineau ${ }^{1}$, I. Nogret ${ }^{1}$, H. Quesnel ${ }^{2}$, N. Bonhomme ${ }^{2}$, M. Génissel ${ }^{2}$, J. Georges ${ }^{1}$, R. Janvier ${ }^{1}$, I. Le Huërou-Luron ${ }^{1}$, D. Val-Laillet ${ }^{1}$

${ }^{1}$ INRA, UR1341 ADNC, St-Gilles, France; ${ }^{2}$ INRA, UMR1345 PEGASE, St-Gilles, France

\section{Email: david.val-laillet@rennes.inra.fr}

Deleterious early nutritional environment can increase not only susceptibility to diseases ${ }^{1}$ but also neurocognitive and eating disorders. ${ }^{2-4}$ The aim of this study was to investigate in a minipig model the impact of maternal diet (standard, SD $v$. western diet, WD) during gestation and lactation on milk composition, sows $(n=18)$ and piglets' metabolism and microbiota activity, as well as on food preferences and cognition in the progeny. Colostrum and milk's dry matter and total lipids content (TFE2000, LECO), as well as microbiota activity via volatile fatty-acid profiles in faeces (GC) were assessed. Plasma glucose, insulin, lipid profiles and haptoglobin were assessed in sows and piglets. Weaned piglets $(n=51$, all fed a SD from weaning) were subjected to food preference tests (SD $v$. WD) and to a cognitive test (holeboard) ${ }^{5,6}$ reinforced with chocolate candies. Dry matter and lipids content were higher in milk of WD $v$. SD sows (at Day 1, Day 14 and Day 28, from $P<0.10$ to $P=0.016$ ). Plasma total cholesterol and free fatty-acid concentrations were higher in $\mathrm{WD} v$. SD sows during gestation and lactation. Microbiota activity was decreased in WD $v$. SD sows at farrowing $(P=0.06)$, and in WD $v$. SD piglets at Day 42 post-weaning $(P=0.046)$. WD piglets displayed dyslipidaemia and increased haptoglobin concentration at weaning compared with SD piglets, with no consequences on glucose homeostasis. Piglets from both groups showed a preference for the known SD $(P<0.0001)$, but WD neophobia was lower in WD piglets that also had higher cognitive abilities (working memory: $P=0.015$; reference memory: $P<0.001)$, probably related to a higher motivation for the rewards. Maternal WD exposed the piglets to a disrupted nutritional environment during gestation and lactation with consequences on piglets' metabolism, microbiota, eating behaviour and cognition. An ongoing study will explore the long-term consequences at the adult age, in terms of glucose homeostasis, behaviour and brain correlates.

\section{Disclosure of Interest: None.}

\section{References}

1. Williams L, Seki Y, Vuguin PM, Charron MJ. Animal models of in utero exposure to a high fat diet: a review. Biochim Biophys Acta. 2014; 1842, 507-519.

2. Bilbo SD, Tsang V. Enduring consequences of maternal obesity for brain inflammation and behavior of offspring. FASEB J. 2010; 24, 2104-2115.

3. Naef L, Moquin L, Dal Bo G, Giros B, Gratton A, Walker CD. Maternal high-fat intake alters presynaptic regulation of dopamine in the nucleus accumbens and increases motivation for fat rewards in the offspring. Neuroscience. 2011; 176, 225-236.

4. Teegarden SL, Scott AN, Bale TL. Early life exposure to a high fat diet promotes long-term changes in dietary preferences and central reward signaling. Neuroscience. 2009; 162, 924-932. 5. Gieling E, Wehkamp W, Willigenburg R, Nordquist RE, Ganderup NC, van der Staay FJ. Performance of conventional pigs and Gottingen miniature pigs in a spatial holeboard task: effects of the putative muscarinic cognition impairer Biperiden. Behav Brain Funct. 2013; 9, 4.

6. Haagensen AM, Klein AB, Ettrup A, Matthews LR, Sorensen DB. Cognitive performance of Gottingen minipigs is affected by diet in a spatial hole-board discrimination test. PLoS One. 2013; 8, e79429. 


\section{EARLY EXPOSURE TO POLLUTANTS AND HEALTH}

EP-1

Effects of in utero exposure to pesticides on foetal development in the Picardie region of France: use of meconium in the MecoExpo cohort

F. Mayhoub ${ }^{1}$, F. Lestremau ${ }^{2}$, K. Tack ${ }^{2}$, A. Léké ${ }^{1}$, T. Berton ${ }^{1}$, P. Tourneux ${ }^{1}$, J. Caudeville ${ }^{2}$, E. Haraux ${ }^{1}$, V. Bach ${ }^{1}$ and K. Chardon ${ }^{1}$

${ }^{1}$ PériTox - UMR-I O1 UPJV INERIS UFR Médecine, Amiens, France; ${ }^{2}$ INERIS, Verneuil-en-Halatte, France

Email: karen.chardon@u-picardie.fr

The objective of the present study was to assess the putative relationships between chronic in utero exposure to pesticides and the clinical parameters of foetal development. Information on various sources of maternal exposure to pesticides was collected with a questionnaire, and foetal exposure to pesticides was measured by assaying the meconium (the newborn's first stools). ${ }^{1}$ Clinical information on the state of foetal development at birth (term, weight, size and head circumference) was also recorded.

The MecoExpo cohort included 993 mother-newborn pairs. Our data revealed an association between the mother's stated occupational exposure to pesticides during pregnancy and the risk of restricted foetal growth for birth weight $(P=0.01)$. An association between the father's stated occupational exposure to pesticides and a greater risk of prematurity was also observed $(P=0.02)$. A total of 21 compounds (nine pesticides and 12 pesticide metabolites) were screened for simultaneously in 462 meconium samples. ${ }^{2}$ Of these 21 compounds, 17 were detected at various prevalences and concentrations; $85 \%$ of the samples contained at least one of the analytes. The highest prevalence of detection (65.5\%) was observed for organophosphorus compounds, followed by carbamate metabolites $(27.3 \%)$. The risk of microcephaly was greater in newborns with ethylene thiourea in the meconium $(P=0.01)$. The presence of the pyrethroiddeltamethrin in the meconium was associated with a lower gestational age ( 2.3 weeks less than for infants without deltamethrin; $P=0.002$ ).

The MecoExpo study is the first in France to use meconium as a marker of chronic foetal exposure to pesticides. We simultaneously quantified 21 compounds from different families of pesticide and observed associations (i) between parental occupational pesticide exposure and foetal development and (ii) between the presence of certain pesticides and the child's clinical characteristics at birth.

\section{Disclosure of Interest: None.}

\section{References}

1. Mayhoub F, Berton T, Bach V, et al. Self-reported parental exposure to pesticide during pregnancy and birth outcomes: the MecoExpo cohort study. PLoS One. 2014; 9, e99090.
2. Berton T, Mayhoub F, Chardon K, et al. Development of an analytical strategy based on LC-MS/MS for the measurement of different classes of pesticides and theirs metabolites in meconium: application and characterisation of foetal exposure in France. Environ Res. 2014; 132, 311-320.

\section{EP-2}

Predictive factors for hypospadias in the Picardie region of France: a preliminary study

E. Haraux ${ }^{1,2}$, K. Braun ${ }^{1}$, E. Stephan Blanchard ${ }^{2}$, P. Tourneux ${ }^{1,2}$, B. Boudailliez ${ }^{1}$, V. Bach ${ }^{2}$ and K. Chardon ${ }^{2}$

${ }^{1}$ CHU Amiens, Amiens, France; ${ }^{2}$ PériTox (EA4285 UMI 01 UPJV INERIS), UFR Médecine, Amiens, France

Email: karen.chardon@u-picardie.fr

The prevalence of hypospadias has risen strongly over the last 20 years. ${ }^{1}$ Hereditary and environmental factors may be involved. The primary objective of this prospective, multicentre, controlled study was to determine environmental factors associated with the risk of hypospadias in male infants born to a cohort of pregnant women in the Picardie region of France. We had clinical information on the parents, plus data on pesticide levels in the meconium (the newborn's first stools) as a proxy for exposure in utero. At present, only the clinical information has been analysed.

The study was conducted between March 2011 and December 2013 in nine maternity clinics in the Picardie region. The data were collected through an interview and a clinical examination of the newborn. A total of 57 cases of hypospadias (48 distal, six middle and three proximal) were compared with 163 controls. Of the infants with hypospadias, $10 \%$ also had undescended testicles.

The hypospadias and control groups had similar mean terms $(39.1 \pm 1.9$ and $39.2 \pm 1.6$ weeks of amenorrhoea, respectively) but did not differ significantly in terms of the parent's age, the duration of pregnancy, weight gain and maternal tobacco consumption during pregnancy, the proportion of pregnancies in women on contraception, the mother's endocrine profile and previous miscarriage.

Relative to the control group, infants with hypospadias were significantly lighter and smaller at birth (3297 421 and $3094 \pm 586$ g, respectively, $P<0.05 ; 49.4 \pm 4.9$ and $48.3 \pm 2.8 \mathrm{~cm}$, respectively; $P<0.05$ ).

The risk of hypospadias was greater for first pregnancies [odds ratio $(\mathrm{OR})[95 \%$ confidence interval $(\mathrm{CI})]=2.1[1.1-4.4]$; $P<0.05]$ and was lower for mothers with a body mass index $>25(\mathrm{OR}[95 \% \mathrm{CI}]=0.47[0.22-0.99] ; P=0.05)$.

The association between low weight, primiparity and hypospadias suggests that placental dysfunction has a role in the occurrence of this malformation (perhaps by decreasing blood flow). The influence of the environment (pesticide exposure) is being investigated.

Disclosure of Interest: None. 


\section{Reference}

1. Nissen KB, Udesen A, Garne E. Hypospadias prevalence, birth weight and associated major congenital anomalies. Congenit Anom (Kyoto). 2015; 55, 37-41.

\section{EP-3}

\section{The determinants of child health in district of Constantine} (Algeria)

L. Rouabah, A. Sayed and A. Rouabah

Laboratory of Molecular and Cellular Biology, Faculty of Natural Sciences and Life, University 1 of Constantine, Constantine, Algeria

Email: leilarouabah27@yahoo.fr

This research aimed to analyze the determinants of child health in Constantine through the impact of household characteristics and background of the mother.

We tried to explain the health of a child by its own characteristics, of his family and the behavior of the mother during pregnancy to determine which of these three components most influence their health. The analysis focused only on women who gave birth to one child. A total of 500 children of 1 month to 12 years of age were recruited. Weight status is highly correlated with sex $(P<0.001)$ and age $(P<0.001)$. Of the women, $89 \%$ had increase in weight during pregnancy. Of the children in single-parent family (mother widowed or divorced), $10 \%$ are unhealthy $v$. $4 \%$ when surrounded by both parents; $90 \%$ of children with mothers who had no prenatal problems are healthy $v .60 \%$ with mothers having had prenatal diabetes and hypertension; $25.71 \%$ of mothers had macrosomic babies.

The household income also impacts child health: the higher the parents' income, the healthier the child. Only 5\% of the children whose parents have high income are in poor health $v$. $20 \%$ when parents' income is low. Children's health and cultural level of parents are not correlated $(r=-0.048$, $P=0.261$ ). The correlation between child health and parental jobs is very highly significant $(P<0.001)$. Children born with a lower weight than $2 \mathrm{~kg} 500 \mathrm{~g}$ are the sickest patients (28.5\%) $v$. $17 \%$ with a weight between 3.5 and $4 \mathrm{~kg} ; 20 \%$ of children having had a diversification of supply before 6 months are sick $v$. only $4 \%$ for those having had diversification after 6 months ( $13 \%$ for those with diversification before 4 months).

\section{Disclosure of Interest: None.}

\section{References}

1. Maera E. Why is health related to socioeconomic status? The case of pregnancy and low birth weight. National Bureau of Economic Research (NBER) JEL No. I1, 8231, 2001.

2. Smith JP. Healthy bodies and thick wallets: the dual relation between health and economic status. J Econ Perspect. $1999 ; 13,145-166$.
3. Smith JP, Kington R. Race, socioeconomic status and health in late life. In Racial and Ethnic Differencesin the Health of Older Americans (eds. Martin L, Soldo B), 1997; 106-162. National Academy Press: Washington, DC.

4. Wadsworth MEJ, Kuh DJL. Childhood influences on adult health: a review of recent work from the British 1946 National Birth Cohort Study, the MRC National Survey of Health and Development. Pediatr Perinat Epidemiol. 1997; 11, 2-20.

\section{EP-4 - oral \\ Consequences of perinatal exposure to a pesticide, alone or combined with a prebiotic: effects on energy metabolism and microbiota composition}

J. Reygner ${ }^{1,2}$, L. Lichtenberger ${ }^{1,3}$, S. Dou ${ }^{1}$, G. Elmhiri ${ }^{1}$, S. Delanaud ${ }^{1}$, J. Gay-Queheillard ${ }^{1}$, N. Bahi-Jaber ${ }^{2}$, F. Depeint ${ }^{2}$, V. Bach ${ }^{1}$, H. Khorsi-Cauet ${ }^{1}$ and L. Abdennebi-Najar ${ }^{2}$

${ }^{1}$ Laboratoire Périnatalité et Risques Toxiques (PERITOX), UMR-I01 INERIS, UFR de médecine UPJV, Amiens, France; ${ }^{2}$ Laboratoire Expression de gènes et régulation Epigénétique par l'Aliment UP 2012-10-101 Institut Polytechnique LaSalle Beauvais, Beauvais, France; ${ }^{3}$ CHU Amiens, Amiens, France

Email: julie.reygner@u-picardie.fr

Mothers and infants are daily exposed to a plethora of food contaminants, pesticides that are suspected to be involved in the increase of metabolic diseases are one among them. We have previously shown in an in vitro model of artificial intestine $\left(\mathrm{SHIME}^{\circledR}\right)^{1}$ that chronic exposure to low-dose Chlorpyrifos (CPF) causes intestinal dysbiosis with an increase in Enterococci and Bacteroides populations in detriment of Lactobacilli and Bifidobacteria. ${ }^{2}$ More recently, we highlighted the importance of supplementing with a prebiotic (inulin) to promote the increase of beneficial populations as Lactobacilli and Bifidobacteria. ${ }^{3}$ These data prompted us to explore the hypothesis that long-time supplementation with inulin could lower the risk of pesticide-metabolic disorders. Rats were challenged from gestation to postnatal day (PND) 60 to inulin and clearances of polyfructosan at the doses of $1 \mathrm{mg}$ and $3.5 \mathrm{mg} / \mathrm{kg}$ of body weight (BW). We measured BW, glucose, insulin, leptin, triglycerides, cholesterol, and the expression and activity of AMPK and insulin receptor (IR) in the hypothalamus and liver at PND60. CPF-exposed rats exhibited an increase of BW at birth $(P<0.035)$ and at PND21 but not at PND59. CPF $1 \mathrm{mg}$ induced an increase of $\mathrm{BW}$ gain from birth to weaning. Interestingly, at PND60, CPF at $1 \mathrm{mg}$ induced an increase of plasma glucose $(P<0.0435)$, triglycerides $(P<0.0310)$, insulin $(P<0.0158)$ and the association with inulin re-establishes the level of these metabolic parameters. All these results suggest that (1) prenatal exposition to CPF disrupts metabolic and endocrine activities in the adult rats; (2) perinatal prebiotic supplementation correct the side effects of CPF, and thus have benefic effects on offspring metabolism 
at later life. The implication of AMPK and IR on prebiotic benefic effects is under investigation.

Disclosure of Interest: None.

\section{References}

1. Molly K, Vande Woestyne M, Verstraete W. Development of a 5-step multi-chamber reactor as a simulation of the human intestinal microbial ecosystem. Appl Microbiol Biotechnol. 1993; 39, 254-258.

2. Joly C, Gay-Quéheillard J, Léké A, et al. Impact of chronic exposure to low doses of chlorpyriphos on the intestinal microbiota in the Simulator of the Human Intestinal Microbial Ecosystem (SHIME ${ }^{\circledR}$ ) and in the rat. Environ Sci Pollut Res. 2013; 20, 2726-2734.

3. Reygner J, Joly C, Mayeur C, et al. Prebiotic modulates microbiota dysbiosis induced by pesticide in an artificial human gut model (SHIME $\left.{ }^{\circledR}\right)$. Rowett-INRA. 2014.

\section{EP-5 - oral}

Maternal smoking during pregnancy and offspring's postnatal body mass index trajectory between birth and 5 years from the EDEN mother-child cohort study

S. Carles, A. Forhan, M.-A. Charles and J. Botton

INSERM, CESP équipe 10, Hôpital Paul Brousse, Villejuif, France

Email: sophie.carles@inserm.fr

Despite public health measures, prevalence of smoking during pregnancy remains high. There is growing evidence that in utero exposure to maternal smoking is associated with an increased risk of offspring's overweight/obesity. ${ }^{1,2}$ To illustrate the timing of fat accumulation, our aim was to characterize height, weight and body mass index (BMI) growth trajectories of exposed compared with non-exposed children.

We studied maternal smoking in relation to offspring's growth from birth to 5 years in 1666 mother-child pairs. We compared non-smokers, smokers, exclusively the first trimester and smokers beyond the first trimester.

Height and weight trajectories were fitted using the Jenss non-linear mixed-effects model and the SAEM algorithm (R-package SAEMIX) from a median of 19 measures [interquartile range, IQR $=2-32]$ and $18[\mathrm{IQR}=2-31]$, respectively. $\mathrm{BMI}$ trajectories were derived from these models.

In a first approach, we compared globally the associations with the height and weight trajectories according to maternal smoking, including potential confounders (study center, gender, parental anthropometry, education level, breastfeeding) in the models. A second approach consisted in fitting models separately for boys and girls (without covariates) to predict height, weight and BMI at specific ages. Associations with maternal smoking were then assessed at these ages through linear regression models adjusted for confounders.
Compared with children of non-smokers, mean BMI trajectory of children whose mothers smoked beyond the first trimester was higher from 2 years onwards and those children had a $0.26 \mathrm{~kg} / \mathrm{m}^{2}(P=0.002)$ higher BMI at 5 years. These children experienced a rapid weight catch-up growth in infancy, followed by a faster weight growth from 1 year onwards, resulting in a higher weight and BMI at 4-5 years.

Our method allowed a precise characterization of growth curves and illustrated a divergence for children of mothers smoking in mid/late pregnancy as early as the first few months of life, after taking into account infant feeding and education.

Disclosure of Interest: None.

\section{References}

1. Oken E, Levitan EB, Gillman MW. Maternal smoking during pregnancy and child overweight: systematic review and meta-analysis. Int J Obes. 2008; 32, 201-210.

2. Ino T. Maternal smoking during pregnancy and offspring obesity: meta-analysis. Pediatr Int Off J Jpn Pediatr Soc. 2010; 52, 94-99.

\section{EP-6}

Maternal exposure to diesel engine exhaust during pregnancy affects fetal and placental growth: validation of a rabbit model

S. Valentino ${ }^{1,2}$, A. Tarrade ${ }^{1,2}$, D. Rousseau-Ralliard ${ }^{1,2}$, M. Dahirel ${ }^{1,2}$, E. Aujean ${ }^{3}$, E. Mourier ${ }^{1,2}$, C. Richard ${ }^{1,2}$, M.-C. Aubrière ${ }^{1,2}$, J. Dorival ${ }^{1,2}$, S. Chaffaux ${ }^{1,2}$, S. Camous ${ }^{1,2}$, J. Boere $^{4}$, P. Fokkens ${ }^{4}$, J. Aïoun ${ }^{1,2}$, M.-S. Lallemand ${ }^{1,2}$, L. Maulny ${ }^{1,2}$, R. Slama ${ }^{5}$, F. Cassee ${ }^{4}$ and P. Chavatte-Palmer ${ }^{1,2}$

${ }^{1}$ INRA, UMR 1198, Biologie du Développement et Reproduction, Jouy en Josas, France; ${ }^{2}$ PremUp Foundation, Paris, France;

${ }^{3}$ INRA, UR1196, Génomique et Physiologie de la Lactation, Jouy en Josas, France; ${ }^{4}$ National Institute for Public Health and the Environment, Centre for Sustainability, Environment and Health, BA Bilthoven, The Netherlands; ${ }^{5}$ INSERM, U823 Avenir Team Environmental Epidemiology Applied to Fecundity and Reproduction, Grenoble, France

Email: svalentino@jouy.inra.fr

Maternal exposure to airborne pollution in humans has been shown to induce intrauterine growth retardation ${ }^{1}$ associated with a decreased placental weight ${ }^{2}$ and mitochondrial function altered in the placenta. ${ }^{3}$ Human studies, however, are limited to investigate underlying mechanisms. Several rodent models were used and maternal exposure in these models has been shown to induce a decreased fetal weight, ${ }^{4,5}$ an increased surface area of fetal capillaries in the placenta and a decreased uterine maternal vessel caliber. ${ }^{5}$ Here we developed a rabbit model to study these potential effects during pregnancy.

Female rabbits were exposed to a representative air pollution mixture, that is, diluted diesel engine exhaust ( $n=7$, group $\mathrm{P})$ 
or clean air ( $n=6$, group C), $1 \mathrm{~h}$ every morning and afternoon, 5 days a week, from 3 to $27 \mathrm{dpc}$ (term $=31$ days). At $28 \mathrm{dpc}$, dams were euthanized; fetuses and placentas were collected, measured and weighed. Data were analyzed by nested ANOVA, including litter size, sex and dam as cofactors.

Altogether, $68 \mathrm{P}$ and $50 \mathrm{C}$ feto-placental units were collected. Exposed fetuses were significantly lighter $(P<0.001)$ than control fetuses. Fetal to placental weight ratio was significantly lower in exposed compared with unexposed fetuses, indicating reduced placental efficiency. In contrast, labyrinthine area weight was not affected and deciduas weight were heavier in the exposed group compared with the control group $(P=0.011)$. Exposure was associated with reduced crown-rump length, abdominal perimeter, head length and biparietal diameter $(P<0.001, P<0.001, P<0.001$ and $P<0.01$, respectively). Brain to fetal weight ratios were increased in $P$ fetuses $(P<0.001)$, whereas the lung, heart, liver and kidney to fetal weight ratios remained unchanged, indicating that the brain was preserved in the $P$ fetuses, as described with disharmonious growth retardation.

These data indicate that repeated exposure to airborne pollution even for daily short periods affects feto-placental development and validate the use of the rabbit model for further studies.

\section{Disclosure of Interest: None.}

\section{References}

1. Slama R, Morgenstern V, Cyrys J, et al. Traffic-related atmospheric pollutants levels during pregnancy and offspring's term birth weight: a study relying on a land-use regression exposure model. Environ Health Perspect. 2007; 115, 1283-1292. 2. Rahmalia A, Giorgis-Allemand L, Lepeule J, et al. Pregnancy exposure to atmospheric pollutants and placental weight: an approach relying on a dispersion model. Environ Int. 2012; 48, 47-55.

3. Janssen BG, Munters E, Pieters N, et al. Placental mitochondrial DNA content and particulate air pollution during in utero life. Environ Health Perspect. 2012; 120, 1346-1352.

4. Rocha ESIR, Lichtenfels AJ, Amador Pereira LA, Saldiva PH. Effects of ambient levels of air pollution generated by traffic on birth and placental weights in mice. Fertil Steril. 2008; 90, 1921-1924.

5. Veras MM, Damaceno-Rodrigues NR, Caldini EG, et al. Particulate urban air pollution affects the functional morphology of mouse placenta. Biol Reprod. 2008; 79, 578-584.

\section{INTER AND TRANSGENERATIONAL EFFECTS}

\section{ITE-1}

Maternal gestational diabetes exposure and higher birth weight: effects on offspring adiposity at 7 years

J. Vigneault ${ }^{1,2}$, V. Garneau ${ }^{1,2}$, A. Tchernof ${ }^{1,2,3}$, S. John Weisnagel ${ }^{1,3,4}$ and J. Robitaille ${ }^{1,2}$

${ }^{1}$ Department of Food Science and Nutrition, Laval University, Quebec City, Canada; ${ }^{2}$ Institute of Nutrition and Functional
Foods, Laval University, Quebec City, Canada $;{ }^{3}$ Endocrinology and Nephrology, Medical Research Center, Laval University, Quebec City, Canada; ${ }^{4}$ Diabetes Research Unit, Laval University Medical Research Center, Quebec City, Canada

Email: julie.robitaille@fsaa.ulaval.ca

Pregnancies complicated by gestational diabetes mellitus (GDM) are associated with adverse outcomes in the offspring including macrosomia and later risk of developing obesity and type 2 diabetes. ${ }^{1-4}$ The aim of the study was to assess the relationship between birth weight and adiposity in offspring previously exposed in utero to their mother's GDM. We conducted a preliminary analysis of 38 offspring and their mother with prior GDM. Weight and height were measured. The body mass index (BMI) $Z$-score was calculated with the most recent World Health Organization criteria. Body fat mass was assessed with bioelectrical impedance. Offspring were stratified into two groups according to the median birth weight $(3.62 \mathrm{~kg})$. Offspring were aged $6.8 \pm 2.4$ years, $60.5 \%(n=23)$ of boys and $39.5 \%(n=15)$ of girls. There were no differences between offspring with higher birth weight $(n=19)$ and those with lower birth weight $(n=19)$ when comparing age, treatment for GDM during pregnancy and BMI $Z$-score. However, our preliminary results indicate that offspring with higher birth weight had a higher BMI (17.2 $\pm 0.6 v$. $\left.15.4 \pm 0.6 \mathrm{~kg} / \mathrm{m}^{2}, P<0.05\right)$, waist circumference $(61.45 \pm 1.92$ v. $54.15 \pm 1.92 \mathrm{~cm}, P=0.01)$, fat mass $(8.70 \pm 0.86 v$. $4.28 \pm 0.99 \mathrm{~kg}, P<0.01)$ and body fat percentage $(23.81 \pm 1.63$ v. $17.67 \pm 1.88 \%, P<0.05)$ than offspring with lower birth weight. Results were similar after age and sex adjustments. Birth weight was positively correlated with BMI $(r=0.57, P<0.05)$, fat mass $(r=0.65, P<0.01)$, body fat percentage $(r=0.52$, $P<0.05)$, waist and hip circumference $(r=0.52$ and $r=0.61$, $P<0.05)$. In conclusion, higher birth weight among offspring exposed to in utero GDM is associated with higher childhood adiposity measures. These preliminary data suggest that prevention of childhood obesity should start before birth.

Disclosure of Interest: Supported by Danone Institute of Canada.

\section{References}

1. Metzger BE, Lowe LP, Dyer AR, et al. Hyperglycemia and adverse pregnancy outcomes. N Engl J Med. 2008; 358, 1991-2002.

2. Dabelea D, Mayer-Davis EJ, Lamichhane AP, et al. Association of intrauterine exposure to maternal diabetes and obesity with type 2 diabetes in youth: the SEARCH Case-Control Study. Diabetes Care. 2008; 31, 1422-1426.

3. Clausen TD, Mathiesen ER, Hansen T, et al. High prevalence of type 2 diabetes and pre-diabetes in adult offspring of women with gestational diabetes mellitus or type 1 diabetes: the role of intrauterine hyperglycemia. Diabetes Care. 2008; 31, 340-346. 
4. Deierlein AL, Siega-Riz AM, Chantala K, Herring AH. The association between maternal glucose concentration and child BMI at age 3 years. Diabetes Care. 2011; 34, 480-484.

\section{FREE TOPICS}

\section{FREE-1}

Moderate maternal diabetes in a rat's model of foetal programming involves modifications of mesenteric arteries reactivity in adult offspring

C. Fassot, E. Lelièvre, E. Vessières, A. Dib and D. Henrion

Laboratoire de Biologie Neurovasculaire et Mitochondriale Intégrée, CNRS UMR6214/INSERM U1083, Angers, France

Email: celine.fassot@inserm.fr

Cardiovascular risk is not only determined by conventional risk factors in adulthood, but also by early-life events, resulting in re-settings of physiological functions. In a rat's model of in utero exposure to moderate maternal diabetes, we previously showed that offspring issued from these mothers (DMO), despite no intrauterine growth retardation, developed hypertension around 6 months of age. ${ }^{1}$ Moreover, we identified a specific gene expression profile of the thoracic aorta in favour of vasoconstriction before the development of hypertension (3 months), including decreased prostacyclin receptor (IP) expression. ${ }^{2}$ This may participate to abnormal regulation of arterial blood pressure in DMO through a defect of vasodilatory response.

However, microvessels and not aortas are the main determinants of blood pressure. Thus, we investigated (1) maternal diabetes effects on microvascular tone and (2) the implication IP decreased expression in the regulation of arterial blood pressure in the mesenteric arteries of 3- and 18-month-old DMOs. Our results show that vasoconstriction induced either by $\mathrm{KCl}(80 \mathrm{mM})$ or by $\alpha$-adrenergic receptor stimulation (phenylephrine) was not modified in DMO compared with CMO. Endothelium-mediated dilation induced by acetylcholine was not affected in 3-month-old DMOs but was reduced in 18-month-old DMOs. Interestingly, prostacycline analogue-mediated relaxation was decreased in both 3and 18-month-old DMOs. We also observed that pressure-induced myogenic tone, which controls local blood flow, was maintained at a high level in old DMO compared with old CMO.

In this study, we highlighted early perturbations of mesenteric reactivity in DMO followed by a high level of myogenic tone in older rats. Moreover, foetal modifications of IP expression could be the starting point of vascular perturbations in adult rats exposed in utero to maternal diabetes, leading to hypertension later in life.

\section{Disclosure of Interest: None.}

\section{References}

1. Nehiri T, Duong Van Huyen JP, Viltard M, et al. Exposure to maternal diabetes induces salt-sensitive hypertension and impairs renal function in adult rat offspring. Diabetes. 2008; 57, 2167-2175.
2. Duong Van Huyen JP, Vessières E, Perret C, et al. In utero exposure to maternal diabetes impairs vascular expression of prostacyclin receptor in rat offspring. Diabetes. 2010; 59, 2597-2602.

\section{FREE-2 - oral}

Specific associations of maternal and paternal obesity risk-allele scores with offspring early growth

B. Heude ${ }^{1,2}$, Y. Koudou ${ }^{1,2}$, C. Elks ${ }^{3}$, K. Clément ${ }^{4}$, K. K. Ong ${ }^{3}$ and M.-A. Charles ${ }^{1,2}$

${ }^{1}$ INSERM, Centre for Research in Epidemiology and Population Health (CESP), U1018, Lifelong Epidemiology of Obesity, Diabetes and Renal Disease Team, Villejuif, France; ${ }^{2}$ Univ Paris-Sud, UMRS 1018, Villejuif, France; ${ }^{3}$ MRC Epidemiology Unit, University of Cambridge, Addenbrooke's Hospital Box 285, Cambridge, UK; ${ }^{4}$ INSERM, UMR_S U1166, Nutriomics, Paris, France; Sorbonne Universités, Université Pierre et Marie Curie-Paris, Paris, France; Institute of Cardiometabolism and Nutrition (ICAN), Assistance Publique-Hôpitaux de Paris, and Human Nutrition Research Center-Ile de France, Hôpital Pitié-Salpêtrière, Paris, France

Email: barbara.heude@inserm.fr

If birth weight is mainly predicted by maternal body mass index (BMI), previous studies have suggested that early postnatal growth would rather be influenced by paternal corpulence. ${ }^{1,2}$ Whether this phenomenon is genetically determined has been hypothesized but never clearly demonstrated. We aimed to investigate the respective role of maternal and paternal genetic susceptibility to obesity in offspring body size and fat mass from birth to 5 years.

A total of 833 trios from the EDEN mother-child cohort were genotyped for a set of 16 polymorphisms previously identified by genome-wide-association studies on adult BMI. A genetic susceptibility score was built by summing the number of alleles carried by each individual. Outcomes were age- and sex-adjusted S.D. scores (SDS) for weight, length, BMI and skinfolds at birth, 1, 3 and 5 years, and fat mass per cent (FM\% obtained from bioelectric impedance) at 5 years. Maternal and paternal scores were investigated in association with these outcomes in repeated cross-sectional analyses using linear regression models allowing adjustment for sex, maternal height and breastfeeding for $>3$ months.

There was no association between maternal genetic score and any anthropometric outcome $(P>0.13)$, whereas paternal genetic score was significantly associated with weight $(\beta=0.053 \pm 0.014$ SDS per allele; $P<0.0001)$, height $(\beta=0.035 \pm 0.014$; $P<0.016)$ and BMI $(\beta=0.047 \pm 0.014 ; P<0.001)$ as early as 3 years. Patterns of associations were similar at 5 years, but at this age paternal score was also significantly associated with skinfolds, S.D. scores $(\beta=0.041 \pm 0.015 ; P=0.007)$ and $\mathrm{FM} \%$ $(\beta=0.032 \pm 0.016 ; P=0.043)$. Paternal and maternal genetic susceptibilities to obesity seem to play distinct roles in offspring early postnatal growth. As the investigated genes are for most not 
submitted to imprinting, further investigations are needed to explain these differences, and especially to find out whether environmental constraints during fetal life could be responsible for the absence of genetic effect from the maternal side.

\section{Disclosure of Interest: None.}

\section{References}

1. Regnault N, Botton J, Forhan A, et al. Determinants of early ponderal and statural growth in full-term infants in the EDEN mother-child cohort study. Am J Clin Nutr. 2010; 92, 594-602.

2. Botton J, Heude B, Maccario J, et al. Parental body size and early weight and height growth velocities in their offspring. Early Hum Dev. 2010; 86, 445-450.

\section{FREE-3 - oral}

Placental prolactin family levels are modified during gestation in the diabetic rat

P. Perimenis ${ }^{1,2}$, E. Moitrot ${ }^{1}$, P. Gosset ${ }^{3}$, E. Eury ${ }^{4,6}$,

L. Storme ${ }^{1}$, P. Fontaine $e^{1,5,6}$ and A. Vambergue $e^{1,5,6}$

${ }^{1}$ EA 4489, Perinatal Environment and Growth, University of

Lille 2, Lille, France; ${ }^{2}$ Department of Diabetology, Hospital

Group of Catholic Institute of Lille (GHICL), Lille, France;

${ }^{3}$ Anatomopathological Department, Hospital Group of Catholic

Institute of Lille (GHICL), Lille, France; ${ }^{4}$ CNRS-UMR8199,

Lille 2 University, Lille, France; ${ }^{5}$ Department of Diabetology,

University Hospital, CHRU Lille, Lille, France; ${ }^{6}$ European

Genomic Institute for Diabetes (EGID), Lille, France

Email: perimenis.pierrette@ghicl.net

Maternal diabetes is associated with feto-maternal morbidity. Prolactin (PRL) is produced by the decidual cells. In rats, the decidual prolactin-related protein (DPRP), member of the PRL family, also has a decidual localization. Although full-length PRL is angiogenic, the processed forms by bone-morphogenetic-protein-1 (BMP-1), known as vasoinhibins, are antiangiogenic. We previously demonstrated that $B m p-1$ and Dprp genes are upregulated with an increase in vasoinhibins and a hypovascularization at late gestation in the placenta of diabetic rats with intrauterine growth retardation. ${ }^{1}$ In this study, placental gene expressions of Dprp, $B m p-1$ and vasoinhibins quantification are analyzed at different significant stages of pregnancy in diabetic rats.

Wistar rats received, at day 7 of pregnancy, streptozotocin (STZ) or nicotinamide (NCT) plus STZ or vehicle and killed at Day 14 ( $n=7$ for C; $n=6$ for STZ; $n=7$ for NCT-STZ groups), Day 17 ( $n=8$ for C; $n=7$ for STZ; $n=6$ for NCT-STZ groups) and Day 21 ( $n=9$ for C; $n=5$ for STZ; $n=9$ for NCT-STZ groups). Dprp and Bmp-1 gene expressions, PRL western blots and histological analyses were performed in the placentas.

Birth weight was reduced in diabetic groups at all stages compared with controls. Dprp mRNA level was not different between all groups at Day 14, but there was a 2.5-fold increase in the STZ $(P<0.01)$ and NCT-STZ $(P<0.05)$ groups at Day 17 , and four-fold increase in the STZ $(P<0.01)$ and NCT-STZ groups $(P<0.01)$ at Day 21 compared with controls. $B m p-1$ was first downregulated at Day 17 in the STZ $(P<0.001)$ and NCT-STZ $(P<0.01)$ groups and then upregulated in the STZ $(P<0.05)$ and NCT-STZ $(P<0.001)$ groups at Day 21 compared with controls. Vasoinhibins were reduced in the STZ $(P<0.001)$ and NCT-STZ $(P<0.01)$ groups at Day 17 and increased in the STZ $(P<0.05)$ and NCT-STZ $(P<0.05)$ groups at Days 17 and 21 compared with controls.

Placental PRL family is involved at last third of pregnancy in the diabetic rat with a role in placental vascularization and adaptation to hyperglycemia.

Disclosure of Interest: None.

\section{Reference}

1. Perimenis P, Bouckenooghe T, Delplanque J, et al. Placental antiangiogenic prolactin fragments are increased in human and rat maternal diabetes. Biochim Biophys Acta. 2014; 1842, 1783-1793.

\section{FREE-4 \\ Night sleep trajectories and associated factors among the preschool children of the EDEN cohort}

S. Plancoulaine, B. Heude, M.-A. Charles and the EDEN

Mother-Child Cohort Study Group

INSERM, CESP/U1018-EQ10, Université Paris-Sud, Villejuif, France

Email: sabine.plancoulaine@inserm.fr

Children sleep has been associated with health outcomes. ${ }^{1}$ Few are known about sleep patterns/trajectories and their associated factors among pre-schoolers. ${ }^{2}$ We used data from the French mother-child EDEN cohort study between the age of 2 and 5.5 years. The analysis included 1078 children with data on night sleep duration. Studied time-stable factors concerned the family (income, education level, familial status), the mother [age at birth, parity, body mass index (BMI) before pregnancy, depression and alcohol consumption during pregnancy, tobacco consumption (none, only after pregnancy, during pregnancy and after), term at delivery] and the child (gender, birth weight, breastfeeding duration); time-dependent factors were working mother (none, part-time, full-time), childcare arrangement, parental presence when falling asleep, BMI $Z$-score, nocturnal awakenings, nap duration, physical activities and TV viewing duration. We used a group-based trajectory modelling ${ }^{3}$ to identify night sleep duration patterns and simultaneously identify time-stable factors explaining differences between patterns and time-dependent factors associated with variations within patterns.

We identified five distinct sleep duration trajectory groups: short sleepers (SS, <10 h, 6.6\%), medium-low sleepers (MLS, <11 h, 46.2\%), medium-high sleepers $(\approx 11 \mathrm{~h} 30 \mathrm{~min}$, 
35.0\%), long sleepers (LS, $\geqslant 11 \mathrm{~h} 30 \mathrm{~min}, 7.3 \%$ ) and modifier sleepers (MS, i.e. LS then MLS, 4.9\%). Multivariate analysis showed that factors associated with increased risk for the SS trajectory group were being a first-born child and having a mother who smoked during pregnancy. In this trajectory group, night sleep duration between 2 and 5.5 years old was negatively associated with TV viewing duration and having a working mother. Time-stable factors associated with increased risk for LS trajectory group were being a girl, having a younger mother who smoked during pregnancy. In this trajectory group, night sleep duration was negatively associated with collective childcare arrangement and parental presence when falling asleep. Time-stable factors associated with increased risk for MS trajectory group were being a girl, having a younger mother and having been breastfed $<3$ months. In this trajectory group, night sleep duration was negatively associated with TV viewing duration, night awakenings, having a working mother and napping duration.

Some early-life factors, namely, maternal smoking during pregnancy and breastfeeding duration were associated with sleep trajectories from 2 to 5.5 years We also identified factors associated with sleep duration changes within trajectory groups, mainly behavioural ones.

\section{Disclosure of Interest: None.}

\section{References}

1. Touchette E, Petit D, Tremblay RE, Montplaisir JY. Risk factors and consequences of early childhood dyssomnias: new perspectives. Sleep Med Rev. 2009; 13, 355-361.

2. Magee CA, Gordon R, Caputi P. Distinct developmental trends in sleep duration during early childhood. Pediatrics. 2014; 133, e1561-e1567.

3. Nagin DS. Group-Based Modelling of Development, 2005. Harvard University Press: Cambridge, MA.

\section{FREE-5}

Longitudinal sleep study among French pregnant women and the impact on birth term and birth weight

S. Plancoulaine ${ }^{1}$, S. Flori ${ }^{2,3}$, H. Patural ${ }^{2,3}$, J.-S. Lin ${ }^{3,4}$ and P. Franco 3,4

${ }^{1}$ INSERM, CESP/U1018-EQ10, Université Paris-Sud, Villejuif, France; ${ }^{2}$ Pediatric and Neonatal Reanimation, Pôle Mère et Enfant, Hôpital Nord, Saint-Etienne, France; ${ }^{3}$ EA SNA-EPIS 4607, University Jean Monnet, Saint-Etienne, France; ${ }^{4}$ Unité pédiatrique du sommeil, Hôpital Femme Mère Enfant, Université Lyon1, Lyon, France; ${ }^{5}$ Integrative Physiology of Brain Arousal System, CRNL, INSERM-U1028, CNRS UMR5292, Université Lyon1, Lyon, France

\section{Email: sabine.plancoulaine@inserm.fr}

Pregnant women are at particular risk for sleep deprivation. ${ }^{1} \mathrm{We}$ studied sleep duration patterns during pregnancy, their associated risk factors and birth outcomes. We used data from the French prospective mother-child AuBE cohort study. The analysis included 200 women with data on sleep duration and various sleep troubles before and in the first, second and third trimester of pregnancy, age, term, parity, work and its duration, depression status and child's birth weight. We used a group-based trajectory modelling $^{2}$ to (i) identify sleep duration patterns during pregnancy; (ii) identify simultaneously time-stable factors, explaining differences between patterns, and time-dependent factors associated with variations within patterns; and (iii) study relationship between sleep patterns and both term and birth weight.

We identified three distinct sleep duration trajectories during pregnancy: short and decreasing (SD, i.e. $<6 \mathrm{~h} 30 \mathrm{~min} / \mathrm{night}$, $10.8 \%$ ), medium and decreasing (MD, i.e. $6 \mathrm{~h} 30 \mathrm{~min}-8 \mathrm{~h} /$ night, $57.6 \%$ ) and long and increasing (LI, i.e. $>8 \mathrm{~h} /$ night, $31.6 \%$ ). Multivariate analyses showed factors associated with increased risk for SD trajectory were older age $(P=0.01)$, specific sleep treatment $(P=0.08)$ and depression $(P=0.09)$. In this trajectory group, sleep duration during pregnancy was negatively associated with occurrence of nocturnal waking and/or early waking and/or and difficulties to fall asleep (IWD) $(P<10-4)$ but positively associated with naps $(P=0.06)$. Depression was also positively associated with increased risk for LI trajectory $(P=0.04)$, but work duration $(P=0.02)$ was associated with a decreased risk. In this trajectory group, sleep duration during pregnancy was negatively associated with restless legs syndrome $(P=0.002)$. In the MD trajectory group that served as reference for time-stable factors, sleep duration during pregnancy was negatively associated with IWD $(P<10-4)$ and pain $(P=0.03)$. Moreover, mean term and birth weight for gestational age were lower for SD trajectory (35.2 WA and $2.3 \mathrm{~kg}$ ) but also for LI (38.9 WA and $2.9 \mathrm{~kg}$ ) compared with MD trajectory (39.9 WA and $3.3 \mathrm{~kg}$ ).

We identified sleep trajectories among pregnant women with specific risk factors and risks for birth outcome. A better care of them could ameliorate both mother and child health.

Disclosure of Interest: None.

\section{References}

1. Pavlova M, Sheikh LS. Sleep in women. Semin Neurol. 2011; 31, 397-403.

2. Nagin DS. Group-Based Modelling of Development, 2005. Harvard University Press: Cambridge, MA.

\section{FREE-6}

The probiotics Lactobacillus reuteri DSM17938 and Bifidobacterium longum ATCC BAA-999 normalize sleep disturbances in prenatally stressed rats

J. Mairesse $^{1}$, M.-L. Reynaert ${ }^{1}$, J. Marrocco ${ }^{2}$, C. L. Garcia Rodenas $^{3}$, A. Giuliani ${ }^{4}$, G. Van Camp ${ }^{1}$, E. Gatta ${ }^{1}$, H. Bouwalerh ${ }^{1}$, G. E. Bergonzelli ${ }^{3}$, F. Nicoletti ${ }^{1}$ and S. Maccari ${ }^{1}$

${ }^{1}$ International Associated Laboratory (LIA) 'Prenatal Stress and Neurodegenerative Diseases', UMR8576 University Lille 
1/CNRS, Villeneuve d'Ascq, France; Sapienza University of Rome/IRCCS Neuromed, Pozzilli, Italy; ${ }^{2}$ IRCCS Centro Neurolesi 'Bonino Pulejo', Messina, Italy; ${ }^{3}$ Nutrition and Health, Nestlé Research Center, Lausanne, Switzerland; ${ }^{4}$ Department of Environment and Health, Istituto Superiore di Sanità, Rome, Italy

Email: marie-line.reynaert@ed.univ-lille1.fr

Excessive crying and/or sleeping alterations are frequent during infancy. Environmental stress and family psychosocial factors including maternal stress and anxiety during pregnancy and postpartum - are strong predictors of infant sleep alterations and colic in humans and animal models. ${ }^{1-3}$ This is possibly owing to subsequent alterations of infant reactivity to environmental cues. Behavioral management techniques can be effective but are often difficult for the parents to apply. Occasionally, drugs may be prescribed, but the efficiency of these drugs is variable and the risk of adverse side effects is high. Mounting evidence indicate that gut microbiota communicates with brain and thus modulate behavior. ${ }^{4}$ In particular, Lactobacillus reuteri DSM17938 (Lr) had been shown to reduce crying time in colicky infants, ${ }^{5}$ whereas Bifidobacterium longum ATCC BAA-999 (Bl) decreased anxiety-like behavior in mice models. ${ }^{6}$ In that context, we aimed at investigating the therapeutic effect of both probiotics in an animal model of prenatal restraint stress, known to induce sleep disturbances in the offspring. ${ }^{7,8}$ Pregnant female Sprague-Dawley rats were submitted to 45-min restraint stress, under a bright light, three times per day, the last 10 days of gestation. ${ }^{9}$ Adult PRS male offspring were implanted with electrodes for polygraphic recordings of frontoparietal electroencephalogram (EEG), and nuchal electromyogram (EMG), and let to recover for 15 days. Then, rats received a daily gavage of $\mathrm{Lr}, \mathrm{Bl}$ or placebo for 14 days, before recording of EEG and EMG activities during $24 \mathrm{~h}$. Wake, NREM sleep or REM sleep duration and number of episodes were recorded. A group of control unstressed rats treated with placebo was used as reference. $\mathrm{Lr}$ and $\mathrm{Bl}$ normalize sleep/wake cycle duration and fragmentation. These probiotics may be of potential benefit in the management of sleep disorders, in particular those associated with perinatal stress.

\section{Disclosure of Interest: None.}

\section{References}

1. Sarimski K. Sleep disorders in early childhood: developmental psychopathologic model and pilot study. Prax Kinderpsychol Kinderpsychiatr. 1993; 42, 2-8.

2. Rautava P, Helenius H, Lehtonen L. Psychosocial predisposing factors for infantile colic. BMJ. 1993; 307, 600-604.

3. O'Mahony SM, Marchesi JR, Scully P, et al. Early life stress alters behavior, immunity, and microbiota in rats: implications for irritable bowel syndrome and psychiatric illnesses. Biol Psychiatry. 2009; 65, 263-267.
4. Forsythe P, Sudo N, Dinan T, Taylor VH, Bienenstock J. Mood and gut feelings. Brain Behav Immun. 2010; 24, 9-16. 5. Urbańska M, Szajewska H. The efficacy of Lactobacillus reuteri DSM 17938 in infants and children: a review of the current evidence. Eur J Pediatr. 2014; 173, 1327-1337.

6. Bercik P, Verdu EF, Foster JA, et al. Chronic gastrointestinal inflammation induces anxiety-like behavior and alters central nervous system biochemistry in mice. Gastroenterology. 2010; 139, 2102-2112.

7. Dugovic C, Maccari S, Weibel L, Turek FW, Van Reeth O. High corticosterone levels in prenatally stressed rats predict persistent paradoxical sleep alterations. J Neurosci. 1999; 19, 8656-8664.

8. Mairesse J, Silletti V, Laloux C, et al. Chronic agomelatine treatment corrects the abnormalities in the circadian rhythm of motor activity and sleep/wake cycle induced by prenatal restraint stress in adult rats. Int J Neuropsychopharmacol. 2013; 16, 323-338. 9. Maccari S, Piazza PV, Kabbaj M, Barbazanges A, Simon $\mathrm{H}$, Le Moal M. Adoption reverses the long-term impairment in glucocorticoid feedback induced by prenatal stress. J Neurosci; 1995; 15, 110-116.

\section{FREE-7}

A modeling approach of the developmental origin of type 2 diabetes through the modulation of the $\beta$-cell mass

N. Bahi-Jaber ${ }^{1}$, B. Blondeau ${ }^{2}$, S. Firmin ${ }^{1}$, B. Breant ${ }^{2}$ and

L. Abdennebi-Najar ${ }^{1}$

${ }^{1}$ UP 2012.10.101, EGEAL, Institut Polytechnique LaSalle

Beauvais, Beauvais, France; ${ }^{2}$ INSERM, UMRS 1138 -

Université Pierre et Marie Curie, Paris, France

Email: narges.bahi-jaber@lasalle-beauvais.fr

Facing the epidemic of type 2 diabetes (DT2), research on the mechanisms underlying the development of DT2 has initiated a shift of paradigm in view of the $\mathrm{DOHaD}$ concept. Indeed, a deleterious fetal environment during critical windows of development, that is, pregnancy and/or lactation, alters the proliferation and/or the differentiation of pancreatic $\beta$-cells, leading to a critical decrease in $\beta$-cell mass at birth. As a consequence, insulin secretion and glucose homeostasis are compromised, leading to the development of diabetes at adulthood. ${ }^{1,2}$

The developmental process is a complex system involving nonlinear interactions between components at different level and time scales. Mathematical modeling provides a powerful tool to make predictions on the behavior of the system under given hypothesis. Here we have built a mathematical model of the $\beta$-cell development to investigate the impact of an impaired $\beta$-cell mass on the risk of DT2. Our model uses a Hybrid Petri $\mathrm{Net}^{3}$ approach that allows to take into account the stochasticity of both differentiation and proliferation processes and integrates differential equations for the modeling of glucose homeostasis and insulin dynamics. 
Even if mathematical models of either pancreatic development $^{4}$ or insulin-glucose regulation ${ }^{5}$ already exist, to the best of our knowledge, it is the first attempt that a model of the developmental origin of DT2 is proposed.

The predictions of our model are in good accordance with experimental data. Indeed, it predicts that impairment of differentiation or proliferation, during fetal life, leads to a decreased $\beta$-cell mass at birth that may not be compensated after birth. Furthermore, we show that the timing at which this impairment occurs differentially modulates $\beta$-cell mass. Finally, decreased mass has an impact on glucose regulation by insulin that may be unable to face an increase of glucose intake at adulthood.

Disclosure of Interest: None.

\section{References}

1. Gatford KL, Simmons RA. Prenatal programming of insulin secretion in intrauterine growth restriction. Clin Obstet Gynecol. 2013; 56, 520-528.

2. Dumortier O, Blondeau B, Duvillié B, et al. Different mechanisms operating during different critical time-windows reduce rat fetal beta cell mass due to a maternal low-protein or low-energy diet. Diabetologia. 2007; 50, 2495-2503.

3. Modeling in Systems Biology. The Petri Net Approach (eds. Koch I, Reisig W, Schreiber F), 2010.

4. Setty Y, Cohen IR, Dor Y, Harel D. Four-dimensional realistic modeling of pancreatic organogenesis. Proc Natl Acad Sci USA. 2008; 105, 20374-20379.

5. Gallenberger M, zu Castell W, Hense BA, Kuttler C. Dynamics of glucose and insulin concentration connected to the $\beta$-cell cycle: model development and analysis. Theor Biol Med Model. 2012; 9, 46.

\section{FREE-8}

Maternal protein restriction induces selective changes in tryptophan metabolism in the brain embryo that are apposite to those observed in adult animals born to and nursed by protein-restricted dams

P. H. de Melo Martimiano ${ }^{1,2}$, A. de Sa Braga Oliveira ${ }^{1,2}$, V. Ferchaud-Roucher ${ }^{1}, K$. Ouguerram ${ }^{1}$, R. Manhães de Castro $^{2}$, B. Kaeffer ${ }^{1}$ and F. Bolaños-Jiménez ${ }^{1}$

${ }^{1}$ INRA-Nantes University, UMR1280 PhAN, Nantes, France;

${ }^{2}$ Departamento de Nutrição, Universidade Federal de

Pernambuco, Recife, Pernambuco, Brazil

\section{Email: Francisco.Bolaños@univ-nantes.fr}

It is clearly established that poor nutrition during early life is a predisposing factor for the development of cognitive and metabolic disorders in adulthood. However, there is almost no information about the cause and effect relationship between the lack of a specific nutrient during the critical stages of development and disease susceptibility later in life. Here we searched to define the potential role of tryptophan (Trp), as metabolic programming factor. Trp is an essential amino acid that is metabolized through the serotonin (5-HT) and kynurenine pathways leading, respectively, to the synthesis of 5-HT and many other neuroactive compounds, including kynurenic (KA) and Xanthurenic (Xa) acids. ${ }^{1}$ Liquid chromatography-tandem mass spectrometry was used to perform a quantitative analysis of the 5HT and kynurenine metabolic pathways of tryptophan in the brain of 13-day-old embryos from protein-restricted (PR) dams as well as in several brain regions of adult animals (7 months), exposed to protein restriction during gestation and lactation. Maternal protein restriction markedly reduced the levels of Trp in the embryonic brains. Accordingly, the concentration of 5-HT was also reduced. Surprisingly, though the concentration of kynurenine was not altered by protein malnutrition, a significant reduction in the levels of all the end-products of the kynurenine pathway, with the exception of Xa, was found in the brain of PR embryos. In contrast, adult rats exposed to protein restriction during gestation and lactation exhibited enhanced concentration levels of Trp in the brain stem and cortex along with increased concentrations of 5-HT, kynurenine and Xa, but not of any other metabolites of the kynurenine pathway. These results show that early protein deficiency induces selective and long-lasting changes in brain tryptophan metabolism. Given the key regulatory function of 5-HT and kynurenine-derived metabolites on feeding, cognition and energy homeostasis, ${ }^{2}$ these changes might play a role in metabolic programming.

Disclosure of Interest: None.

\section{References}

1. Le Floc'h N, Otten W, Merlot E. Tryptophan metabolism, from nutrition to potential therapeutic applications. Amino Acids. 2011; 41, 1195-2005.

2. Oxenkrug G. Insulin resistance and dysregulation of tryptophan-kynurenine and kynurenine-nicotinamide adenine dinucleotide metabolic pathways. Mol Neurobiol. 2013; 48, 294-301.

\section{FREE-9}

Methyl donor deficiency during gestation and lactation produces hepatosteatosis and myocardium fibrosis in rat offspring fed a high-fat diet in adult life

A. Bison, A. Bressenot, B. Beck, G. Pourié, J.-M. Alberto, R. Umoret, J.-P. Bronowicki, J.-L. Guéant and R. M. Guéant-Rodriguez

INSERM U954, Nutrition-Genetics-Environmental Risk Exposure (N-GERE), University of Lorraine, Vandoeuvre-lès-Nancy, France

Email: anais.bison@gmail.com

Methyl donor deficiency (MDD) during pregnancy and lactation is an experimental model of fetal programming. ${ }^{1,2}$ It produces a steatosis in the liver and myocardium that results, in part, from decreased fatty-acid oxidation. ${ }^{3,4}$ The underlying 
molecular mechanisms are related to a decreased expression of HNF4, ER $\alpha$ and $\operatorname{ERR} \alpha$, and a hypomethylation of PGC- $1 \alpha$. The steatosis is reversible when the animals are fed subsequently a normal diet. ${ }^{1-4}$

This study evaluated the effects of MDD during gestation and lactation after two successive periods, normal diet between weaning and day 50 and subsequent exposure to high-fat (HF) diet in adult life.

Wistar female rats were assigned to a standard diet (C) or MDD (no folate and no vitamin $B_{12}$ ) 1 month before pregnancy and during pregnancy and weaning. Pups received a normal diet after weaning, from days 21 to 50 . At day 50, four groups were studied, C, MDD, C-HF (high fat) and MDD-HF. The animals were killed either at day 50 or day 180 . We observed no morphological and metabolic abnormalities at day 50. In contrast with the other groups, the MDD-HF had a severe steato-hepatitis and severe inflammation and fibrosis in myocardium at day 180 . The underlying mechanisms were related to increased expression of genes involved in inflammation, remodeling and fibrosis, including tnfa, ila and ilb, tgfb,

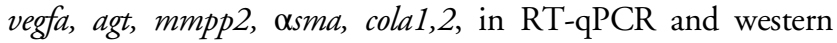
blotting.

In conclusion, MDD during gestation and lactation produces steato-hepatitis in animals subjected to $\mathrm{HF}$ diet during adulthood, despite the recovery of a normal histological and metabolic presentation by a control diet between weaning and day 50. These results suggest investigating whether MDD during gestation and lactation is a risk factor of steato-hepatitis in subjects who are subsequently exposed to HF diet.

Disclosure of Interest: None.

\section{References}

1. Guéant JL, Namour F, Gueant-Rodriguez RM, Daval JL. Folate and fetal programming: a play in epigenomics? Trends Endocrinol Metab. 2013; 24, 279-288.

2. Guéant JL, Elakoum R, Ziegler O, et al. Nutritional models of foetal programming and nutrigenomic and epigenomic dysregulations of fatty acid metabolism in the liver and heart. Pflugers Arch. 2014; 466, 833-850.

3. Pooya S, Blaise S, Moreno Garcia M, et al. Methyl donor deficiency impairs fatty acid oxidation through pgc-1alpha hypomethylation and decreased ER-alpha, ERR-alpha, and HNF-4alpha in the rat liver. J Hepatol. 2012; 57, 344-351.

4. Garcia MM, Guéant-Rodriguez RM, Pooya S, et al. Methyl donor deficiency induces cardiomyopathy through altered methylation/acetylation of PGC-1alpha by PRMT1 and SIRT1. J Pathol. 2011; 225, 324-335. 